\title{
Ambulatory phlebectomy
}

Citation for published version (APA):

de Roos, K-P. (2003). Ambulatory phlebectomy. [Doctoral Thesis, Maastricht University]. Datawyse / Universitaire Pers Maastricht. https://doi.org/10.26481/dis.20030626kr

Document status and date:

Published: 01/01/2003

DOI:

$10.26481 /$ dis.20030626kr

Document Version:

Publisher's PDF, also known as Version of record

\section{Please check the document version of this publication:}

- A submitted manuscript is the version of the article upon submission and before peer-review. There can be important differences between the submitted version and the official published version of record.

People interested in the research are advised to contact the author for the final version of the publication, or visit the DOI to the publisher's website.

- The final author version and the galley proof are versions of the publication after peer review.

- The final published version features the final layout of the paper including the volume, issue and page numbers.

Link to publication

\footnotetext{
General rights rights.

- You may freely distribute the URL identifying the publication in the public portal. please follow below link for the End User Agreement:

www.umlib.nl/taverne-license

Take down policy

If you believe that this document breaches copyright please contact us at:

repository@maastrichtuniversity.nl

providing details and we will investigate your claim.
}

Copyright and moral rights for the publications made accessible in the public portal are retained by the authors and/or other copyright owners and it is a condition of accessing publications that users recognise and abide by the legal requirements associated with these

- Users may download and print one copy of any publication from the public portal for the purpose of private study or research.

- You may not further distribute the material or use it for any profit-making activity or commercial gain

If the publication is distributed under the terms of Article $25 \mathrm{fa}$ of the Dutch Copyright Act, indicated by the "Taverne" license above, 
Ambulatory PHLEBetomy 
Dit proefschrift is tot stand gekomen zonder enige vorm van externe financiering of sponsoring.

ISBN $90-9016918-0$

O K-P de Roos, Uden 2003

Layout and Printing: Datawyse / Universitatue Pers Maastricht 


\title{
AMBULATORY PHLEBECTOMY
}

\author{
PROEFSCHRLFT
}

ter verkrijging van de graad van doctor aan de Universiteit Maastricht

op gezag van de Rector Magnificus,

Prof. dr A.C. Nieuwenhuijzen Kruseman, volgens het besluit van het College van Decanen in het openbaar te verdedigen op donderdag 26 juni om 14.00 uur

door

KEES-PETER DE ROOS 


\section{PROMOTOR}

Prof. dr H.A.M. Neumann

\section{BEOORDELINGSCOMMISSIE}

Prof dr J. Drukker, voorzitrer

Prof. dr W.R. Faber (Universiteit van Amsterdam)

Prof. dr P.M. Steijlen

Dr J.C.J.M. Veraatt

Dr R.A. Weiss (Johns Hopkins University School of Medicine, Baltimore, USA) 


\section{CONTENTS}

1. General introduction and aims

2. Varicose veins; diagnosis and treatment

updated persion based on:

- Roos K-P de, Neumann. HAM. Treatment of varicose veins; "The Maastricht perspective in Phlebology. Praktická Flebologie, 1993; 1: 5-11.

- Neumann HAM, Roos $\mathbb{K}$-P de. Microchirurgische ambulatoire flebectomie. Ned Tijdschr Dermatol Venereol 1994; 4: 343-9.

\section{Compression therapy}

3.1 Tazelaar DJ, Neumann HAM, Roos K-P de. Long cotton wool rolls as compression enhancers in macrosclerotherapy for varicose veins. Dermatol Surg 1999; 25: 38-40.

3.2 Neumann HAM, Roos K-P de, Veraart JCJM. Muller's ambulatory phlebectomy and compression. Dermatol Surg 1998; 24: 471-4.

4. Semicirculatory varicosis

4.1 Roos K-P de. Semicirculatory varicosis: tributary vein treatment. Phlebology Digest 1997; 9: 6-9.

4.2 Roos K-P de, Nieman FHM, Neumann HAM. Ambulatory phlebectomy versus compression sclerotherapy; results of a randomized controlled trial. Dermatol Surg 2003; 29: 221-6.

5. Foot varicosis

5.1 Roos de K.P, Neumann HAM. Muller's ambulatory phlebectomy for varicose veins of the foot. Dermatol Surg 1998; 24: 465-70.

5.2 Roos de K-P, Nieman FHM and Neumann HAM. Patient satisfaction after ambulatory phlebectomy for varicose veins in the froot. Dermatol Surg 2002; 28: 1027-30. 
6. Special indications and locations

6.1 Roos K-P de, Neumann HAM. Vein biopsy; a new indication for Muller's phlebectomy. Dermatol Surg 1995; 21: 632-4.

6.2 Roos K.P. de, Neer PAFA van, Go IH, Neumann HAM. Non leg varicose veins and ambulatory phlebectomy; a special technique for special cases. (submitted)

7. Complications

7.1 Roos K-P de, Neumann HAM. Traumatic neuroma; a rare complication following Muller's phlebectomy. J Dermatol Surg and Oncol 1994; 20: 681-2.

7.2 Roos K-P de, Neumann HAM. Hematomas are underrepresented in studies on complications of ambulatory phlebectomy. Letter to the editor. Dermatol Surg 2002; 26: 544-5.

7.3 Bullens-Goessens YIJM, Roos K-P de, Kockaert MA, Neumann HAM. Survenue d'un vitiligo après phlébectomie ambulatoire. Phlébologie 2002; 55:275-7.

8. Implementation

8.1. Roos K.P de, Neumann HAM. Flebectomie op schapenpoten; het lange-termijneffect van praktische instructie. Medisch Contact 2001; 56: 1382-4.

8.2 Roos K-P de, Neumann HAM. Flebologie in de dermatologische

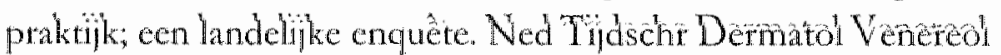
$2002 ; 12: 194-7$.

9. General discussion and summary 153

$\begin{array}{ll}\text { 10. Samenvatting } & 161\end{array}$

11. References 171

12. Dankwoord 183

$\begin{array}{ll}\text { Curriculum vitae } & 187\end{array}$

$\begin{array}{ll}\text { Bibliography } & 189\end{array}$ 
CHAPTER 1

\section{GENERAL INTRODUCTION AND AIMS}




\section{INTRODUCTION}

There seems to be an incteased interest in phlebology in recent years. This interest may be the result of an increase in diagnostic and therapeutic possibilities for phlebologic disorders or a shift in interest from arterial disease. It may even be the result of an increased understanding of the pathophysiology of phlebologic disorders or the awareness that phlebologic disorders such as varicose veins and chronic venous disease and its sequelae matter to the public. Some even suggest socio-economic reasons (Kitslaar \& Rutgers 1993). This increased interest in phlebology holds also true for ambulatory phlebecromy. Since its introduction in the United States somewhere during the 1980's there is an increased number of publications on this subject in the English language. Until then publications on ambulatory phlebectomy were predominantly either in French or in German. It has been demonstrated that ambulatory phlebectomy can be safely and effectively used for different types of varicose veins and at different locations. A definite orientation of this procedure however seems to be lacking.

\section{WHERE TO BEGIN?}

It may very well be that bloodletting or phlebotomy was already en vogue in prehistoric times, because it seems to have been well established as a procedure when recorded history began (Brecher 1969). Veins have always been correctly described as being filled with blood. However the misconception of the arteries (Gr: aer =air, terein=to keep) as air-carrying ducts or as tubes, only partially filled with blood, persisted throughout the classical Greek time from Aristotle (384-322 BC) until it was disproved by Claudius Galen of Pergamum (129-199 AD) (Brecher 1969, Gardner 1993). Gallen who started as a physician to the gladiators inevitably became an expert on trauma and is believed to be the first to use a vascular ligature. He also used a hook to remove varicose veins through several incisions. Eventually he was appointed as Emperor Marcus Aurelius' personal surgeon (Rose 1993). He believed that blood was distributed throughout the venous system much like the sea: ebbing and flowing in the vessels (Gardner 1993). His theory on circulation would be the standard for the next 14 centuries. In ancient Greek and Roman times phlebotomy was used as a remedy for various ailments including varicose veins.

On the basis of his Greek and Roman predecessors Oribasius of Pergamum (325-405 AD) a Byzantinian physician described surgery on varicose veins of the 
legs: more specific a phlebectomy (Lascaratos et al. 2001). In part XIV of his book "Synogogue Medicae" Oribasius extensively describes this technique using a:

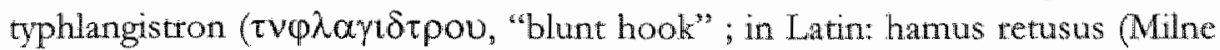
1976)) to "hook up and remove" varicose veins (Lascaratos et al. 2001).

During the dark ages there seemed to have been little interest in science and medicine. In 1536 Giambattista Canano was one of the first anatomists to demonstrate that veins contained valves (Brecher 1969, Scultetus et al. 2001). Hieronymus Fabricius ab Acquapendente, anatomist in Padua (1533-1619) is generally thought to have been the first to describe the most important part of the venous system: the valves (James 1990). He suggested the function of valves was to control centripetal flow in the veins (Novel 1990, James 1990) which would avoid the extremities to be undernourished in the proximal parts and permanently swollen in the distal parts (Anonymous 1966). Later his student William Harvey (1578-1657) wrote his thesis: "Exercitatio Anatomicae de Motu Cordis et Sanguinis in Animalibus" ("On the movement of the beart and blood in animals")(1628). Based on his experiments he deduced that the valves prevent blood from flowing bi-directional and must therefore flow unidirectionally in the veins. Since Galen it was assumed that veins drew nourishment from the intestines and distributed it to the liver. The liver then rapidly produced blood from chyle (Brecher 1969). Harvey revised this opinion by adding how much blood the body would have to make from the daily food uptake. He measured that the heart could contain $2 \mathrm{oz}$ $(60 \mathrm{~g})$ of blood, multiplied this by 65 heartbeats per minute $(8 \mathrm{lb}, 2 \mathrm{~kg})$ and the minutes in a day $(11.500 \mathrm{lb}$ or $5.600 \mathrm{~kg}$ ). He concluded that blood must circulate in a closed system (Scultetus et al. 2001). In his time Harvey's work revolutionized the concept of flow of blood that had been unchanged since Galen's era. He discovered the blood circulation which corners the beginning of angiology.

\section{WHAT'S IN A NAME?}

One of the first recorded definitions of varicose veins was by Oribasius of Pergamum who stated that "this condition is a broadening of the veins in such a way that they contain increased blood" (Lascaratos et al. 2001). A varicose vein or varix has been defined as "a permanently swollen or enlarged and aften torthous venous blood-vessel" (Arnoldi 1957). The World Health Organisation has defined primary varicose veins as: "Sacular dilatation of the weins, which are often tortwous. The dilatation or tontuosity of small subcutaneous veins (venestasias) is not considered as varicose veins. Neither does the diffuse dilatation of superfial weins (so-alled secondary varicose verns) Jollowing 


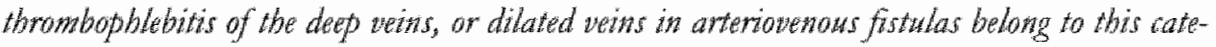
gory" (Prerovsky 1964). In their textbook "Diseases of the veins" Browse et al. (1999) define varicose veins as "twins which bune become excesswely tortwous and dilated". Although imprecise and open to considerable observer variation they prefer this description because of its simplicity. Note that in all the aforementioned definitions no restriction is giwen as to the location or to the diameter of the afflicted vein. Most authors however agree that dilated venules, venectasias, or brush veins do not constitute varicose veins.

Varicose veins can occur as a result of an underlying disonder e.g. occlusion of a proximal part of a vein (thrombosis) or as a result of valve dysfunction or absence e.g. due to genetic disorders.

Varicose veins play an important role in our society because many people are affected and even more are at risk of becoming affected. Varicose veins are generally referted to in relation to the lower extremities but can also occur in other parts of the body such as the arms, the abdomen, the face and internal organs such as the colon or the esophagus. Varicose veins may occur secondary to phlebitis or deep venous thrombosis when occlusion of veins induces redistribution of venous blood through other veins causing them to dilate. If this dillatation can not be compensated in time the increased pressure will cause further dilatation and an inability for the valves to function which may lead to decompensation of the venous system.

Primary varicose veins ate the result of insufficiently functioning or absent valves or weakness of the venous wall. This has led to several theories as to the cause of varicose veins.

Molecular biological investigations have revealed a change in the matrix vesicle (Staubesand 1978), leukocyte adhesion at the cusps of the valves (Naschitz et al. 2000), apoptosis of cells in the vessel wall (Ascher et al. 2001) and a change in expression of matrix metallo-proteinases (MMP's) (Gillespie ct al. 2002) in the course of varciose veins. It is unclear if this is the result of primary hemodynamic changes or an autonomous process leading to the loss of valve function.

\section{"ON THE ORIGIN OF VARICOSE VEINS"}

Other than in humans varicose veins are virtually non-existent. It has been supposed that one of the reasons is the upright position of humans. This would lead to a larger blood column which would cause high pressures in the venous system. 
This in turn would lead to dilatation of veins in the legs which would inevitably lead to varicose veins.

The former would infer that varicose veins are the inevitable result of an inadequate adaptation, or to short a period of adaptation to the aforementioned change in posture.

Modern man (H sapiens sapiens $(130,000$ y BC - current)) was not the first creature to use bipedalism as a means of locomotion. He has probably evolved from an ape-like ancestor: Australopithecus afarensis (3.7 - 3 milj. y BC) who probably was the first real bipedal (Wood \& Collard 1999). Its ancestor Ardipithecus or Australopithecus ramidus (pithecus $=$ ape; ramidus $=$ root) $(5.8-5.2$ milj. y BC), lived in the African jungle and still combined upright walking with tree climbing (Balter 2001). In this context A. ramidus may be seen as a transitional species. The possibility of bipedal movement made it feasible for these species to move more rapidly and to hunt for snall animals that lived outside the jungle. This made it possible for these species to leave the African jungle and migrate to other areas and eventually spread all over the world. As mentioned above this postural. change may also have had great implications for the blood column in the thorax and legs.

In evolution many species have adapted to changing circumstances to survive. In animals such as the giraffe the arterial and venous system has adapted excellently to the great pressure differences during walking standing and drinking (Hargensson 1987). The giraffe - with an average height of $3.5 \mathrm{~m}$ - has developed a natural 'anti-gravity-suit' to overcome theoretical arterial pressures varying from $110 \mathrm{~mm} \mathrm{Hg}$ in the head when standing and $310 \mathrm{~mm} \mathrm{Hg}$ in the feet (Pedley 1987). Varicose veins are generally not observed in these or other mammals.

During the transition from walking on all fours to bipedalism something else changes in the function of the chest cavity. In quadrupeds the thorax is part of the locomotor apparatus. There is a one-to-one correlation between breathing pattern and stride because the lungs must be fully inflated to add rigidity to the thoracic complex that absorbs forelimb impacts during running. The thorax is funnelshaped.

Bipedalism enables the species to breath independently from locomotion. The thorax is no longer a part of the locomotive apparatus and is barrelshaped. This probably is one of the most important factors in the development of speech (Ohman 1986, MacLarnon \& Hewitt 1999).

Furthermore we need to realize that the first bipedal creatures were about 1 to 1.2 $\mathrm{m}$ in height (Helmuth 1992). Pressure changes due to the postural change are 
subsequently very small and can not be held responsible for the occurrence of varicose veins alone.

The popular held conception that venous insufficiency has occurred in humans because of their postural change and subsequent pressure changes in the inferior vena cava alone is therefore not valid. One co-factor may be the possibility of independent breathing as described above which enabled humans to build pressure in the thorax (eg. lifting weights). Another co-factor may be the apparent inability to develop a firm fascia in the legs to function as an antigravity suit for the deep veins.

Thermoregulation is probably the most important function of the superficial venous complex (Browse et al. 1999). In cold surroundings vasoconstriction will prevent superficial venous blood from cooling whereas in warm surroundings and during exercise vasodilatation will enable humans to lower their body temperature. This may explain why most patients with varicose veins have more complaints during the summer. Reduction of collagen fibers and loss of function of the sympathetic nerve system may be other co-factors for the accurrence of varicose veins.

Knowledge about the adaptations of our ancestors from the fossil remnants is understandably sketchy (Wood \& Collard 1999). As a consequence it has been very difficult to confirm or falsify any hypothesis regarding the evolutionary causes of varicose veins.

\section{SOME BASIC FIGURES}

Since the beginning of dermatology phlebology is embedded in general dermatological practice. Initially dermatologists treated crural ulcers because of their knowledge of skin disease and the treatment of other - e.g. luetic - ulcers. They understood the rationale of compression as the cornerstone of therapy for ulcers caused by venous insufficiency. As a consequence dermatologists started to treat varicose veins that could not be treated by general surgeons. Phlebology plays an important role in every day dermatology practice and has therefore become an integral part of training of dermatologists in the Netherlands.

Because of our interest in phiebology the department of dermatology in our hospital another wanted to make an inventory of all patients with varicose veins that visited the clinic. The out-patient clinic is situated in a rural part of the Netherlands, partly in-hospital (Sint Joseph ziekenhuis', Veghel) and partly in Uden in an outpatient clinic. Both practices have been managed in the same manner for a 
large number of years and thete are no differences in therapy modalities available. Together these practices can be viewed as one unit in a well demarcated area. The adherence figures ${ }^{2}$ for our practice in 1999 were: 121,348 for out-patients and 124,426 for admitted patients. For the Sint Joseph hospital these figures were 100,833 and 99,694 respectively (Anonymus 2000).

There is no dermatological/surgical/phlebological center in the neighborhood which would suggest that there is a normal supply of patients with phlebologic pathology. The distribution of pathologic findings in these patients should be representative for this region. There is an excellent cooperation with other specialties especially with the (vascular) surgeons in the hospital.

From April 1997 to April 1998 all patients who made an appointment for a phlebological intake were registered using a specially designed form. Over this one year period a total of 4,856 new dermatological patients were registered and 12,108 control visits were made. Patients were registered as "new" if they had never been treated for varicose veins or as "old" if they had not been treated for at least two previous years. At the time of the inventory there were three dermatologists working in our clinic (a total of 2.5 full time equivalent). These dermatologists practiced all aspects of dermatology and phlebology.

In the above mentioned period a total of 580 new phlebologic patients were seen. This is $11.9 \%$ of the total amount of patients during that period. The average age was 46.3 year. Ninety men were seen (average age: $49.5 \mathrm{yr} /$ range: $21 \mathrm{yr}, 10$ months- $83 \mathrm{yx}, 9$ months) and 490 women ( $45.7 \mathrm{yr} / 12 \mathrm{yr}, 4$ months $-83 \mathrm{yr}, 9$ months). The youngest patient was a girl suffering from varicose veins due to Klippel-Trenaunay's syndrome. Of these 580 patients $245(42.2 \%)$ had been previously treated for waricose veins (table 1).

Of al] patients the largest diameter of the varicose veins was tegistered (table 2). From this table it can be deduced that more than half of our patients have significant varicose veins: either great saphenous vein (GSV) or short saphenous vein (SSV) incompetence or side branch varicosis. One might differ on the significance of reticular varicose veins (aprox. $11.5 \%$ left and right) because these veins

1. In 2000 the Sint Joseph ziekenhuis in Veghel merged with the Sint Anna ziekenhuis in Oss to form Ziekenhuis Bemboven.

2. There is no correct translation for "adherentecifer" in the English language. Therefore a one-on-one translation is used: "adherence figure". 
14. CMAPTER 1

Table 1. "Old" ws. "new" patients registered during a one year period

\begin{tabular}{|c|c|c|c|c|}
\hline & "new" & & "oldi." & \\
\hline \multirow[t]{2}{*}{ total 580 patienrs } & $335(57.8 \%)$ & & $245(42.2 \%)$ & \\
\hline & $59(17.5 \%) \mathrm{men}$ & $276(82.4 \%$ women & $31(12.7 \%)$ men & $214(87.3 \%)$ women \\
\hline axterage age & $48.0 \mathrm{yr}$ & $42.9 \mathrm{yr}$ & $523 \mathrm{ym}$ & $49.3 \mathrm{yr}$ \\
\hline
\end{tabular}

Table 2. Largest diameter of varicose vein per patient per leg

\begin{tabular}{lcc}
\hline largest diarneter & left $(\%)$ & right $(\%)$ \\
\hline branch varicosis & $164(28.3)$ & $157(27.1)$ \\
side branch & $145(25.0)$ & $174(30.0)$ \\
reticular weins & $69(11.9)$ & $64(11.0)$ \\
brush veins & $63(10.9)$ & $59(10.2)$ \\
unknown & $139(24.0)$ & $126(21.7)$ \\
botal & $580(100)$ & $580(100)$ \\
\hline
\end{tabular}

do not always lead to physical complaints. Only one in every ten patients present themselves with brush veins (venectasias) which are predominantly cosmetically disturbing.

With the exception of patients with brush veins all patients underwent Doppler investigation using a so-called handheld $\mathrm{cw}$-Doppler instrument to evaluate saphenofemoral en saphenopopliteal (SP) crosse patency. Of all patients in 54 cases the left saphenofemoral (SF) junction was incompetent in 81 cases the right $\mathrm{SF}$-junction and in 79 cases both sides were incompetent.

The left SP-junction was incompetent in 20 cases, the right in 33 and bilaterally in 10 cases. At the time of this inventory it was not possible to routinely confirm the results of the Doppler investigation with the use of Duplex ultrasound investigation. However $\mathrm{cw}$-Doppler can still be used as a screening technique (Coleridge Smith 2001) (table 3).

In 94 out of 335 "new" patients (28.1\%) an incompetent saphenofemoral junction was found (left (25), right (39) or bilateral (30)). A saphenopopliteal junction was found to be incompetent in 23 out of 335 of patients $(6.8 \%)$. 
Table 3. Results of Doppler investigation

\begin{tabular}{llll}
\hline $\begin{array}{l}\text { Doppler investigation }(n=523 ; \text { all } \\
\text { patients) }\end{array}$ & left & right & both sides \\
\hline SF junction incompetence & $54(10.3 \%)$ & $81(15.4 \%)$ & $79(1.5 .1 \%)$ \\
SP junction incompetence & $20(3.8 \%)$ & $33(6.3 \%)$ & $10(1.9 \%)$ \\
\hline
\end{tabular}

Table 4. Previous treatment in "old" patients

\begin{tabular}{llcc}
\hline previously treated patients $(\mathrm{n}=245)$ & left & right & both sides \\
\hline stripping procedure & $14(5.7 \%)$ & $15(6.1 \%)$ & $25(10.2 \%)$ \\
GSV crosse-ectomy & $14(5.7 \%)$ & $20(8.2 \%)$ & $27(11.0 \%)$ \\
SSV crosse-ectomy & $10(4.1 \%)$ & $8(3.3 \%)$ & $2(0.8 \%)$ \\
compression sclerotherapy & $8(3.3 \%)$ & $13(5.3 \%)$ & $157(64.1 \%)$ \\
ambulatory phlebectomy & $1(0.4 \%)$ & 0 & $2(0.8 \%)$ \\
\hline
\end{tabular}

Table 5. Recurrence rates in previously treated patients

\begin{tabular}{llll}
\hline & left & right & together \\
\hline recurrent GSV & $34 / 75(45.3 \%)$ & $39 / 81(48.1 \%)$ & $73 / 156(46.8 \%)$ \\
recurrent SSV & $7 / 10(70.0 \%)$ & $6 / 11(54.2 \%)$ & $13 / 21(61.9 \%)$ \\
\hline
\end{tabular}

Table 4 provides information of all previous treatments of the "old" patients. Patients are equally divided between stripping procedure (no distinction was made between short or long stripping procedures) and crosse-ectomy ${ }^{3}$ of the GSV. Almost $65 \%$ of patients had received compression sclerotherapy for both legs and only $8.6 \%$ unilaterally.

Although ambulatory phlebectomy was introduced in the practice in 1994 no conclusion can be drawn from the fact that only one patient had received this therapy previously.

3. Ligation of the so called "crosse" is the ligation of the saphenofemoral junction and its tributaries. Ligation of the SF junction is therefor an incorrect rerm. "The correct tanslation inro Eng. lish/American would be a "crook-ectomy" (the French word "crosse" is translated into crook and has more than one connotation). It is however common practice in the lirerature to use ligation where in fact a crook-ectomy is meant. 
Next we were interested in the recurrence rates after previous surgical treatment (table 5). Thirty-nine of the 81 patients who had undergone surgery for incompetent $\mathrm{SF}$-junction (stripping or crosse-ectomy of right GSV) had recurrence of the right $\mathrm{SF}$-junction ( $48.1 \%$ ) as determined with $\mathrm{cw}$-Doppler investigation.

For patients who had been treated for the left SF-junction these numbers are similar: $34 / 75$ patients (45.3\%). These numbers are high and somewhat biased because no distinction was made between stripping procedures and crosse-ectomy.

However the choice for either technique had been made by surgeons based on their findings and their experience. Doppler examination is less reliable in patients with recurrent LSV or SSV varicosis it is therefore advisable to confirm these findings with Duplex-examination.

For the SP-junction the numbers are smaller: $7 / 10(70 \%)$ right and $6 / 11(54.4 \%)$ left side. A more general overview of phlebology and varicose veins is described in chapter two. From these data it is clear that the phlebological part of a general dermatological practice in the Netherlands is substantial and that most patients have varicose veins with hemodynamic disturbances in need of treatment to avoid later complications.

\section{"THE AIMS OF THIS THESIS}

Although ambulatory phlebectomy has been practised for more than forty years we were unable to find any evidence that this technique is more effective than the alternative: compression sclerotherapy. It is generally excepted that ambulatory phlebectomy will lead to excellent (cosmetic) results and a high degree of patient satisfaction. However evidence in the literature about indications, final results and complications is lacking. As ambulatory phlebectomy can play an important role in the treatment of varicose veins and chronic venous insufficiency different studies seem to be necessary to give this technique its proper place in the wide range of treatment possibilities for venous disease.

To date there are also no prospective studies in the literature in which the results of ambulatory phlebectomy and compression sclerotherapy have been compared. In this thesis special attention is given to make a comparison between ambulatory phlebectomy and its most frequently used opponent: compression sclerotherapy. Because side branch varicose veins are considered to be an ideal 
indication for both compression sclerotherapy and ambulatory phlebectomy, the varicose vein of choice in this comparison should probably be a side branch. The relation between success of treatment and compression and especially the so-called dangerous anatomic sites will also be addressed. Since Muller's first publication it has been assumed that some form of compression has to be applied during the post-operative period (Muller 1966). Initially Mulier even advised patients to walk vigorously for several hours after the operation. We became interested in possibilities to increase the effectiveness of compression in the post-operative period.

Because of initial adverse events one of the most important maxims in compression sclerotherapy has been: "never treat below the ankle". From personal experience we found that ambulatory phlebectony could be used safely in this region. A theoretical background for this indication seemed to be lacking. Furthermore a definite orientation of the technique among other options such as compression hosiery, compression sclerotherapy or surgery was absent. In order to investigare these and other aspects of ambulatory phlebectomy several studies were designed.

The ains of the thesis were formulated as follows:

1. Is ambulatory phlebectomy more effective than compression sclerotherapy for the treatment of side branch vaticosities.

2. Can compression therapy after treatment of varicose veins improve results?

3. Is ambulatory phlebectomy a safe and effective therapy modality for varicose veins of the foot.

4. What are the indications and possible complications of ambulatory phlebectomy in different types of varicose veins.

5. What is the effect of continuing education on ambulatory phlebectomy? 



\title{
CHAPTER 2
}

\section{VARICOSE VEINS \\ Diagnosis and treatment}

\author{
Based on: \\ Roos K-P de, Neumann HAM. \\ Treatment of varicose veins; The Maastricht perspective in Phlebology.
}

Praktická Flebologie, 1993; 1: 5-11.

Neumann HAM, Roos K-P de.

Microchirurgische ambulatoire flebectomie.

Ned Tijdschr Dermatol Venereol 1994; 4: 343-9. 


\section{INTRODUCTION}

In the last three decades there has been an increasing interest in venous circulatory disorders, probably because of the increased number of possibilities to treat varicose veins successfully.

On the basis of ptevious work done by Orbach (1950a) and Sigg (1952), Fegan $(1963,1967)$ introduced compression sclerotherapy as a modification of to injection sclerotherapy (without compression) which was then the therapy of choice. In combination with selective surgical intervention to eliminate the major points of reflux, this development has attributed to the improvement of therapy (Neumann 1993a). Although it has opened new possibilities there are still a number of unsolved problems in the treatment of varicose veins. Ambulatory phlebectomy contributes to a more differentiated approach (Neumann 1992). Complications due to primary varicose veins and other forms of venous insufficiency are a major socio-economic problem (Bartolo 1992, Jantet 1992). Feuerstein calculated that $50 \%$ of crural ulcers arise because of primary varicose veins (Feuerstein 1979). This was later confirmed by Nelzén who in a cross sectional study calculated that $54 \%$ of leg ulcers originate from venous causes (Nelzén et al. 1994). Contrary to what some may think (van der Veer 1993) the number of venous ulcers can be halved if superficial venous insufficiency is adequately treated.

Large epidemiological studies (Widmer et al 1981, Fisher et al. 1981) have emphasized the importance of venous disease in western society. In 1990 Nelzén et al. carried out a postal questionnaire among 12.000 randomly selected persons (age 50-89) in two defined regions in Sweden (Nelzen et al. 1996). They concluded that the observed point prevalence of open leg ulcers was $0.63 \%$ of the total population. The overall prevalence of leg ulcer history (open plus healed) was around $2 \%$. In this study the ratio open vs. previous ulcer was $1: 2$. A Swedish prospective epiclemiological study revealed that the incidence of crural ulcers is $1.2 \%$ (Andersson et al 1993).

In a recent publication Adhikari et al. (2000) state that, based on the avallable epidemiological studies, the overall adult prevalence of active and inactive chronic venous ulcers is around $1 \%$. In the Netherlands with a population of 16 million, this would implicate a prevalence of 160,000 venous ulcer patients, of which approximately 50,000 are active. These estimated figures are lower than eartier estimations for the Netherlands of about 95,000 venous ulcers (Neumann 1988). 
In a retrospective review Heit et al. found no change in incidence of venous stasis syndrome since 1966 and an unchanged venous ulcer incidence since 1981 (2001).

The medical importance of venous disease is demonstrated by the high rate of complications such as thrombophlebitis, edema, chronic venous reflux, embolism and venous ulcers. Although there is no information on the numbers of hospitalized leg ulcer patients in the Netherlands it has been calculated that in Western-Germany 275 million D-Mark (aprox. 143 million Euro) was spent on patients with leg ulcers in the last decade of the last century (Wienert 1992). Elimination of superficial venous insufficiency plays an important role in the prevention of complications.

There is a tendency in the medical profession to accept these facts. This is illustrated by the observation that little attention is drawn to venous disorders in medical training and general textbooks. However varicose veins occur on the top ten list in the Netherlands of complaints patients consult their general practitioner with. The morbidity of varicose veins varies in the literature from $15 \%$ (Rudolfsky 1978) up to 62\% (Da Silva et al. 1974).

In a representative epidemiologic study in the Munich area Eberth-Willerhausen and Marshall examined 1000 unselected persons. They found peripheral venous abnormalities in $50 \%$ of persons. Twenty-five percent were unimportant, $10 \%$ relevant and $15 \%$ pathologic. The prevalence of peripheral venous disease grew with increasing age and no sex difference was found (Eberth-Willerhausen \& Marshall 1984).

Dermatologists play a crucial role in diagnostic procedures and therapy of venous circulatory disorders. Accurate diagnosis and systematic treatment, specially in early cases, are the major contributions to prevent serious complications as mentioned above.

If early, well performed, and continuously supervised treatment of varicose veins would be generally accepted it would lead to a considerable reduction in cost for society and to an improvement of the quality of life for many patients. 


\section{PATIENT HISTORY AND PHYSICAL INVESTIGATIONS}

Probably the most important question asked at the beginning of each new phlebologic consultation is the reason for consultation. This provides the physician with valuable information on the expectations the patient has of the results of the treatment offered.

If varicose veins are cosmetically disturbing patients expect to leave without any blemishes. If the patient is restricted in daily activities the end result of therapy should relieve him or her of those complaints.

With the exception of venous claudication venous complaints are non-specific. Patients medical history should therefore include questions regarding ankle edema, muscular or nocturnal cramps, restless legs (which increase during the day) etc. as well as questions pointing on arterial diseases (eg. claudication, nocturnal pain, arterial bypass surgery, etc. [table 1]).

Tablle 1. Patient history

1. Reason for consultation

2. Verous complaints

- diffuse dull ache

- night cramps increase during the day

- pain

- ankle ordema

3. Arterial complaints

- claudication

- nocturnal pain

- ressing pain

4. General and family history (eg. cardiac on respiratory problems).

5. Patient history

- general: previous treatment, smoking

- venous: thrombosis, phlebitis, erysipelas, pperation, sclerotherapy, use of elastic stockings

- arterial: trauma, operation etc.

6. Medication

7. Mllergies 
Table 2. Methods of Clinical Investigation

\begin{tabular}{|c|c|c|}
\hline Measurement & Techrique & \\
\hline Volume changes & Plethysmography & $\begin{array}{l}\text { - Strain gauge } \\
\text { - Foot volumetry } \\
\text { (waterplethysmograply) } \\
\text { - Light Reflection Rheography } \\
\text { d-PPG } \\
\text { - Videophotography } \\
\text { - Air }\end{array}$ \\
\hline Fllow & $\begin{array}{l}\text { - Optic-electronic volumetry } \\
\text { - Doppler altrasound }\end{array}$ & $\begin{array}{l}\text { - One-directional } \\
\text { - Bidirectional } \\
\text { - Pulsed Doppler } \\
\text { - Laser-Doppler }\end{array}$ \\
\hline & - Duplex scanning & \\
\hline Anatomy & $\begin{array}{l}\text { - Duplex scanning } \\
\text { - Phlebography }\end{array}$ & $\begin{array}{l}\text { - Descending } \\
\text { - Ascending } \\
\text { - Dynamic (=functional) }\end{array}$ \\
\hline & - Capillary videomicroscopy & \\
\hline Pressure & $\begin{array}{l}\text { - Percutaneous Oxygen pressure (PcPO2) } \\
\text { - Venous pressure }\end{array}$ & \\
\hline Restgroup & $\begin{array}{l}\text { - Radionucleic investigations } \\
\text { - Thermography }\end{array}$ & \\
\hline
\end{tabular}

Taking the patients medical history should be followed by a physical examination. to estimate the severity of the venous problem and to exclude other pathology. An inventory should be made of the varicose veins and telengiectasias.

Further instrumental diagnostics will help the clinician to identify the problem and to avoid pitfalls. Many different devices have been developed for this purpose over the years (table 2).

Most patients however can be sufficiently diagnosed with a combination of lightreflection rheography and. Doppler ultrasound as non-invasive screening tools in a general phlebologic practice. 
Or as Schultz-Ehrenburg put it:

"Today photopletbysmograpby and Doppler ultrasonograpby are part of the basic phlebologic diagnostic arsenal. They represent the examination methods of choice and in most cases obviate the necessity for resorting to invasive methods" (1993).

\section{VASCULAR LABORATORY ANALYSIS}

It is important that diagnostic procedures deliver information on venous hemodynamics. When venous hemodynamics are disturbed decisions have to be made on if and how these should be corrected. Detected reflux in the venous system does not necessarily mean there is a hemodynamic relevant reflux. Reflux as. such may not have any consequence for a patient's hemodynamic status. When the calf muscle pump function is capable of compensating the reflux there is no need to correct this - physiologic - situation. At all time however a distinction has to be made between superficial and complicated venous insufficiency.

\section{Detection of reflux}

In parients with varicose veins reflux develops when valves lose their function. This can be seen as one of the key deviations of venous insufficiency. Doppler-ultrasound technique has been propagated as 'the' technique for the detection of reflux. In recent years there is a tendency for investigators to use Duplexscanning technique as a standard technique. It has great advantages because of the anatomic picture of the vessel structure which is made visible through an echo image which is combined with flow direction information detected with Doppler ultrasound. Because deviations can be recorded with cameta or video patients venous status can be documented which can be useful in the event of a later recurrence. However one has to take into account that Duplex-scanning investigations are time-consuming and have a cost-raising effect which is not necessary in most cases of uncomplicated varicose veins. Athough these instruments have become more affordable over the years as a screening device Doppler-ultrasound will - for the time being - remain the first choice (Neumann 1988, Felix 1988, Coleridge Smith 2001).

\section{Doppler Ultrasonim}

A moving structure will cause the reflected or backscattered signal frequency to be shifted up or down by an amount proportional to the interface velocity acting 
allong the sound beam axis. This phenomenon was first described in 1843 by the Austrian physicist Christian Johann Doppler (1803-1853)(Felix 1988). In its simplest form, this shift is given by the following equation:

$$
\sigma f=\frac{2 V f^{\prime \prime} \operatorname{Cos} \Phi}{C}
$$

In this equation, " $\sigma \mathrm{P}$ " represents the Doppler shift (a change in frequency between the transmitted and received sound waves) expressed in $\mathrm{Hz}$; "V" represents the vector velocity of interface expressed in $\mathrm{cm} / \mathrm{sec}$; " $\Phi$ " represents the angle, in degrees, between the sound beam axis and the velocity vector; "fo" represents the carrier frequency; and " $\mathrm{C}$ " represents the speed of sound in tissue (approximately $1540 \mathrm{~m} / \mathrm{sec}$ ). Since $\mathrm{f}^{\star}, \cos \Phi$ and $\mathrm{C}$ can be constant, $\sigma$ f is proportional to the velocity of the moving interface (eg. bloodcells) (Baker 1988). It can also be deduced that if the angle $\Phi$ is $90^{\circ}$ its cosine and $\sigma \mathrm{f}$ will equal 0 , hence there will be no signal which has practical implications for placing the probe on the patient. The maximum shift will occur parallel to the direction (to and fro) of motion, where the $\cos \Phi=1$.

The presence or absence of a moving interface is detected by observing the Doppler shift (eg. blood flow). This frequency shift is in the audible range (between $20 \mathrm{~Hz}$ and $20,000 \mathrm{~Hz}$ ), which enables an audioamplifier with earphones or loudspeakers to be used as output devices. A strip chart recorder may be used to generate a hardcopy printout of the frequency shift (Hykes et al. 1985).

In using this phenomenon one can determine the speed and direction of the moving object, for instance blood cells. Therefore we can use Doppler ultrasound to investigate arterial or venous blood flow.

The most important indications for Doppler uitrasound in phiebologic practice are:

- saphenofemoral and saphenopopliteal junction insufficiency;

- great saphenous vein (GSV) insufficiency;

- femoral valve insufficiency and detection of retrograde flow in the decp venous system;

- perforating vein insufficiency.

There are several types of Doppler ultrasound available (table 2). Depending on the frequency of the ultrasound emitted by the probe more or less is absorbed by tissue and inversely more or less is reflected to the probe. For example the depth of penetration for $2 \mathrm{MHz}$ transducers is approximately 15 centimeter. For 8 $\mathrm{MHz}$ transducers this is approximately 3.5 centimeter. Therefore high frequency 
probe (eg. 8-10 MHz) should be used for when investigating superficial veins and low frequency (eg. $3-5 \mathrm{MHz}$ ) for deep veins and arteries. Although higher frequencies do not penetrate deep into the tissue they are mote efficient in detecting low bloodflow. Since flow in veins is low higher frequencies can be used effectively in veins (Waxman 1988).

Doppler ultrasound instruments are often referred to as 'Doppler-flowmeters' but this is an unfortunate term since the information derived is not flow but velocity and because quantitative precision, as implied by the word 'meter', is not really achieved (Waxman 1988).

The simplest Doppler ultrasound instrument (one-directional) transmits a continuous beam of ultrasound into tissues and vessels of interest at fixed frequencies. It cannot give information on velocity or direction of the blood flow. But is however useful in detecting reflux in venous patients.

Bi-directional Doppler ultrasound instruments also give information on direction and, semi-quantitative, blood flow, they also have the advantage of variable penetrance because of variable frequencies (Markward 1988).

\section{Doppler examitation}

Patients are best inspected in standing position at which time most important veins can be marked with indelible pen. All footwear and elastic bandages should be removed from the legs and feet. For the examination with Doppler ultrasound the patient is either standing or placed in a supine position with the head slightly elevated to assure filling of the lower extremity veins with blood (Felix 1988). In this position the venous blood flow in the large veins is influenced by respiration (S-sound) (Sigel et al. 1968, Feuerstein 1981). Venous flow can easily be differentiated from arterial blood flow because of its slow and continuous character. We preter to use a bi-directional Doppler ultrasound apparatus to examine the total venous system. The superficial system is best examined in patients in a standing position.

The Doppler ultrasound probe is first placed in the inguinal space with conducting hydro-gel, just medial from the femoral artery and the thigh-muscle compartment is compressed (augmentation according to Sigel) (1972). With this distal compression venous blood will move toward the heart producing a signal. Compression is followed by decompression. A competent saphenofemoral junction (SF-junction) should produce a short signal after decompression indicating the closing of the valves. In applying Vasalva's maneuver this can be demonstrated even better. Rising intra-thoracic pressure through forced expiration will prevent venous reflux into the right ventricle; in patients with competent venous valves 


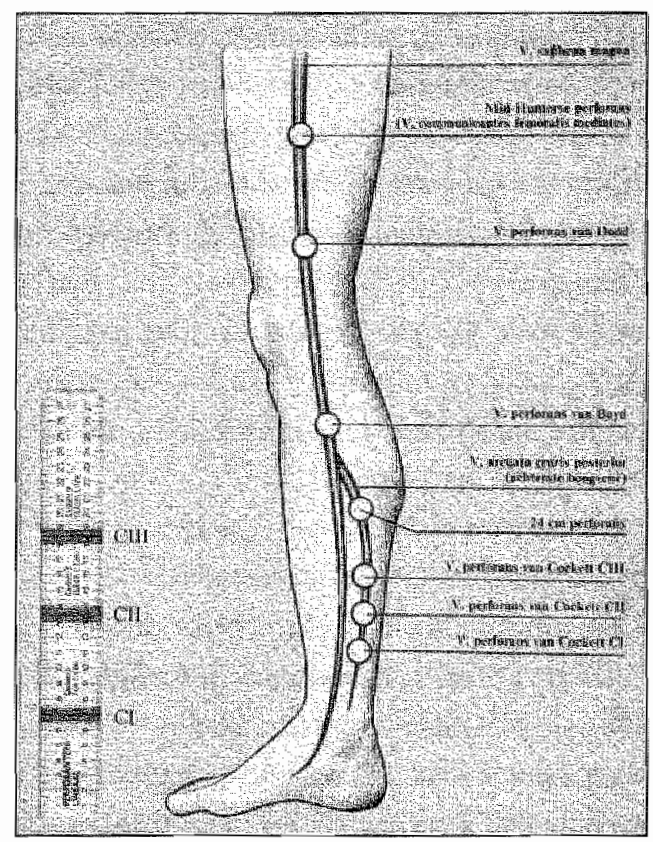

Figure 1. Perforating veins on the medial side of the $\operatorname{leg}$ (Neumann 1988)

no significant reflux will be detected. Incompetent valves will produce a much longer and continuous sound due to the existing reflux.

After determining $\mathrm{SF}^{-j u n c t i o n}$ incompetence the length of the reflux is measured according the stages of Hach (Hach et al. 1977, Hach 1981). By using a tourniquet just proximal to Hunter's perforating vein (figure 1) the great saphenous vein (GSV) is blocked. Again by compression and decompression patency of the valves is determined. If backflow occurs Hunter's perforating vein is considered to be insufficient. The rest of the connections between superficial and deep veins (saphenopopliteal junction, Dodd's, Boyd's and sometimes May's perforating veins) are then subsequently examined.

Since there is still is no communios opinio about the venous nomenclature in the literature, Staubesand and Yi Li have proposed changes to the Parisian Nomina Anatomica (PNA)(1992). Transfascial or perforating veins of the lower extremity should, in their opinion, be divided into three major groups, femoral, crural and pedal perforating weins which should further be determined according to their distance from the plantar plane in centimeters (measured in upright position). 
For example Cocketts third perforating vein (C III) should become the $18 \mathrm{~cm}$ perforating vein to avoid discrepancies in the literature (figure 1).

Recently an International Interdisciplinary Consensus Committee on Venous Anatomical Terminology conceived a consensus document to offer an internationally acceptable venous anatomical terminology that would satisfy both anatomists and clinicians (Caggiati et al, 2002). To date some confusing names are used for superficial veins. Greater, internal, or long saphenous vein and short, external, or lesser saphenous vein - both abbreviated to LSV - are frequently used. To avoid such confusing names the committee recommended only to use great saphenous vein (GSV) and short saphenous vein (SSV).

\section{Duplex ultrasound}

Duplex ultrasound instruments are real time B mode ultrasound scanners with Doppler capabilities. With Duplex ultrasound investigation reflux can be made visible, but as with Doppler examination the results of this investigation is very dependant on the experience of the investigator. Although in most cases Doppler can be used to analyze phlebologic patients (Bradbury et al. 1994) there is a tendency to routinely use Duplex ultrasound.

\section{Functional investigations}

The detection of reflux does not give any information on the seriousness of venous insufficiency. The venous pressure that is measured during muscle pump activity (walking venous pressure [WVP]) is the real measure for the function or dysfunction of the venous system (Kuiper \& Brakkee 1971). It is indicative of the amount of venous working pressure and therefore also of the degree of venous hypertension. Because it is hardly recommendable to routinely measure direct venous pressure an indirect and non-invasive diagnostic tool is preferable. Van Gerwen published a simplified setup with the strain-gauge plethysmogtaph to measure ambulatory venous pressure (van Gerwen et al. 1992). This technique however demands a well equipped venous laboratory, which is why in general practice another non-invasive technique is chosen to measure venous refilling time (VRT).

VRT' is dependant on WVP and of the surrounding temperature. Light reflection rheography (LRR) and digital photoplethysmography (d-PPG) are techniques that are applied the most. Several investigations have established that there is a definite correlation between VRT which has been measured with LRR and the results of ambulatory venous pressure measurements (Muhl 1984). There has 
been some criticism towards the reliability of these plethysmographic tools (Rutgers et al. 1993, van Bemmelen et al. 1992). If one takes into account that the positive predictive value is very high then both technicues, although low in their negative predictive value, are very suitable as a screening device for every day practice (Veraart \& Neumann 1993). LRR can significantly demonstrate differences in VRT of the limbs of normal subjects and those with signs of venous stasis $(\mathrm{p}<0.0001)$ (Williams 1994). There is no significant difference found between the results with the use of LRR or d-PPG (Veraart et al. 1994).

\section{Light-reflection-rbeograpby}

In general phlebologic practice photoplethysmography as lightreflection rheography (LRR) can be used as a non-invasive screening device to distinguish between superficial and deep venous insufficiency. LRR is a variant of photoplethysmography and was developed by Wienert and Blazek in the early 1980s (Wienert \& Blazek 1982). The major difference from the classic photoplethysmography lies in the construction of the measuring probe (Wienert: 1984). This probe contains three light emitters, a detector for the reflected infrared light, and a temperature sensor.

Photoplethysmography is based on the registration of the light rays reflected by the skin. The density of the skin and its ability to reflect light depends on the volume of the blood in the capillaries within the skin. Increased or decreased flow of blood through the skin will result in a different reflected signal which can be made visible. The probe is fixed to the skin usually in the area between the 12 and $18 \mathrm{~cm}$. (Cockett II and III) perforating veins. The measurement probe is constructed in such a manner that outside light will not influence it when attached to the skin. The patient is placed in a sitting position with the knee at an angle of about 110 degrees to facilitate flexion of the ankle.

An installed metronome gives 10 "bip" signals within 15 seconds. With each signall, the parient moves his foot with a dorsal flexion. By moving the foot in this way, the muscle pump will be activated and venous drainage of the lower limb occurs (pump phase).

After this movement phase the leg must be kept still (reflux or refilling phase). The result of the measurement, a light reflection theography diagram is a combination of these two parts (figure 2).

The pump phase is a reflection of the muscle pump activity but as the LRR is a relative measure it can not serve to calculate the amount of blood pumped back 


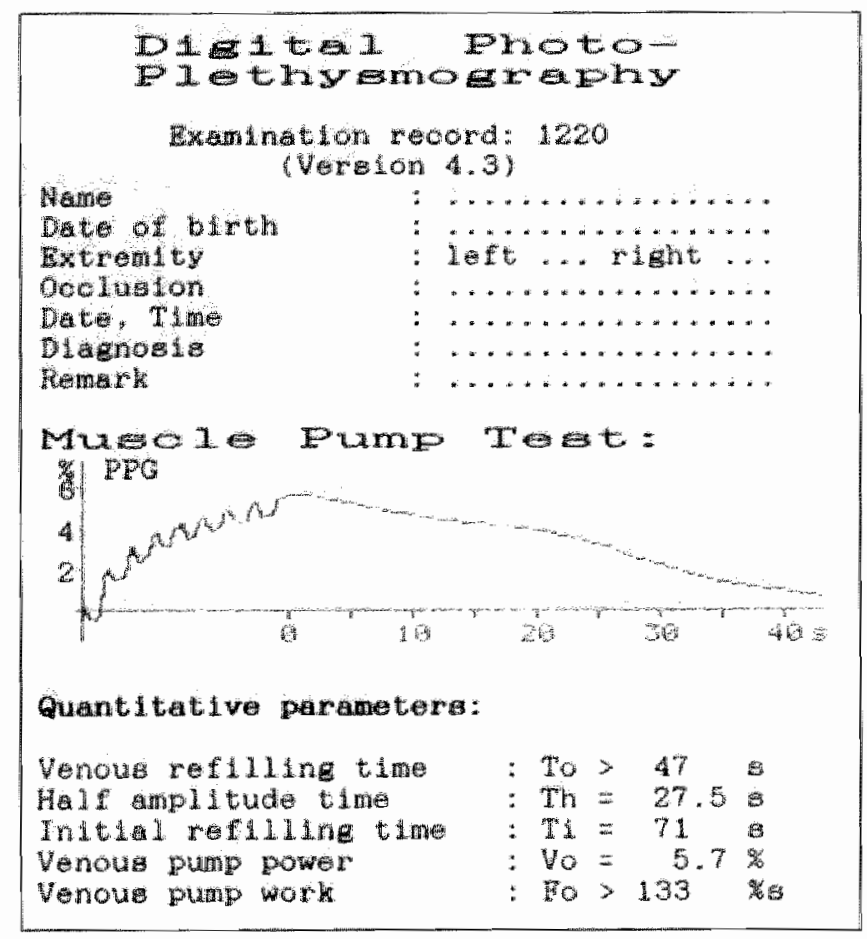

Figure 2. Digital PhotoPlethysmography Diagram (d-PPG)

Table 3. Interpretation of LRR refil time (Neumann \& Boersma 1992)

\begin{tabular}{lll} 
Venous refill time VRT) & Time in seconds & Interpretation \\
\hline & $>25$ seconds & Normal \\
$15-25$ seconds & Uncomplicated varicose veins \\
$15-10$ scconds & CVIIII (according to Widmer) \\
$10-5$ seconds & CVI II-HI (according to Widmer) \\
$<5$ seconds & Post Thrombotic Syndrome (PTS)
\end{tabular}

to the heart. The second part represents the refill phase that follows after calf-muscle activity. The time needed is defined as the venous refill time. The venous refill time is indicative for the function of the venous system as compared with direct venous pressure measurements (Wienert \& Blazek 1982, Nuzzaci et a. 1986), with a $98 \%$ accuracy if performed accurately.

One should bear in mind that plethysmography is dependent on temperature and that a reliable en reproducible result can only be obtained at room temperature (Neumann \& Boersma 1992). 
If the refill time is 25 seconds or longer the measuring results are regarded as normal (table 3). A shorter refill time (15-25 sec.) indicates uncomplicated varicose veins, a refill time between 10 and 15 seconds indicates chronic venous insufficiency (CVI) grade I-II and between 5 and 10 seconds CVI grade II-III (Widmer et al 1981).

If a refill time is shorter than 5 seconds, severe CVI and in general a post-thrombotic syndrome will be the cause. The given figures are indicative as a wide overlap between the different stages exist. By partially blocking the superficial venous system with a tourniquet, the physician can differentiate between superficial and deep venous insufficiency. If the refill time also remains reduced after the closure of the entire superficial venous system, there is a high suspicion for deep venous insufficiency (Neumann \& Boersma 1992).

More than two decades ago Partsch suggested to differentiate venous insufficiency not according to a clinical scale (eg. Widmer) but according to whether the insufficiency can be expected to be corrected through therapy (Partsch 1980). Thus patients who have been examined with LRR and Doppler ultrasound can be divided into two groups:

- Improvable venous insufficiency

- Non-improvable venous insufficiency.

Wienert suggested to use LRR in combination with occlusion tests to differentiate between the two groups. In his article he refers to intra-fascial and extra-fascial leg vein insufficiency (Wienert 1988). This functional view on venous insufficiency is the basis for a pragmatic approach of varicose vein therapy based on hemodynamic disturbances.

\section{THERAPEUTICAL PLAN}

In designing a therapeutical plan for the treatment of varicose veins the physician should follow the extent of the varicose veins from major to minor. Treatment of varicose veins has several objectives. Relief and prevention of complications, prevention of recurrence, telief of symptoms and cosmetics. Therefore the first step must be to determine whether there is a hemodynamic disturbance caused by superficial venous insufficiency alone (improvable) or on deep venous insufficiency (non-improvable) (Partsch 1980, Wienert 1988). The different types of venous insufficiency are listed in table 4 . 
Table 4. Types of venous insufficiency

1. Deep venous insufficiency:

- deep venous thrombosis

- congenital aplasia of venous valves and veins

- angiodysplasias (cg. Klippel-Trenaunay)

2. Superficial vaticose vein wihout deep venous insufficiency

- Saphenofemoral junction insufficiency

- Accessory vein insufficiency

- isolated perforating vein insufficiency

- dilated intradermal veins (syn brush or spiderveins)

- a combination.

3. A combination of 1 and 2 .

The diagnosis deep venous insufficiency (DVI) is based on LRR and Doppler ultrasound and should always be confirmed by Duplex-sonography and in selected cases by phlebography and precise calf muscle pump tests (table 2). When the diagnosis deep venous insufficiency is established up to now compression therapy is the only possibility.

There are several forms of compression: bandages, elastic stockings and external pneumatic compression. When compression with the use of bandages is applied two basic forms of this therapy ate recognized: non-elastic and elastic compression. The first should be used to make the legs free of edema after which the latter may follow. Elastic hosiery's should be tailor-made for each individual patient. It should be borne in mind that compression normally does not influence venous pressure but improves refill-time and microcirculation (Stemmer et al 1980) by reduction of venous volume and reduction of flow in the superficial system.

Compression therapy was extensively reviewed by Neumann and Tazelaar (1993). Compression can be used alone or to support other therapies (e.g. after compression sclerotherapy, stripping procedures), as a preventive measure (e.g. following Deep Venous Thrombosis), or permanently in cases of Post Thrombotic Syndrome. Although some differences exist (Neumann \& Tazelaat 1993, Partsch 1984), elastic or compression hosiery's can be divided into five different 
Table 5. Adopted European Prestandard on medical compression hosiery (CEN 200)

Pressure at the ankle*

\begin{tabular}{lll}
\hline Compression class & $\mathrm{hPa}$ & min $\mathrm{Hg}^{*}$ \\
Col A light & 13 to 19 & 10 to 14 \\
Cel I mild & 20 to 28 & 15 to 21 \\
Coll II moderate & 31 to 43 & 23 to 32 \\
Col In strong & 45 to 61 & 34 to 46 \\
Col IV very strong & 65 and higher & 49 and higher \\
\hline
\end{tabular}

* the values indicatc the compression exerted by the hosiery at a hypothetical cylindrical ankle;

** $1 \mathrm{mmHg}=1,333 \mathrm{hP}_{\mathrm{a}}$

categories (table 5) according to the European Committee for Standardization (Neumann 2000, CEN 2001).

Most stockings for venous insufficiency are categories II or III. Compression category IV stockings are especially suitable for compression of lymphedema. Category I stockings are only suitable for the prevention of deep venous thrombosis in operative patients.

Modern surgical techniques such as valve reconstructions or stent placements may in the future be of value to patients.

Some patients have difficulties with their stockings when the circumference at the ankle is much smaller than the circumference distal to the ankle. This makes it impossible for these patients to put on their stockings. These patients may benefit from wearing two sets of low compression class stockings over one another (class I $+I=$ class II). If not they should be taughe to use elastic bandage therapy. In cases of non-improvable venous insufficiency patients must wear elastic stockings for the rest of their lives since further therapy is not possible. New hosiery's should be provided every four to six months (Veraart 1997, Neumann 1998, Hulpmiddelenkompas 2002).

The next step will be to distinguish between significant superficial venous insufficiency and only cosmetically disturbing varicose veins (eg. telengiectasia or brush veins).

In patients without DVI several therapeutic options are available depending on localization and severity of venous insufficiency and the preferences of both patient and physician. If the saphenofemoral, or saphenopopliteal junction is incompetent this should be treated. 
Athough sclerotherapy is propagated by some (Hördigen 1986), we consider surgical treatment of incompetent junction to be the standard. It is a procedure which has been adequately performed under local anesthesia in many outpatient-clinics for a long time (De Takats \& Quillin 1933). It has less disadvantages and risks than classical compression sclerotherapy. Recent developments however warrant re-evaluation of compression sclerotherapy for incompetent GSV and SSV and perhaps its junctions. Echo-guided sclerotherapy or echosclerosis combines a simple and effective technique (sclerotherapy) with accuracy of Duplex-sonography. This technique will be discussed further down.

Dependant on the severity of the varicose veins total or partial stripping of the great and short saphenous veins may be indicated and performed by a general or vascular surgeon. However even surgeons nowadays tend to be more selective in the use of total stripping as a treatment for varicose veins. (Hobbs 1968, Hobbs 1974, Jacobsen 1979, Negtén 1986, Rutgers \& Kitslaar 1994, Noppeney et al, 2002). In most cases a combination of surgical treatment and sclerotherapy both in an outpatient setting will suffice (surgical intervention may nevertheless be indicated in some cases of proximal or high deep venous thrombosis).

If the abnormal hemodynamics of the venous system is corrected surgically the remaining varicose veins can be treated with compression sclerotherapy. We use the so called "empty vein technique" as described by Hobbs (1976).

\section{COMPRESSION SCLEROTHERAPY}

In supine position the patient is inspected and varicose veins are marked with an indelible pen. It may be useful to mark the perforating veins and sites of injection. The patient will then be treated lying on a horizontal couch to empty the veins and to prevent vasovagal collapse during therapy. If the sclerosing fluid is injected into a patient in the upright position these fluids will flow into the deep system at the theoretic risk of developing deep venous thrombosis.

First ether is used to remove sebum and ointments from the skin, rendering adhesive tape a better surface to attach to. Injection should be started distally and with small intervals. After inserting into the vein the physician should confirm the position of the needle by withdrawing some blood into the syringe. Then the fingers of the physicians free hand should empty the vein slowly away from the needle and simuitaneously injecting $0.25-0.75 \mathrm{ml}$ of sclerosing fluid. After 
removal of the needle the assistant compresses a cotton wool ball on the vein which is fixed with adhesive tape.

When all the pathologic veins have been treated or when the maximum amount of fluid is reached the leg is bandaged using a non-elastic bandage or elastic hosiery. The patient is advised to walk as much as possible during the first hours after therapy. One week after therapy results are assessed and if necessary adjuvant injections are performed. Once the final result has been reached the patient will only be checked if there are residual complaints or recurrent varicose veins. There is no need for check-ups annually.

Other methods have been developed by Fegan and Sigg (Fegan 1963, Fegan 1969, Sigg 1952) for example but have disadvantages either because they are more difficult or carry the risk of vasovagal collapse. Ouvty and Davy only give one or two injections per session which make this therapy very laborious for the physician and especially time consuming for the patient (Ouvry \& Davy 1986). In 1996 a consensus paper on sclerotherapy was published (Baccaglini et al.).

Over the past century several sorts of sclerosing fluid have been used including ferric chloride, iodotannin, phenol, alcohol, Lugol's Iodine and Sodium-chloride (Foote 1954). We prefer sodium tetradecyl sulfate (Thrombovar ${ }^{(3)}$ ) 1-3\% for large and $0.5-3 \%$ polidocanol (Aetoxisclerol $\left.{ }^{(}\right)$) for minor veins. A basic rule generally used in compression scletotherapy is never to use more $12 \mathrm{cc}$ of $1 \%$ sclerosing fluid per session. (eg. $24 \mathrm{cc} .0 .5 \%$ polidocanol or $4 \mathrm{cc} 3 \%$ sodium tetradecyl sulfate) to prevent systemic complications (the "rule of 12 "). If patients are treated with sodium tetradecyl sulfate they are advised to stay under observation at the clinic for approximately one hour because of the risk of systemic (allergic) reactions. In 1995 a prospective single-arm study was performed in Australia in which polidocanol was compared with each investigators previous experience with other solutions. They concluded that polidocanol is a safe sclerosing solution with less than average side effects (Conrad et al 1995). Recently Goldman published the first prospective study on polidocanol in direct comparison to sodium tetradecyl sulfate. Both solutions were equally effective in causing the disappearance of varicose veins of different diameters $(<1 \mathrm{~mm}, 1-3 \mathrm{~mm}$, and 3-6mm). Although pain, inflammation, hyperpigmentation, ecchymosis and vein thrombosis was similar with both solutions, polidocanol caused less localized urticaria and skin necrosis than sodium tetradecyl sulfate (Goldman 2002). 
As with any therapy compression sclerotherapy is never without any risks (van der Plas et al. 1994, Massocco-Trischitta et al. 2002) there is a common opinion among phlebologists that polidocanol is probably the most safe agent to use.

There have been phlebologists who have advocated the treatment of short saphenous vein with compression sclerotherapy. Because of its anatomical position under a fascia this has never replaced surgical intervention. Some investigators have advocated the use of cw-Doppler (Comu-Thenard et al. 1995) or Duplex ultrasound (Knight et al. 1989) during compression sclerotherapy. Preliminary results of a multi-centre study in France revealed only four failures one year after $175 \mathrm{legs} \mathrm{had} \mathrm{been} \mathrm{treated} \mathrm{with} \mathrm{echo-guided} \mathrm{compression} \mathrm{sclerotherapy}$ ("echosclerosis") for incompetent SSV (Schadeck 2001). The long term effects still have to be established.

Another recent development is the introduction of known sclerosing fluids in a new appearance: (micro-) foam. A technique that has arisen directly from earlier work by Orbach $(1944,1950 \mathrm{~b})$ who advocated the use of an airblock to improve contact of sclerosing fluid with the vein wall. Although currently under investigation there are indications that microfoam sclerosants are significantly more effective in the treatment of varicose veins (Cabrera et al. 2001, Tessari et al. 2001, Frullini \& Cavezzi 2002).

\section{AMBULATORY PHLEBECTOMY}

As an alternative to compression sclerotherapy as well as classical vascular surgery certain varicose veins can also be treated with a special and elegant operative technique: percutaneous phlebectomy or ambulatory phlebectomy. Robert Muller, a Swiss dermatologist started experimenting with this technique in the mid-fifties because he was unsatisfied with the results of sclerotherapy. Moreover he wanted an alternative for the large eyecathing scars patients were left with after classical varicose vein surgery. After ten years of experience he demonstrated this technique during the annual meeting of the French Phlebology Society (Muller 1966, Olivencia 1998).

As with compression sclerotherapy before treatment the patient is inspected in supine position. The skin overlying the varicose vein that is to be extracted is marked with indelible pen (figure 3a). Then the patient takes place on the operating table. Along the marked area the skin is infiltrated with a local anesthetic (with or without epinephrine). The area is then disinfected and cotton or dispos- 


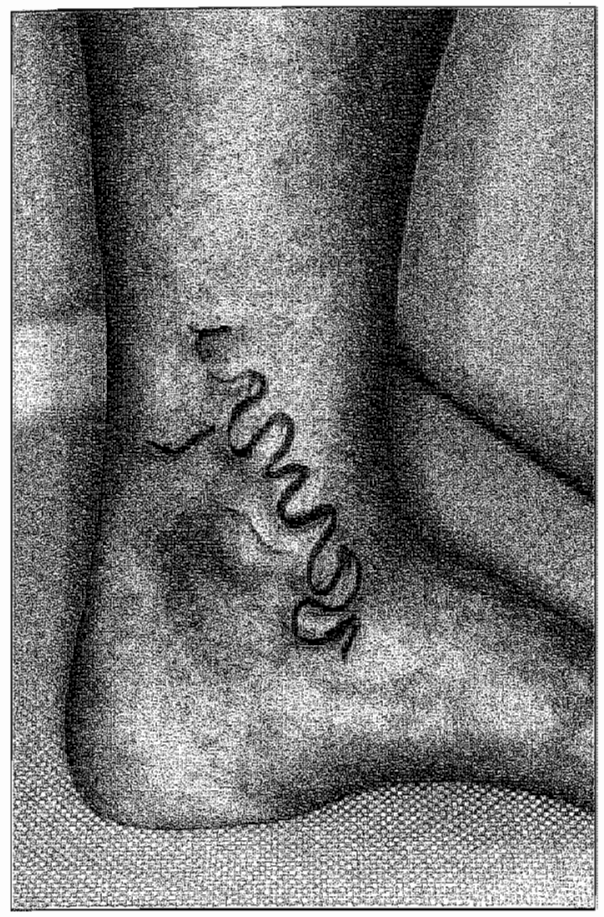

Figure 3a. Varicos vein in the ankel region

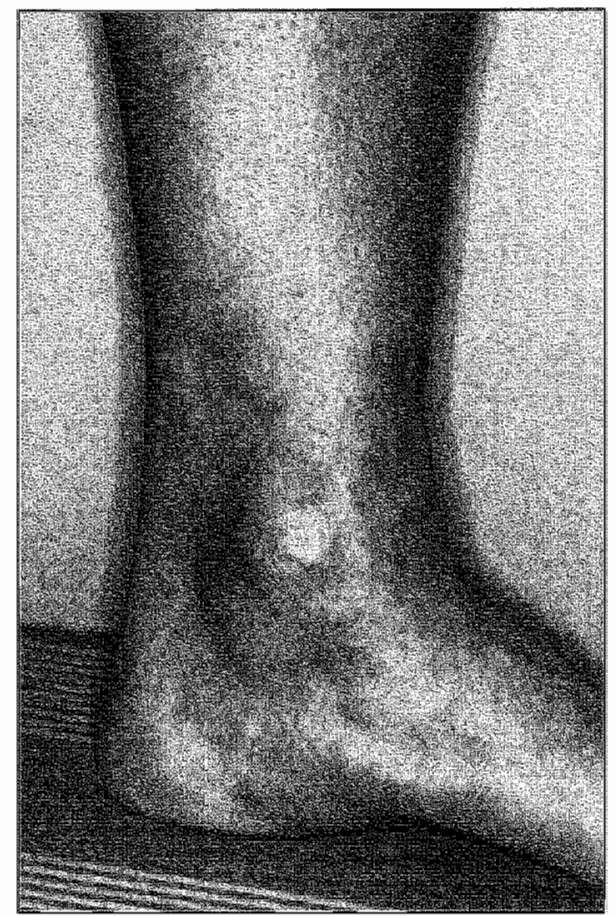

Figure 3b. Same ankle as shown in figure 3a. 6 weeks after complete removed of varicosevein

able paper drapes are put in place. The procedure begins with a minute incision parallel to the marked line and approximately $2-3 \mathrm{~mm}$. long. Through this incision the phlebectomy hook is inserted and the varicose veins is hooked, extracted, and subsequently fixed with a clamp (e.g. Mosquito). Next the vein is pulled out by turning or "wenching" the exteriorized part of the vein and moving the clamps as the vein is pulled out further. Dependent on the amount of varicose vein that has been removed the next incision is made 5 to $10 \mathrm{~cm}$. along the markings.

When the vein has been "harvested" completely (figure 4) the incisions need no sutures and are closed with a Steristrip. After the procedure the treated leg is bandaged for five days and elastic hosiery is worn for another five days. The result is evaluated after six weeks (figure $3 \mathrm{~b}$ ). The cosmetic result is excellent and side effects such as pigmentation, phlebitis and loss of sensitivity are rare. Although in theory preferable to sclerotherapy, in reticular veins this is a very time consuming technique. 


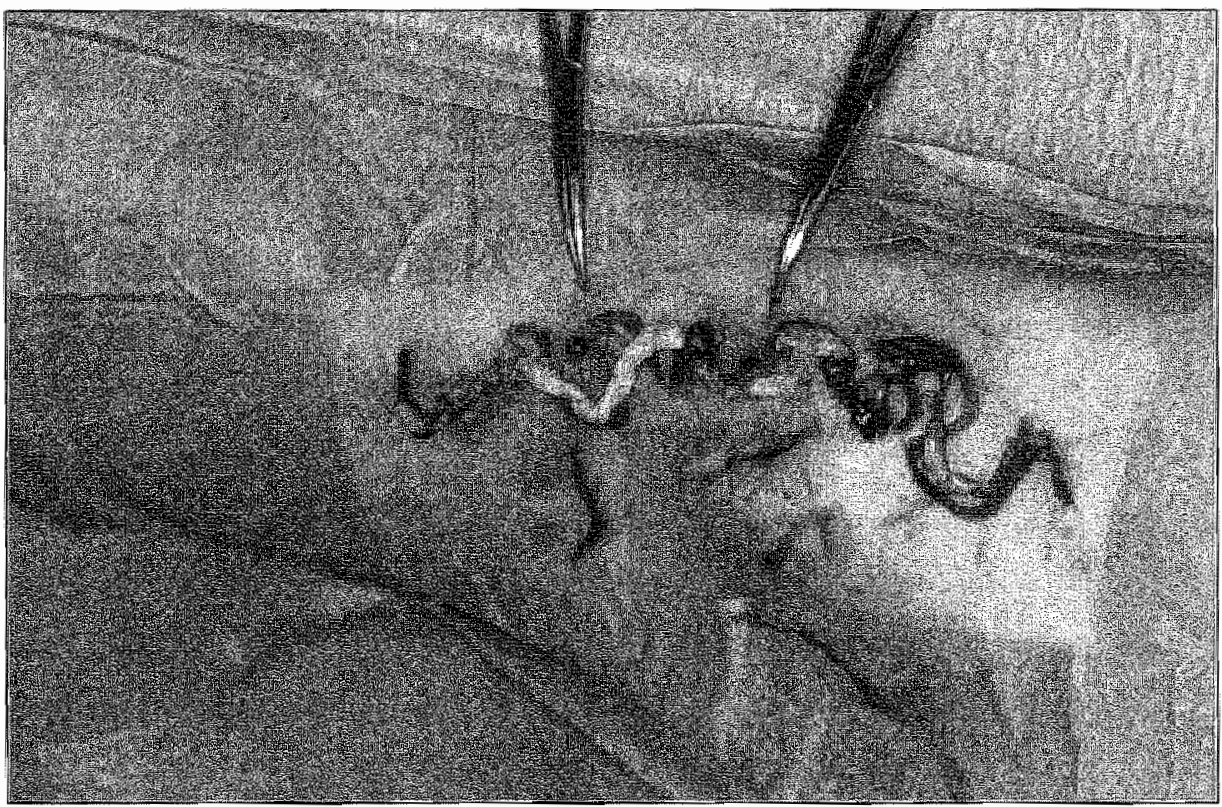

Figure 4. Complete extraction of varicose vein through two incisions.

Ambulatory phlebectomy (AP) is performed in an out-patient setting for different types of varicose veins. With the exception of saphenofemoral or saphenopopliteal junction insufficiency all other types can be treated. The most appropriate indications for this technique are listed in table 6.

Muller, Dortu and others have used this technique for the treatment of GSV or SSV varicosis in the presence of an insufficient junction (Dortu \& Dortu 1990). It is not possible to use this technique to treat insufficient junctions adequately. Like other forms of treatment the best results are obtained when the technique is used in a strict framework. The information for this framework consists of the inventory of the individual hemodynamic situation and patient wishes.

As with compression sclerotherapy ambulatory phlebectomy is most effective when the most important points of reflux are eliminated (de Roos \& Neumann 1993). Table 6 also shows that especially mid-size varicose veins are suitable and that side-branch varicosities form an ideal indication. Recurrent semicirculatory varicose veins in particular can be treated effectively with the use of ambulatory phlebectomy (Neumann 1993b). It does require more experience to treat recurrences after comptession sclerotherapy.

Anatomical areas that have a reputation of a high risk of intra-arterial injection on other complications such as hyperpigmentation - ankle region and popliteal fossa 
Table 6. Indications for ambulatory phlebectomy

side branch varicositas;

esp. semicirculatory varcositas

excellent

varicose veins of the:

- foot

- perimalleolar region

preferred treatment

- popliteal fossa

branch varicositas

in selected casses

reticular varicosis

in selected cases

brush varicosis

in selected cases

- ambulatory phlebectomy has been a safe treatment option (Neumann 1992, Ramelet 1993). Several authors have pointed out that for varicose veins of the foot $\mathrm{AP}$ is the only safe treatment option (Neumann 1992, Muller 1990).

The most important instrument for this technique is the vein retractor or phlebectomy hook. There are two ways by which the veins can be grasped. Into the vein itself or into the adventitia with a sharp instrument or around the vein with a blunt instrument. The first instrument used was designed and introduced by Muller. It is a rounded instrument with a rather circular hook which has a sharp point. Then there was the Oesch hook which has a longer grip and semi-circular end with a single semi-blunt beard. In our opinion a semi-blunt instrument is easier in use because it does not get entangled into subdermal tissue.

More recently Ramelet introduced an instrument which is smaller than the first two and has a sharp point (Ramelet 1991). The different types are shown in figure 6. All these instruments are available for left and right handed phlebectomists and come in several sizes. On the far left the instrument introduced by Varady (1988) is depicted which is similar to previously introduced phlebectomy hooks but has the possibility to undermine tissue. 
$40 \mid$ CHAPTER 2

\section{OTHER THERAPEUTIC OPTIONS}

Although the above mentioned compression sclerotherapy and ambulatory phlebectomy as well as stripping procedure and classical crosse-ectomy (= ligation of the incompetent junction) are the most important therapeutic options currently in use, there are other modalities available. These will be discussed in short.

\section{Pblebotropics}

Microcirculation can be influenced by a great variety of drugs. Although it will never be feasible to treat insufficient valves with drugs, many can either be used in early stages of venous insufficiency or as adjuvant or supporting therapy in more extreme cases (Felix 1988). The most important phlebotropics will be discussed in this paragraph.

Although ergotamine seems useful on a theoretical basis, because of its sympatolytic and thus venotoning properties it has major disadvantages. In practical use the therapeutical dosage is very neat its toxic dosage and ergotism is a serious risk.

Diuretics - especially slow acting such as thiazide-derivates - are used, but should only be used for a short period of time in the management of severe venous edema.

Wadsworth and Faulds have reviewed the pharmacology and therapeutic efficacy of hydroxyethylrutosides in venous insufficiency and related disorders (Wadsworth \& Faulds 1992). It is a standardized mixture of semisynthetic flavonoids which act mainly on the microvascular endothelium where it reduces hyperpermeability and edema. Its efficacy has been established. In patients with chronic insufficiency, hydroxyethylrutosides 0.6 to $1.2 \mathrm{~g} /$ day for up to six months significantly improves objective and subjective measures of lower limb venous insufficiency.

An adjuvant therapeutical effect was proven by a study with CVI-patients wearing elastic hosiery. Alleviated symptoms include pain, "heaviness" and restless legs, cramps, irritation and swelling (Neumann \& van den Broek 1995). The recommended dosage of hydroxyethylrutosides is 0.9 to $1.2 \mathrm{~g} /$ day, for patients with venous insufficiency, and $3 \mathrm{~g} / \mathrm{day}$, for patients with lymphoedema. It should not be administered during the first three months of pregnancy. 


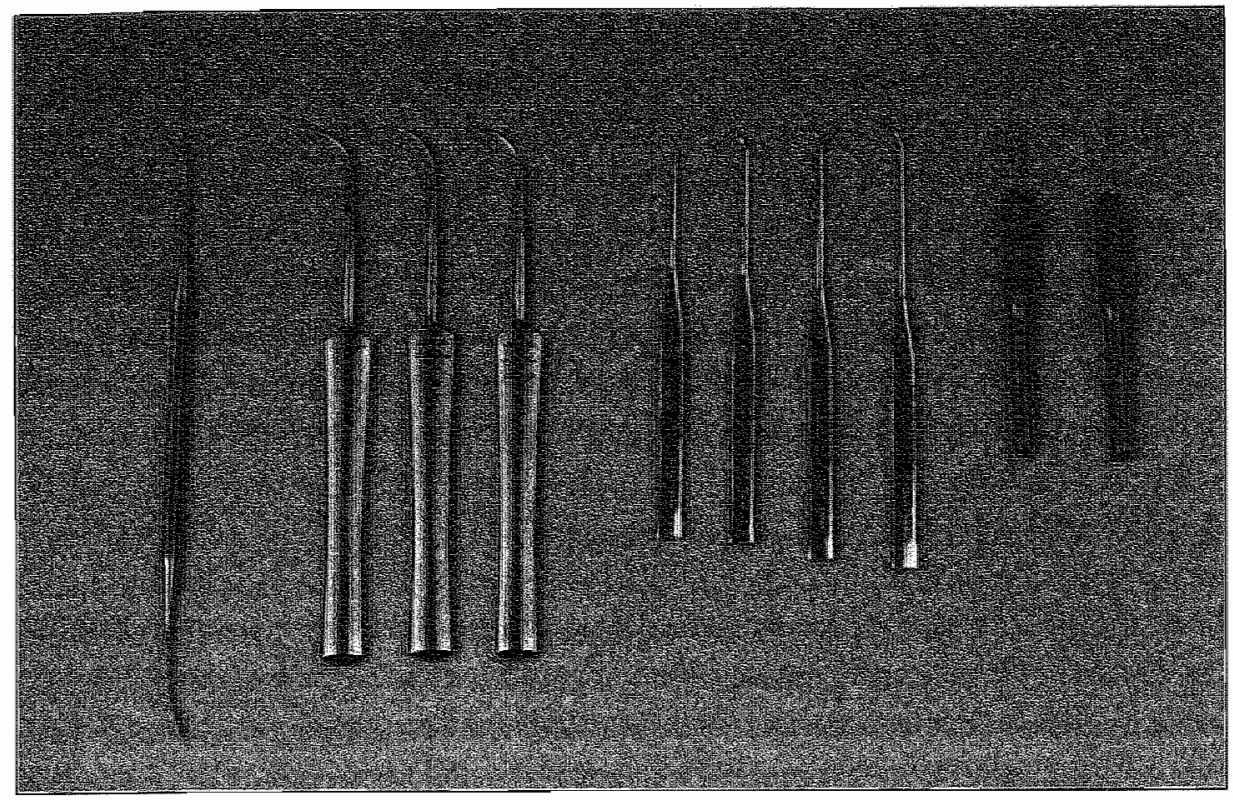

Figure 6. Instrurnewts used for Ambulatory phlebectomy.

Left to right: phlebodissector, phlebectomy hooks according to Oesch, Muller and Ramelet.

\section{Venous surgery}

Since Trader performed the first successful operation on a traumatic lesion in a femoral vein (Rich et al. 1978) in 1816, venous reconstruction has been the focus of many surgeons. Valve transplant and reconstructive 'valve' surgery have been experimental techniques for some time (Taheri et al. 1982, Taheri et al. 1986). Recent developments include autogenous stent placements and valve reconstruction that not only have been used experimentally in animals (Dalsing et al. 1996, Gomes-Jorge et al. 2000) but also in humans (Cheatle \& Perrin 1994, Plagnol et al. 1999). Two decades ago investigators aimed their interest at deep venous repair. In recent years there have been interesting new techniques developed for the reconstruction of superficial venous insufficiency. Incandela et al. published their results on external valve support or valvuloplasty (Gore External Valve Support-EVS). They were able to testore valve function in all treated patients. The absence of reflux was evaluated with color-Duplex (Incandela et al. 2000). In a recently published study external stenting of the saphenofemoral junction is considered to be the preferred option in patients with early to moderate varicose veins involving the long saphenous vein (Lane et al. 2002). 
Introduced in the 1930 's the "open Linton perforator interruption operation" was used only reluctantly because of its latge incisions and morbidity (Bergan 2002). Towards the 1990's Fisher and Hauer introduced the use of an endoscopic technique: endoscopic ligation and minimal excess surgery for perforating veins: Subfascial Endoscopic Perforator Surgery (SEPS) (Bergan 2002). Prospective studies have demonstrated the excellent effect of this technique on recalcitrant venous ulcers (Pierik et al. 1997, Sybrandy et al. 2001) although there is no consensus on the long term tesults. Other possibilities include gastrocnemic muscle corrections and new possibilities for (intra-vascular) laser-therapy.

\section{Laser therapy and transluminal technigues}

With the introduction of modern laser instruments there are several possibilities for transdermal and intraluminal obliteration of varicose veins of different caliber's. Smaller varicose veins ancl telengiectasias can be treated transdermally with the use of several coherent (laser) and non-coherent light (IPL) sources (Schroeter \& Neumann 1998, Reichert 1998). Both techniques use selective photothermolysis for specific targeting of blood vessels with minimal damage to surrounding tissues. Both techniques have developed into therapy modalities for telengiectasias and varicose veins up to $4 \mathrm{~mm}$ in diameter (Sadick et al. 2002). Even red telengiectasias can now be treated consistently with the use of a Copper Bromide (CuBr/ $578 \mathrm{~nm}$ ) laser (Sadick \& Weiss 2002).

In the last 5 years several endovascular techniques have emerged. Navarro et al. bave used a diode laser $(810 \mathrm{~nm}$ ) with excellent results: $0 \%$ recanalization in 125 treated limbs after a mean follow up of 7 months (Navarro et al. 2001).

Another possibility for coagulation of varicose veins currently under investigam tion is radiofrequency (Closure System VNUS Medical Technologies inc. Sunnyvale Ca.). A technique where occlusion is obtained by endovenous heating of the vein wall to $85^{\circ} \mathrm{C}$. Weiss and Weiss demonstrated that this so-called RF Closure procedure has low short-term recurrence rates ( $90 \%$ occlusion at one year in 140 treated legs) and $98 \%$ patient satisfaction (Weiss \& Weiss 2002). In another study a successful atrempt was made to equal the results of this technique to ligation of the SF junction (Goldman \& Amiry 2002). This technique has also been successfully used in great saphenous vein recurrences (Fassiadis et al. 2002). Rautio et al. recently demonstrated the advantages of this technique in comparison to conventional stripping procedure. They concluded that RF Clo- 
sure of varicose veins is both cost-saving, reduces post-operative pain, and makes a faster return to normal activities possible (Rautio et al. 2002.).

Endovenous laser photocoagulation or EVLP is based on the concept of lasertissue interaction using a Neodymium:Ytrium Aluminium Gamet (Nd:YAG/ $1064 \mathrm{~nm}$ ) laser. The laser light is delivered through an optical fiber to coagulate the incompetent GSV. Although preliminary results seem excellent $(96.8 \%$ : remarkable improvement) there are no data on long term follow up nor compared to conventional therapies (i.e. ligation and stripping of GSV). In this study all patients underwent ligation of SF junction prior to the EVLP procedure (Chang \& Chua 2002). Endovenous ligation without high ligation of the SF junction dramatically reduces the presence of varicosities and reflux and is comparable with vein stripping at 1 and 2 years (Merchant et al. 2002).

The latest minimal invasive technique for the treatment of varicose veins to be discussed in this chapter is the "powered phlebectomy" (Trivex ${ }^{(i)}$ ). This technique uses subcutaneous illumination to locate and visualize the varicose vein which is subsequently extracted through a cannula. This resector has a rotating tubulat inner cannula encased in a stationary outer sheath dissector. 'The procedure can be used for removal of varicose veins and initial results ate satisfactory although there are no data on recurrences or cost effectiveness. (Cheshire et al. 2002).

\section{DISCUSSION}

As stated earlier varicose veins are in the top ten list of discases patients consult their family doctor. Although there is a low mortality rate involved, there is however a significant morbidity. There is therefore a need for a rational, efficient, efficacious, fast and preferably cheap treatment strategy that is custom-made for each patient. A pragmatic approach to venous disease as described above will lead to an effective eradication of varicose veins and alleviation of complaints preventing complications such as hypodermitis, dermato- et liposclerosis, white atrophy, and leg ulcers. A decision tree for diagnosis and treatment of varicose veins is depicted in table 7 .

The ongoing nature of venous disease should be borne in mind. "Once varicose veins, alurys varicose veing?". Therapy will not change the cause of the disease it may 
only change its course. In other words varicose veins can be (permanently) eradicared; the occurrence of new varicosis however is inherent to the disease. In the literal sense varicose veins are not treated or healed but only made non-functional, occluded, or even absent.

If reflux is detected this does not necessarily mean that there is also a functional disturbance. Nevertheless detecting the point of origin of reflux is crucial when a therapy plan is made. The hand-held Doppler is adequate in most cases and there still is a place for plethysmography as a screening device.

Top of the therapeutic list is of course the elimination of the major points of reflux. A choice has to be made between a simple ligation and ligation in combination with short stripping procedure of the GSV or another technique. At the moment in most cases the latter will be the best choice.

If the SSV is incompetent in future surgery may be abandoned in favor of echosclerosis. Although evidence is lacking first clinical results are very promising. Along the line of this therapeutic approach varicose veins should be treated according to their caliber: from large to small. New sclerosing techniques such as micro-foam also seem very promising for the future. Until this moment there is insufficient evidence that the long term effects are comparable to conventional techniques. Other techniques such as EVLP and RF-Closure still are in experimental stages but may deserve a place in future.

There are insufficient studies concerning post-treatment compression. Most phlebologists will have empirical knowledge on the amount of time necessary after therapy but lack prospective data. Although there is no etiologic treatment for varicose veins early treatment may nevertheless be cost effective since the seriousness of venous insufficiency will be minimized and the occurrence of leg ulcers may be prevented. This will ultimately improve quality of life of our varicose vein patients. 


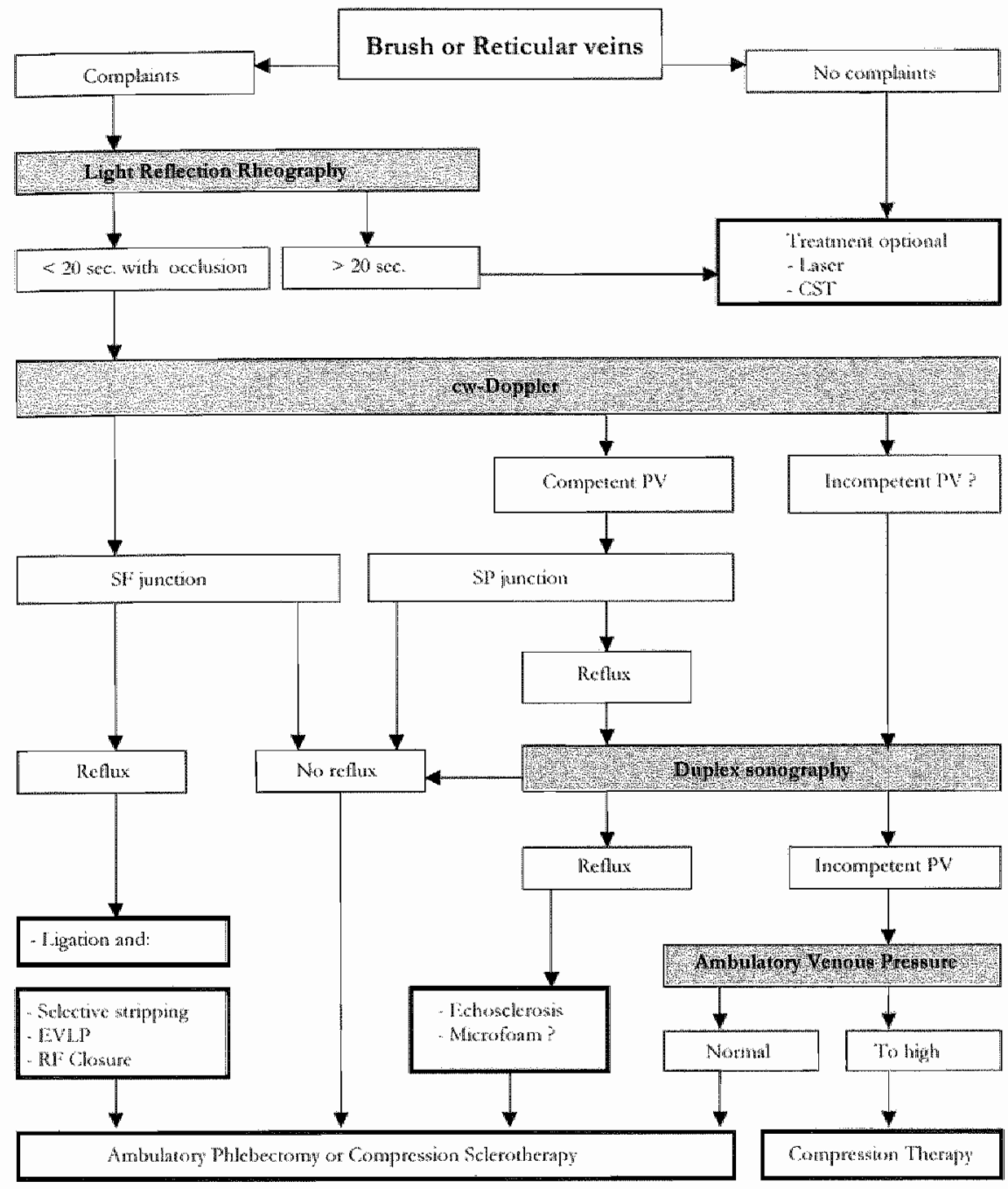

Table 7.a. Decision tree for diagnosis and treatment of brush and or reticular veins. 


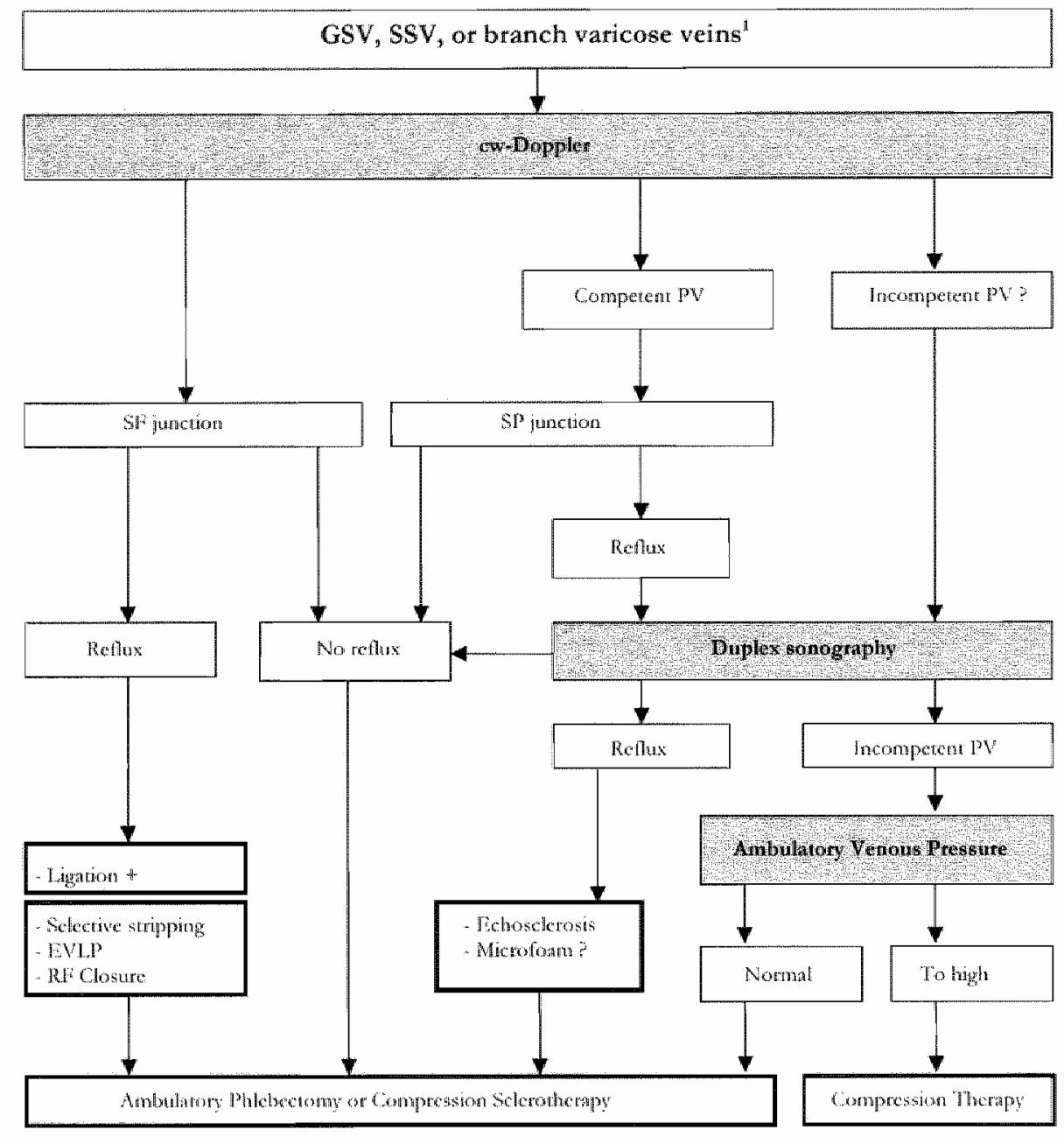

Table 7.b. Decision tree for diagnosis and treatment of GSV, SSV or banch waricose veins.

1 II Duplex investigation is better avalable, the algorithm depicted in table 7 can be simplified. 


\section{CHAPTER 3}

\section{COMPRESSION THERAPY}

Tazelaar DJ, Neumann HAM, Roos K-P de.

Long cotton wool rolls as compression enhancers in macrosclerotherapy for varicose veins.

Dermatol Surg 1999; 25: 38-40.

Neumann HAM, Roos K-P de, Veraart JCJM.

Muller's ambulatory phlebectomy and compression.

Dermatol Surg 1998; 24: 471-4. 

3.1.

\section{Long cotton wool rolls as compression enhancers in macrosclerotherapy for varicose veins}

Background. Macrosclerotherapy in combination with compression has proven to be safe and effective in the treatment of varicose veins. Local compression is increased by pads, according to Laplace law. Firm rolls of cotton wool are fixed over the course of the entire vein to increase local compression and to reduce complications. Additional compression is given by a combination of a class I (day- and nighttime) and class II (daytime only) medical compression hosiery.

Purpose. To evaluate the effectiveness and side effects of sclerocompression therapy with cotton wool rolls in combination with medical compression hosiery.

Method. Prospective study with 100 patients (120 legs) with primary varicose veins, which are treated with polidocanol as sclerosant with the empty vein technique. Immediately after the injection a long cotton wool roll is placed over the entire vein and fixed. Additional compression is obtained with a class $I$ and a class II medical compression stocking. The interface pressure on the skin, just under the cotton wool roll, is measured on 12 legs with the aid of an interface pressure measuring instrument (Oxford Pressure Monitor).

Results. Good sclerosing results are obtained in all patients. Side-effects are classified as early and late. In 16 patients, minor side-effects which needed no treatment are observed. In only 3 cases $(2.5 \%)$ intravascular blood clots (2) and phlebitis (1) needed incision and expression. The mean interface pressure of all measuring sensors under the cotton wool roll is $84 \mathrm{~mm} / \mathrm{Hg}$ (68 to $122 \mathrm{~mm} / \mathrm{Hg}$ ).

Conclusion. This study proves the high effectiveness of a cotton wool roll compression right at the place of treatment. By using these long cotton wool compression rolls, the compression part of sclerocompression therapy becomes more effective and much easier to perform. 


\section{INTRODUCTION}

According to Fegan, most physicians use some kind of compression in sclerotherapy (Fegan 1967). A major reason is to prevent deep venous thrombosis by compressing the perforator veins and by increasing the venous flow in the untreated veins. A second motive is to bring the venous walls close together to promote endofibrosis and to prevent accumulation of blood in the injected veins (Tazelaar \& Neumann 1996). The duration of compression and the amount of pressure is still being discussed. Fegan advocated continuous compression for 6 weeks (Fegan 1967). Raj found no statistical significant difference in short-term results between 8 hours and 6 weeks of compression (Raj \& Makin 1981). Usually, local pads over the injected sites and some kind of elastic bandages are used (Fegan 1967, Fraser et al. 1985, Fentem et al. 1976). Intravascular clots and phlebitis are frequently seen in the veins which are not compressed by pads. The aim of this study is to evaluate the value of local increase of compression pressure by using long cotton wool rolls in combination with medical compression hosiery for macrosclerotherapy.

\section{PATIENTS, MATERLALS AND METHODS}

One hundred patients (120 legs) are treated from September-December 1995 in the outdoor clinic of "De Tjongerschans" in Heerenveen, The Netherlands (60 patients, 66 legs), and in the "Academisch Ziekenhuis Maastricht" in Maastricht, The Netherlands ( 40 patients, 54 legs), for primary varicose veins. Details are summarized in table 1 .

All patients are screened for venous discase as described earlier (Neumann \& Boersma 1992). This includes light reflection rheography for measuring the venous tefill time and Doppler ultrasound for detecting reflux. Major points of reflux, such as insufficient crosse (junction) of the saphenous veins, are treated first with selective surgery.

A flat piece of absorbent cotton wool (Klinion) is twisted into a firm, cotton wool roll with a diameter of $\pm 2 \mathrm{~cm}$. Sclerosing is performed, using the "empty vein technique" as described earlier (Fentem et al. 1976). As sclerosans, polidocanol $(1-3 \%)$ is used in all patients. After injection, the cotton wool roll is placed over the course of the entire vein and then fixed with tape (Fixomull and Pre-Tape). Additional compression is given by a combination of a class I medical compression hosiery (anti-embolia hosiery, Comprinet-S) and a class II medical 
compression hosiery (Souplesse - Varoedem, Belgium). The cotton wool rolls and a class I medical compression hosiery are used during the day and the night; the class Il medical compression hosiery is worn during daytime only. The cotton wool rolls and class I medical compression hosiery are removed after $5-14$ days. The class II medical compression hosiery is wom during daytime for three weeks.

The patients are screened after five days, two weeks and two months. Special attention has been paid to bulla formation, pigmentation, and intravascular clot formation. Side-effects are classified as early (directly after removing the cotton wool roll) and as late.

The interface pressure under the cotton wool rolls is measured in 12 aselect-chosen patients from the Maastricht-group as described earlier (Veraart \& Neumann 1996). The interface pressure underneath the cotton wool roll is measured with a commercially available micro-processor control system for interface measurements, the Oxford Pressure Monitor (Talley Medical Group Ltd., Romsey, UK). Pressure recordings with this device have proven to be well reproducible and accurate (Allen et al. 1993). The measuring strip with 12 small air chambers is placed under the cotton wool roll, then fixed, and a class I medical compression hosiery covered the roll. All measurements are done after 30 minutes in supine position.

\section{RESULTS}

The different types of varicose veins are classified in table 1. The early side-effects after removing the cotton wool rolls are summarized in table 2. Intravascular blood clots (2) and phlebitis (1) needed small incision and expression in three cases $(2.5 \%)$.

The mean interface pressure of all measuring sensors below the cotton wool rolls and a class I medical compression hosiery is $84 \mathrm{~mm} / \mathrm{Hg}(68-122 \mathrm{~mm} / \mathrm{Hg})$. 


\section{CHAPTER 3}

Table 1. Types of treated varicose weins

\begin{tabular}{ll}
\hline Types of Varicose Vein & Number of Legs \\
\hline Side branch LSV* & 49 \\
Anterolateral & 15 \\
SSV** & 17 \\
Perforating vein & 18 \\
Miscellaneous: & \\
Giacomini & 4 \\
Posterolateral & 6 \\
Lateral & 4 \\
Reticular and teleangiectatic & 7 \\
Total & $120 \mathrm{legs}$ \\
\hline
\end{tabular}

* $\mathrm{LSV}=$ longer saphenous vein; $*$ SSV = shorter saphenous vein

Table 2. Types of treated waricose veins

"Types of Treated Varicose Veins

Side Effects Side Branch Antero- SSV** Perforating Miscel-

\begin{tabular}{llllll} 
& LSV & lateral & Veins & laneous \\
\hline Early side effects & & & & & \\
- Small intravasal cloting & 5 & 0 & 1 & 2 & 2 \\
- Peri-phlebitis & 0 & 0 & 1 & 0 & 0 \\
- Pigmentation & 0 & 0 & 0 & 1 & 1 \\
- Bullat & 2 & 0 & 0 & 0 & 3 \\
\hline
\end{tabular}

Latte side effects

$\begin{array}{llllll}- \text { Intravasal clotung } & 2 & 0 & 0 & 0 & 0\end{array}$

(incision and expression)

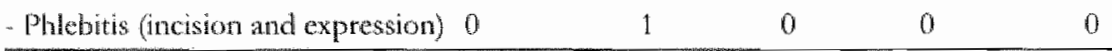

* ISV = longer saphenous vein; ** SSV = shorter saphenous vein 


\section{DISCUSSION}

The aim of compression immediately after the injection of the sclerosing agent is to prevent thrombophlebitic reactions, intravascular clots and to induce a firm, fibrotic cord. By narrowing the vein and compressing the walls, immediate sclerosing will improve and less canalization of thrombi will occur afterwards, preventing a higher rate of recurrences (Wenner 1986, Staubesand \& Seydemitz 1991).

Bandages and medical compression hosiery are equally effective (Neumann \& Tazelaar 1995, Scurr et al. 1985). Pads over the injected sites are used to augment local pressure (Fentem et al. 1976, Goldman 1987). Intravascular clots often occur in the sections between these pads. We supposed that high pressure over the entire course of the injected vein by using firm cotton wool rolls would prevent this accumulation of blood.

This study improves the effectiveness of these tolls for extra compression over the entire length of the vein. A high pressure (mean $84 \mathrm{~mm} / \mathrm{Hg}$ ) occurs just below the pelotte, according to Laplace law. Intravascular clots are present in $12 \mathrm{legs.}$ Ten are modest in size $(<1.0 \mathrm{~cm}$ in length) and only two needed a small incision or puncture to express this "necrotic blood mixed with residuals of sclerosing agent"(Baccglini et al. 1996). Two months after sclerotherapy blood clots are present in two legs, which had not been found after two weeks.

Filling up in parts of the vein which are not completely obliterated from non-occluded side branches is probably the main cause. One of the two phlebitis accurred next to the cotton roll, which was not quite correctly fixed over the injected vein, thus emphasizing the need for following the curves accurately.

There is no agreement about the best type and duration of compression in sclerotherapy (Baccglini et al. 1996). The long cotton wool rolls, impressed over the skin, just in the course of the entire injected vein, combined with a class I medical compression hosiery, is a simple, effective and cheap type of compression in macrosclerotherapy. In addition, we use a class II medical compression hosiery to maintain the compression pressure during daytime and after removal of the cotton wool rolls. Another trial has to demonstrate the need of this class II medical compression hosiery. The low rate of complications, the simplicity and the low costs of this method make it a very good technique for daily practice. 



\section{2 . \\ Muller's ambulatory phlebectomy and compression}

Budkground. Compression therapy will relieve patients of symptoms of venous disease, if not prevent the occurence of complications, and is used either alone or in combination with other treatment options.

Objective. To describe the use of compression in the two main therapy modalities: sclerocompression and ambulatory phlebectomy.

Methods. Aim and mechamism of compression therapy are analyzed and clinical implications are discussed.

Results. A modification of compression therapy after ambulatory phlebectomy is suggested based on empirical evidence.

Condusions. The use of comptession pads after ambulatory phllebectomy reduces hemorrhage and enhances resorption. 


\section{INTRODUCTION}

Compression therapy is the most important therapeutic modality available to the phlebologist. It may be used either alone or in combination with sclerotherapy, surgery, or any other treatment for venous diseases. Compression therapy will relieve patients of symptoms of venous disease such as edema, (allergic contact) dermatitis, phlebitis, and thrombosis, if not prevent the occurence of complications. Hospitalisation and incapacity for work can be avoided using compression therapy. However, the function of, and the ability to use, the muscle pumps, especially the calf muscle pump, is what makes compression therapy work. The term "ambulant or ambulatory compression therapy", therefore, is used to emphasize the close relationship between bandage and muscle pump activity. The active muscle pump in combination with the pressure of the bandage or elastic stocking on vessels and surrounding subcutaneous tissue are responsible for the effect of compression therapy. Recently, compression therapy was reviewed. (Neumann \& Tazelaar 1995).

Although the essence of compression therapy will not change, for special indications the technique has to be adjusted. Recently, attention was given to the use of long cotton wool rolls for compression therapy in combination with macrosclerotherapy (Tazelaar et al. 1999).

The aim of this article is to outline the use of compression therapy in combination with microsurgical or ambulatory phlebectomy.

\section{AIM AND MECHANISM OF COMPRESSION THERAPY}

The venous system is, more than any other 'vessel system', affected by compression therapy. Epifascial and subfascial veins are compressed, as has been documented with the use of Doppler-ultrasound, duplex-sonography, and phlebography. Subseguently thrombi, if present, are fixated against the vessel wall. Even incompetent perforator veins can be compressed by using special pelottes. This will result in at least a partial correction of the reflux and will diminish the venous volume. When the venous volume is decreased with compression, the muscle pump will become more effective. Venous flow velocity will increase, which will prevent thrombophlebitis and deep vein thrombosis (Partsch 1991). A recently published well-executed five year follow-up study has shown that adequate compression therapy (ie class III elastic stockings) may prevent postthrombotic syndrome in up to $50 \%$ of cases (Brandjes et al. 1997). 
Not only does compression therapy influence macrocirculation, it also influences microcirculation. This is of special interest because the microcirculatory alterations induced by venous insufficiency are responsible for the skin changes that accur in the venous insufficiency syndrome. These changes may lead to crural eczema, dermatoliposclerosis, and ultimately to venous leg ulcers. Abnormal collagen synthesis can result in dermoliposclerosis on the one hand, and lead to increased formation of collagen IV in the capillaries on the other hand (Neumann \& van den Broek 1991). These increased levels of collagen IV will lead to fixation of capillaries in an ectatic situation reducing capillary flow. Compression therapy will increase tissue pressure, but decrease the postcapillary pressure and reduce the transcapillary filtration (Kuiper \& Brakkee 1990). Absorption will increase as well as the lymph drainage. We can speculate that this will lead to reduction of edema and rebuilding the collagen synthesis, leading to normal parts of collagen I and III. The latter will result in diminishing the dermal thickness in dermatoliposclerosis (Blaauw et al. 1993). The increased velocity in the capillaries due to compression however, will prevent formation of microthombi and white-cell trapping (Veraart et al. 1993).

Well-executed compression therapy using short stretch bandages will not influence arterial inflow significantly. It will lead to a high pressure during walking and muscle pump activity and a very low pressure when resting (Veraart et al. 1997a). Skin circulation will be reduced, especially by the so called resting pressure of the bandage. In elastic bandages this resting pressure is higher as compared to nonelastic or short stretch bandages. As a consequence of this elasticity, the risk for ischemia and subsequent necrosis will be much higher when using these elastic bandages rather than nonelastic bandages. However, in experienced hands, compression therapy, either with elastic or non-elastic bandages can be used with great success.

\section{AIM AND MECHANISM OF MULLER'S AMBULATORY PHLEBECTOMY}

Phlébectomie ambulatoire, microsurgical phlebectomy, minisurgical phlebectomy, office phlebectomy, ambulatory stab avulsion phlebectomy, ambulantory phlebectomy, and Muller's phlebectomy are all synonyms for a simple and elegant procedure by which varicose veins can be avulsed through multiple stab incisions. This technique was developed by the Swiss dermatologist Robert Muller in the mid-fifties (Muller 1966). He designed his own instruments and 
presented his technique in 1966. In his footsteps Dortu (Dortu \& Raymond-Martimbeau 1993), Ramelet (1993), and Varady (1993) suggested modifications of the procedure and introduced new instruments. Ambulatory phlebectomy has become more and more popular among phlebologists worldwide over the last decade.

First the varicose vein is marked in standing position using indelible ink. Then after placing the patient on an operating table the marked skin is anestherised using lidocain with or without epinephrine. The advantage of epinephrine is a longer period of anesthesia and more importantly constriction of the varicose vein making it possibly less fragile and thus easier to harvest. Parallel to the markings $2-\mathrm{mm}$ stab incisions are made every $5-10 \mathrm{~cm}$, through which the vein is grasped using a phlebectomy hook. The vein is then secured with clamps and extracted untill it breaks. This procedure is repeated untill the vein is extracted or "harvested" completely. The incisions need no suture and can be closed by surgical tape (e.g. Steristrip; 3M, St Paul, MN).

The indications for ambulatory phlebectomy include both primary varicose veins of all calibres and recurrent varicose veins. This surgical technique converts it's major disadvantage - a time consuming skill - into it's major advantage: excellent cosmesis.

Escape varicose veins, hemodynamic important secundary varicose veins and hypercoaguiable states are the main contra-indications. Relative contra-indications include overweight, deep venous insufficiency. Recurrent varicose veins as well as fibrosis due to previous sclerotherapy make ambulatory phlebectomy a challenging procedure. This technique only has a few side effects (Gauthier 1993).

\section{COMBINATION OF MICROSURGICAL PHLEBECTOMY AND COMPRESSION}

Although in contrast to sclerotherapy the veins are removed by the phlebectomy technique, most physicians use compression immediately after phlebectomy. This is mainly to prevent hemorrhages after surgery. In his initial presentation Muller advised to apply several days of firm local compression after which light compression should be applied for up to 3 weeks (Muller 1966). In a recently published textbook on phlebectomy compression is advised for upto 2 months after phlebectomy dependant on the calibre of the treated varicose veins (Ricci \& Georgiev 1995). 
In out opinion also it is essential to combine phlebectomy with compression therapy. During ambulatory phlebectomy the varicose vein is extracted, inevitably rupturing side branches. Minimal bleeding will always occur. In the aftermath of the procedure, compression therapy will therefore block leaking of blood out of ruptured perforating veins and side branches. It will furthermone enhance woundhealing and it will stimulate resorption of hemorthage.

\section{THE AMOUNT OF PRESSURE}

The amount of pressure depends on the intravascular pressure of the treated vein and the pressure of the surrounding tissue. With the patient in supine position, a pressure of approximately $30 \mathrm{mmHg}$ is sufficient to make all superficial veins collapse. With the use of angioscopy van Cleef was able to demonstrate the narrowing of the longitudinal veins in supine position with pressures below 20 mmHg (van Cleef 1993). However, reflux still exists when an intercorneal space at valves commissures is involved.

In a special vein model, a volume reduction of $94 \%$ can be demonstrated with a pressure of $54 \mathrm{mmHg}$. Depending on the size and shape of a pelotte, according to Laplace's law, less bandage pressure is tequired to obtain the same result (Fentem et al. 1976). As shown by duplex scanning, a medium pressure of 89 $\mathrm{mmHg}$ is necessary to occlude the greater saphenous vein when the patient is standing. Reflux is abolished in 8 out of 19 patients at a medium pressure of 31 mmHg (Sarin et al. 1992). One has to keep in mind that all these studies are static and that the pressure in the venous system is affected by the characteristics of the type of compression bandage and the intravenous pressure profile, which is highly influenced by walking.

Furthemote, one has to remember that according to Laplace's law the pressure at the medial site will be $30 \%$ less than average around the leg. By using pelottes medial, one can overcome this problem (Veraart et al. 1997b).

\section{THE MAASTRICHT APPROACH}

Pretreatment investigations include clinical history, physical examination, and noninvasive examination. In most cases, photoplethysmography in combination with Doppler ultrasound provides enough information to develop an individual therapeutical strategy (Neumann \& Boersma 1992 ). First, major sources of reflux 
have to be eliminated. Ligation of an incompetent perforator vein and/or ligation of the saphenofemoral and/or saphenopopliteal junction - so called crosse-ectomy -, whether or not in combination with short stripping of the greater saphenous vein, is our preferred method of selective surgery. (The French word "crosse" means crook in more than one connotation. So maybe we have to translate this surgical procedure into English/American as "crook"ectomy"). All other varicose veins are treated with sclerocompression therapy or ambulatory phlebectomy. We have a preference for the hooks of Oesch. After sclerotherapy compression has to be maintained untill endofibrosis has occurred. In ambulatory phlebectomy, as mentioned above, compression has to be applied to prevent hemorrhaging. In our practice we have more than ten years of experience with compression and sclerotherapy (Neumann \& Tazelaar 1995). We have studied several types of bandages and duration of compression, and we have adjusted the usual technique for compression after sclerocompression therapy for use after ambulatory phlebectomy. We have found this method to be most satisfactory.

Under normal circumstances we apply cotton wool and adhesive tape directly after sclerotherapy. For compression we combine two different elastic stockings. First a class $I$ elastic stocking is pulled over the treated leg. This has to be left in place for the first 4 days. Over this stocking a ready-made elastic stocking class II has to be worn at day time. After the first 4 days the class I stocking, adhesive tapes and cotton wool is removed by the patient. Patients are allowed to shower briefly. Patients are treated in 2 -week intervals during which class II stockings have to be worn during the day (Tazelaar et al. 1999).

However, for ambulatory phlebectomy the long cotton wool rolls will not sufFice, because they "push" the extravasate aside, in the area just beside the rolls, which will have-due to Laplace's law- hitherto low compression. So we changed to a $7-\mathrm{cm}$ broad foam compression pad (figures 1 and 2). Moreover, the amount of hemorthage was reduced signifiantly since the introduction of the foam pads. Second, a firm compression bandage (adhesive, $10-\mathrm{cm}$ broad adhesive bandage; Pan-Elast, Lohman, Germany) is applied over the treated area (figure 3), over. which compression class II hosiery is worn. This is to prevent formation of edema in the distal 'noncompressed' areas. After 5 days the bandage is removed, as are the surgical tapes, and the rreated area is inspected. The elastic hosiery is worn during the day for another 5 days. During the post-operative period and beyond all normal daily activities are maintained. In our experience, longer compression is not necessary when only ambulatory phlebectomy is performed. Since 


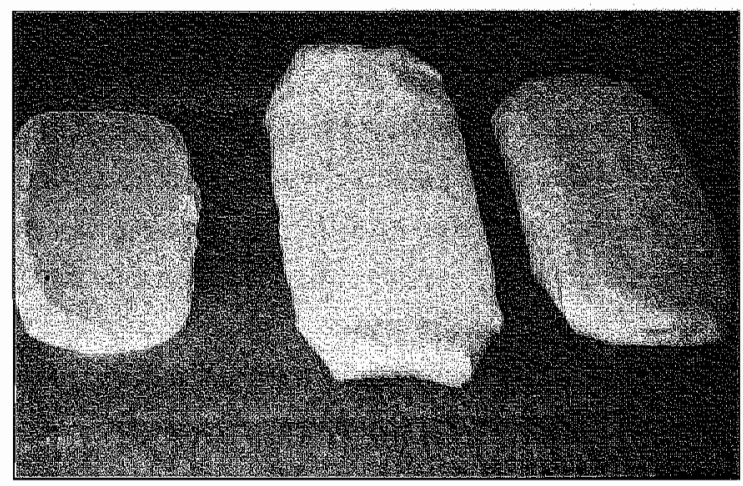

Figure 1. Example of a pelotte or foam nubber pad (Komprex; Lohman, Neuwied, Germany). On the right side is shown the way it has been cut to size by the nurse. On the left side a tubular ba (Tubigrip; Seton, Oldham, Great Britain) is placed over it to protect it.

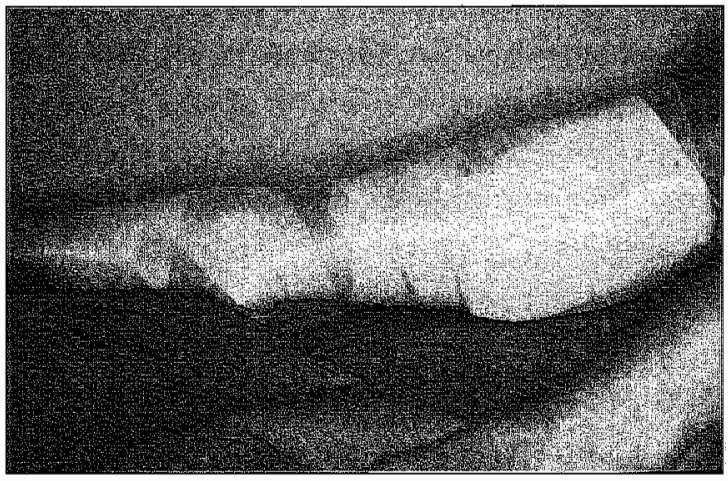

Figure 2. Manner in which the pelote is placed over the operated area and fixated.

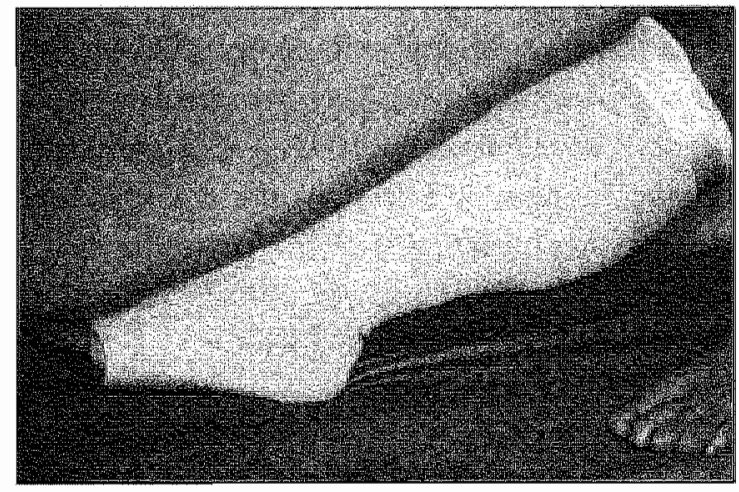

Figure 3. Complete bandaged leg after an ambulatory phlebectomy of the lower leg with a pelotte at the medial site. 
1996 we have treated several patients in this way without serious complications after the compression had been removed.

We use elastic stockings instead of elastic bandages, because they are easy to handle and do not have to be renewed during the different treatment sessions. In the long term this is more cost effective and less burdening for the patient. Moreover, elastic stockings or hosiery prevent slipping, even on very obese thighs, and therefor the pressure decline will be much less. The stockings also secure the pelottes putting extra pressure on the underlying skin and subcutaneous tissues. The more serious the venous insufficiency, the more important the efficiency of the muscle pump becomes (Stöberl et all. 1989).

\section{DISCUSSION}

The aim of varicose vein treatment should be the restoration of venous hemodynamics to physiological ambulant pressure profiles and permanent eradication of varicose veins with optimal cosmetic result. This can only be achieved after making a tailor-made therapeutic plan for each patient using information from the patients history, physical examination, and from additional phlebological investigation(s). Although comparable, sclerotherapy and ambulatory phlebectomy are not each others' equals entirely, one supplements the other. Athough all treatment possibilities for varicose veinstequire compression therapy, the manner in which compression is applied for each treatment differs from therapy to therapy. With the introduction of a more rational use of broad pelottes or pads for ambulatory phlebectomy, the incidence of post-operative hemorthage decreased whereas resorption was enhanced. This minimized the rates of side effects.

Duration of compression therapy after ambulatory phlebectomy, although based on empirical evidence alone, should not have to exceed a period of 10 days. Since the time that is needed for initial woundhealing is approximately 48 hours, one could argue that it may be feasible to reduce the postoperative period of compression even more. Further investigations may therefore lead to an extra reduction of this period, increasing the patients comfort without loosing any of the aforementioned benefits of the procedure.

Ambulatory phlebectomy is presently a very interesting and important tool for the treatment of varicose veins. By using a combination of this technique and compression with broad pads and short stretch bandages for a short time, final results will be excellent. 


\section{CHAPTER 4}

\section{SEMICIRCULATORY VARICOSIS}

Roos K-P de.

Senicirculatory varicosis: tributary vein treatment

Phlebology Digest 1997; 9: 6-9.

Roos K-P de, Nieman FHM, Neumann HAM.

Ambulatory phlebectomy versus compression sclerotherapy; results of a randomized controlled triall

Dermatol Surg 2003; 29: 221-6. 

4.1.

\section{Semicirculatory varicosis: tributary vein} treatment

Semicirculatory varicosis (SCV) is a clinical diagnosis of a tortuous and varicose vein typically located on the latero-ventral side of the upper leg. This varicose vein originates on the lateral side of the leg distal to the knee, moving upward, crossing the leg semi - circularly and draining just $10 \mathrm{~cm}$. distal to the sapheno-femoral junction and into the greater saphenous vein. SCV is most consistant with one of the four major side branches or tributary veins of the greater saphenous vein: the lateral accessory vein. The clinical-phlebological concept of SCV is based on the arciform course of this vein which is relatively constant. However there may be many anatomic variations of this varicose vein.

When reviewing the literature $S C V$ is often referred to as a tributary vein without further specification. Staubesand has drawn attention to discrepancies between the official nomenclature of the superficial veins in the leg and the anatomical reality. He has suggested changes to the Nomina Anatomica that would leave the greater saphenous vein five side branches: the lateral and medial accessory vein, the posterior and anterior arcuate crural vein and the medial marginal vein (Staubesand \& Li 1992).

Dortu's (1989) extensive and accurate observations of numerous patients with varicose veins provide us an excellent insight into the complex superficial venous anatomy of the legs. Approximately 10 centimeters distal to the sapheno-femoral junction and slightly medial to the greater saphenous vein (GSV) an important perforating vein can be located in the adductor muscle sulcus. "This perforating adductor vein can be found to be insufficient in many cases of SCV. On the ventral side of the upper leg there are several veins that are connected to one of the two so-called axis: the GSV or to the lateral accessory vein. SCV is probably the visual and varicose exponent of this complex of interaxial collateral veins.

The aim of varicose vein treatment should be permanent itradication of varicose veins with optimal cosmetic result. This can only be achieved after making a tailomade therapeutic plan for each individual patient using information from 
the patients history, physical examination and from additional phlebological investigation.

Patients with SCV may consult their physician because of physical complaints or for cosmetic reasons. 'Typical venous complaints such as sluggishness, heavyness, cramps, tired feeling and pain are not specific for venous disfunction. There seems to be no correlation between physical complaints presented by the patient and the extent of the varicose veins. In order to assess the amount of venous insufficiency it is necessary to fully investigate all patients with SCV.

There are many possibilities to assess venous insufficiency. Footvolumetry, strain gauge plethysmography, air plethysmography, phlebography are too time consuming to be used as standard investigations in every day practice. The combination of a functional test such as photoplethysmography and a test to measure reflux such as Doppler-ultrasound is both rational and practical since both techniques are easy to apprehend, to perform and to evaluate the results in an outpatient setting.

Plethysmography either with light-reflexion-rheography (LRR) or digital-photo-plethysmography (d-PPG) can be used to distinguish between deep and superficial venous insufficiency (Wienert \& Blazek 1982). A venous refilling time of 25 seconds or longer is considered to be normal (Neumann \& Boersma 1992). However one should keep in mind that when the plethysmography-probe is placed on the medial side of the ankle only the GSV is tested and not the effect of SCV.

With the use of Doppler-ultrasound greater sapheno-femoral or lesser sapheno-popliteal valve incompetence as well as perforator insufficiency can easily be determined. Furthermore it can be of use in detecting femoral valve insufficiency, retrograde flow in the deep venous system and deep venous thrombosis.

The aim of the therapeutic plan can only be achieved when major points of reflux are eliminated before the remaining varicose veins can be treated. For the treatment of SCV there are three options. The first is simply to alleviate complaints by means of compression either with bandage or compression hosiery. The real treatment options are therefore surgery, sclerocompression therapy or a combination of both.

The technique of sclerocompression therapy has been well documented. Patients are best treated in lying position. This reduces the pressure in the venous system and avoids the possibility of injury after vasovagal reflex or syncope when treated 
in the upright position. Except for the saphenous veins all varicosities can be efficiently treated with $0,5 \%-4 \%$ polidocanol. For SCV the most frequently used solutions are 2 and $3 \%$ polidocanol. Saphenous veins should be treated with either sodium-tetradecyl-sulphate (STS) $3 \%$ or iodine.

After confirming by aspiration that the needle is in the vein this is then emptied by stroking the overlying skin. A small amount of sclerosing fluid is injected followed by immediate compression using cotton balls and fixation with tape. Many injections using small amounts of fluid are needed.

In my view this so-called 'empty vein technique' is the safest technique because it combines small amounts of sclerosing fluid with maximum contact with the vein wall. Thus minimising the risk of adverse sequelae such as necrosis, pigmentation, phlebitis and thrombosis. It does require more training than regular injection techniques because of the risk of extravasation during the empying of the vein. Sclerotherapy of SCV seems to lead to more postsclerotherapy phlebitis and pigmentation and recurrences, although there is no "hard evidence" to substantiate this statement. Five year recurrence rates for sclerotherapy in general are estimated at $20 \%$ or higher. There are no data on SCV in particular.

Ambulatory phlebectomy has become more and more popular among phlebologists world-wide over the last decade. It combines multiple stab incisions with selective avulsion of varicose veins. First the vein is marked in standing position using indelible ink. Then after placing the patient on an operating table the marked skin is anesthetised using lidocain with or without epinephrine. The advantage of epinephrine is a longer period of anesthesia and more importantly constriction of the varicose vein making it probably less fragile. Parallel to the marking $2 \mathrm{~mm}$. stab incisions are made through which the vein is grasped using a phlebectomy hook. 'The vein is then fixed with clamps and extracted untill it breaks. This procedure is repeated untill the vein is extracted completely. The incisions need no suture and can be closed by Steristrip ${ }^{\text {(3). }}$. To prevent extensive hemorrhage bandages ate applied for a period of five days after which elastic stockings are worn for another period of five days. The indications for ambulatory phlebectomy include both primary varicose veins of all calibes and recur-w rent varicose veins (Constancias-Dortu \& Dortu 1991). This surgical technique converts it's major disadvantage (a time consuming skilly into it's major advantage: excellent cosmesis.

It has been almost a century since the introduction of varicose vein surgery by Mayo, Babcock, Narath and others. Stripping the greater saphenous vein had 
become a routine operation by the beginning of the first World War and was one of the most efficient methods in treating patients with chronic venous insufficiency due to saphenous vein varicosity. As a matter of routine procedure many patients were also treated with convolutectomy or perforantectomy. Tributary veins e.g. lateral or medial accessory vein were often excised through multiple large incisions.

Combining sclero-compression-therapy as introduced by Fegan and others in the mid-fifties with selective surgery, physicians were able to treat varicose veins of almost all calibres: waricose saphenous, tributary, reticular and brush veins. This in my view marked the beginning modern phlebology. The introduction of ambulatory phlebectomy by a Swiss dermatologist, Robert Muller in the mid-sixties (Muller 1966) madle a more differentiated therapeutic approach possible. Srill new technology is developped (e.g. Lasers) to give phlebologists more therapeutic modalities in treating their patients. These and other developments direct more attention towards a variety of old and new fields of interrest: specific phlebologic problems, diagnostic possibilities and the pathogenesis of venous disorders.

There are little or no studies on recurrence rates after sclerotherapy and or ambulatory phlebectomy. This is best illustrated by two recently published textbooks on both sclerotherapy in which only one paragraph is dedicated to recurrences (Goldman 1995) and on ambulatory phlebectomy in which recurrences are only discussed in relation to sclerotherapy (Ricci \& Georgiev 1996). Ambulatory phlebectomy is - in theory - a definite solution for varicose veins of all calibres. The effect of therapy is apparent during surgerv the moment the vein is granconed Lven if the varicose vein is not completely extracted the remaining parts will obliterate because its continuity is disrupted. Some problems may occur however when treating previously sclerosed veins. Fibrosis and subsequent fragility of these recurrent veins may make it impossible to harvest most or even part of the vein.

Standardisation of therapy, type of sclerosant solutions used and of varicose veins treated seem to be the major problems for prospective or even comparitive studies.

The semicirculatory vein is a clinically distinctive vein when it has become varicose. As mentioned above the SCV originates on the lateral side of the knee tortuously following the lateral and ventral side of the upper leg to end into the larger saphenous vein just 10 centimeter distally to the sapheno-femoral junction. 
Often it ends in the so-called perforating vein of the adductor muscles. Because of the complexe anatomy of the superficial venous system $\mathrm{SCV}$-recurrence rates will probably be higher than the overall percentage (20\%). Inadequate detection of sapheno-femoral. junction insufficiency, inadequate treatment of the insufficient perforating vein and varicose veins parallel the the SCV (pseudo-recurrence) can be the explanation of these recurrence rates. Short term recurrences (within 2 years after initial therapy) can be specificly treated. Long term recurrences should be totally reevaluated by Doppler-ultrasound and plethysmography. Ambulatory phlebectomy should be considered to treat these recurrent cases. To date there have been no prospective studies addressing these specific problems.

Recently we started a prospective randomised trial to evaluate the result of treatment, the incidence of complications and recurrence rates of both sclerocompression therapy and ambulatory phlebectomy. Hopefully we will be able to shed some light on this therapeutical problem. 



\section{2}

\section{Ambulatory phlebectomy versus compression sclerotherapy; results of a randomized controlled trial}

Background. Although no randomized controlled trial has assessed the effects of either compression sclerotherapy of ambulatory phlebectomy, both techniques are used to treat varicose veins world-wide. We performed a randomized controlled trial to compare recurrence rates of varicose veins and complications following compression sclerotherapy and ambulatory phlebectomy.

Methods. From September 1996 to October 1998, we randomly allocated 49 legs to compression sclerotherapy and 49 legs to ambulatory phlebectomy. Our primary outcome parameters were: recurrence rates at 1 and 2 years and complications related to therapy. Eighty-two patients were included of whom 16 were included with both their legs. The number of treated legs was therefore 98 , but 2 patients were lost to follow-up.

Results. One year recurrence amounts to 1 out of 48 for phlebectomy and 12 out of 48 for compression sclerotherapy $(p<.001)$, at 2 years six additional recurrences were found, but then solely for compression sclerotherapy $(p<.001)$. Significant differences in complications occurring more in phlebectomy than in compression sclerotherapy therapy were: blisters, teleangiectatic matting, scar formation and bruising from bandaging.

Conclusion. Our results show that ambulatory phlebectomy is an effective therapy for varicose veins of the leg. Recurrence rates are significantly lower than for compression sclerotherapy therapy. If varicose veins persist 4 weeks after compression sclerotherapy, it can be argued that to reduce the risk of future recurrence ambulatory phlebectomy should be considered as the better treatment option. 


\section{INTRODUCTION}

Chronic venous disease is an important cause of morbidity in a significant percentage of the worlds population (Adhikari et al. 2000). In the USA, the prevalence of varicose veins for populations above 10 years of age is estimated at about $12 \%$ (Coon et al. 1973).

The combination of compression therapy with intravenous injection of a sclerosing agent for the treatment of varicose veins was introduced in 1953 (Fegan 1963). Early studies indicated that this compression sclerotherapy would be an efficient addition to the varicose vein surgery in use at the time. Although ambulatory phlebectomy was "invented" around the same period (Muller 1966), this technique needed more time to become well-established world-wide. In view of these facts it is astonishing to find that there are no randomized controlled trials (RCT) on recurtence rates and other complications after compression sclerotherapy and ambulatory phlebectomy.

The main aim of this study was to compare two accepted treatment modalities for varicose veins: ambulatory phlebectomy and compression sclerotherapy. We started a RCT to evaluate the results of treatment, incidence of complications and recurrence rates of both compression sclerotherapy and ambulatory phlebectomy. Only a specific varicose vein was included for this trial to avoid discussion on the importance of the treated vein if varicose veins of different caliber's were included (CEAP classification: C2 Ep A5 Pr). Between September 1996 and October 1998 we were able to include the number of patients required (figure 1). Before final inclusion patients underwent Doppler-ultrasound investigation to exclude Greater saphenous vein (GSV) incompetence. Using a continuous-wave Doppler instrument (Dopplex ${ }^{\text {is }}$, Huntleigh, U.K.) sapheno-femoral or sapheno-popliteal valve incompetence as well as perforator insufficiency can casily be determined (Coleridge Smith 2001). Finally digital-Photo-Plethysmography (d-PPG, ELCAT, ELCAT GmbH, Germany) was used to measure venous refilling time.

This type of plethysmography can be used to distinguish between deep and superficial venous insufficiency (Wienert \& Blazek 1982, Nuzzaci et al. 1986). A minimal venous refilling time of 20 seconds is considered to be normal (Neumann \& Boersma 1992). Upon their inclusion patients gave their written consent. A computer-generated randomization list done in blocks of four was transferred to a sequence of sealed envelopes. Envelopes were subsequently 
opened for each included leg. In cases were patients were included with both legs the envelope was first opened for the left leg and than for the right leg.

\section{METHODS}

\section{Anatomy}

Lateral accessory varicose vein (LAV) is a clinical diagnosis of a tortuous and dilated vein typically on the antero-latero side of the thigh. This varicose vein originates on the lateral side of the leg distal to the knee, moving upward, crossing the leg semi-circularly draining just $10 \mathrm{~cm}$ distal to the sapheno-femoral-junction and into the GSV or directly into it's junction. LAV is most consistent with one of four major side branches or tributary veins of the GSV: the lateral accessory vein. The clinical concept of LAV is based on the arciform course of this second largest superficial vein on the leg and is relatively constant.

\section{Compression sclerotherapy}

Compression sclerotherapy (Sclero) has been well documented. Patients are best treated in supine position, reducing pressure in the veins and avoiding flow of sclerosing fluid into the deep system. It also diminishes the risk of injury as a result of vasovagal collapse when patients are treated while standing. In this study polidocanol was used in a $3 \%$ solution (Aethoxysclerol ${ }^{16}$, Kreussler $\&$ Co., Germany), which is equivalent to $1.5 \%$ sodium tetradecyl sulphate.

After confirming by aspiration that the needle is located within the vein, the vein is then emptied by stroking the overlying skin while injecting a small amount of sclerosing fluid. This is followed by immediate compression using cotton balls and fixation with tape (Tazelaar et al. 1999). Several injections using small amounts of fluid are needed. Although many techniques have been described we consider this so-called 'empty vein technique' to be the safest and most efficient (Green 1998). It allows the sclerosing fluid to come directly in contact with the vein wall, minimizing the risk of adverse sequelae such as necrosis, hyperpigmentation, phlebitis and thrombosis. The amount of sclerosing fluid used was recorded (figure 1 ).

Immediately after sclerotherapy compression class I stockings (Ccl I: $<25 \mathrm{~mm}$ $\mathrm{Hg}$ ) (CEN 2001) are put on to be worn for four consecutive days and nights. Patients were also instructed to wear compression class II stockings (Ccl II: 25 - 


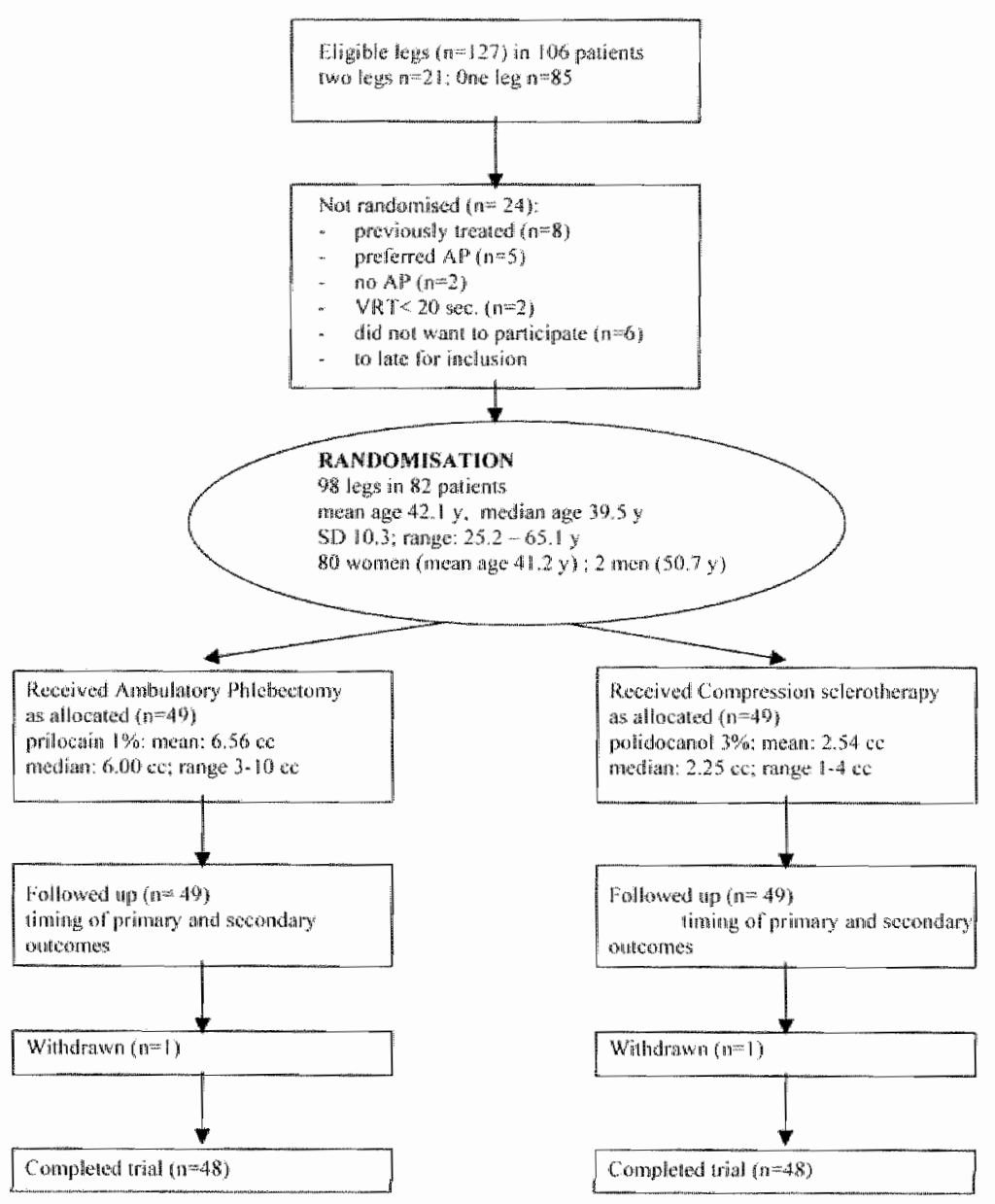

Figure 1. Trial Profile

$35 \mathrm{~mm} \mathrm{Hg}$ ) during the day. After four days patients were allowed to remove the Col. stockings, adhesive tape and cotton balls. Patients should then wear Ccl II stockings during the day for a period of ten days.

\section{Ambulatory phlebectomy}

With ambulatory phlebectomy (AP) the vein is first marked while the parient is standing. In supine position the skin is then infiltrated with $1 \%$ prilocain with epinephrine $(1: 80,000)$. The amount of anaesthetic used is then recorded. Parallel to the marking several $2 \mathrm{~mm}$ stab incisions are made through which the vein is 
Table 1. Inclusion and exclusion criteria for SCV trial.

Inclusion:

- patients older than 18 year

- no previous treatment for L AV

- signed informed consent

Exclusion:

- deep venous insufficiency

- relewant hemodynamic post-thrombotic syndrome (VRT' $<5$ seconds)

- GSV incompetence

- pregnancy

- myocardial decompensation

- migraine

- hyperconguable state

- other serious illness

- dependency edema

- allergic reaction to: 1. Thrombovar (sodium tetradecyl sulphate)

2. Aethoxysclerol ${ }^{\text {Bi }}$ (polidocarol.)

3. Lidocain

4. Bandage

- arterial clisease

grasped using a phlebectomy hook. For this study Oesch phlebectomy hooks (Salzmann, Sankt Gallen, Switzerland) were used. The vein is then fixed with artery clamps and extracted until part of the varicose vein is either extracted or ruptured. This procedure is repeated until the vein is extracted completely. The incisions are closed by surgical tape only. To prevent extensive hemorthaging bandages are applied for a period of five days (Neumann et al. 1998). All patients treated with $A P$ were seen for removal of the bandages. They were instructed to wear $\mathrm{Cll}$ II stockings for another five days.

\section{Follow-up}

Sclerotherapy patients returned fourteen days after treatment. If remaining varicose veins were present they received follow-up treatment. This could also be performed at four weeks after the initial treatment session. 
AP patients retumed to the clinic five days after the operation for removal of the bandages and were checked after two and four weeks for residual varicose veins.

The trial design concerns a randomization of operation modalities, i.e. Sclero or AP. For the total group of 98 operations the treatment period could last for one day only $(A P)$, or from one day up to four weeks after the operation/treatment. (Sclero). After four weeks the evaluation period started culminating into a one-year and a two-year observation for recurrences. At each measurement point complications were also recorded. The parameters scored were: blister formation, hematoma, engorgement/thrombophlebitis, necrosis, dysesthesia, teleangiectatic matting, scar-formation and other adverse effects caused by bandages.

\section{Statistioal analysis}

One or two year observed recurrence was analyzed for both operation modalities by loglikelihood chi-square $\left(\chi_{i}^{2}\right)$, relative risk (RR) and odds ratio (OR). Statistical control for after woperation treatment was done by logistic regression. Only parameters significant by backward elimination change in $\chi_{1}^{2}$. were kept within the reported model. Complications occurring during follow-up were ordered into classes of (non-) appearance, and $\chi_{1 .}^{2}$ was calculated for operation modalities. A significance level of less than .05 was used in all statistical tests; all analysis was done by SPSS-pc, version 10.0 (SPSS-inc., Chicago, Illinois, USA).

\section{RESULTS}

A total of 98 operations was randomized (figure 1) for either AP (49) or Sclero (49) in a total number of 82 patients ( 80 women, 2 men). In sixteen patients both legs were included, in 66 only one leg. During the follow-up period two one-leg-operated patients were lost: they withdrew their consent after randomization (one AP and one Sclero).

At two weeks six of the remaining 96 operations could not be observed for their results, because two one-leg-operated AP patients and two both-legs-operated patients (one with both modalities and one with both legs treated by Sclero) did not show up for their control visit. At four weeks only one patient (one-legScleto) did not show up for control visit. Four Sclero patients teceived follow-up treatment at five days, three one-leg-operated and one both-legs-operated, while ten Sclero patients received adjuvant treatment at two weeks, seven 
one-leg-operated and three both-leg-operated (of which two with both legs sclerotherapeuted and one with both modalities). Four one-leg-operated Sclero patients received follow-up treatment at four weeks. Two weeks later no residual varicose veins were observed in these patients.

\section{Recurrence rates}

One year after Scleto 12 LAV's had recurred $(25 \%)$ and only one post-phlebectomy LAV (2.1\%). The relative risk or risk ratio for recurrence (RR) at one year is 12.00 ( $95 \%$ C.I: $1.62-88.70$ ), and the odds tatio (OR) is 15.67 (1.95 $-126.12) \cdot \chi_{i}^{2}$ for adding "type of therapy" into a logistic regression model is $12.34,1$ df., $\mathrm{p}<.001$.

After the two years the difference in recurrence was even larger, because another six recurrences occurred, making a total of eighteen recurrences in the Sclero -group (37.5\%), and still only one recurrence in the AP-group (2.1\%). The RR for recurrence at two years is $18.00(2.50-129.53)$, and the $\mathrm{OR}$ is $28.20(3.58$ 222.39). $\chi^{2}$. ratio for adding "type of therapy" into the two year model is $22.29,1$ dif., $\mathrm{p}<.001$.

If the remaining varicose veins (i.e. need for adjuvant therapy) at five days, two and four weeks after the operation were added to the one-year-recurrence model, only remaining varicose vein at four weeks turn out to be a statistically significant risk factor for one-year recurrence (backward elimination change in likelihood ratio at four weeks is $4.57,1 \mathrm{df} ., \mathrm{p}=.033$ ).

Table 2.a shows - controlled for type of therapy - a 3.21 times higher risk to one-year recurrence, if the patient's leg still has remaining varicose veins at four weeks after operation. Model $\chi_{1}^{2}$ ratio $=16.99$ with $2 \mathrm{df}$, $\mathrm{p}<.001$, and variance explained amounts to $22 \%$. In standardized form the therapy modality partial odds ratio effect turns out to be about 2.6 times larger than the four weeks remaining varicose effect (Menard 1995).

If remaining varicose veins up to four weeks after operation are included in the two-year recurrence regression model, those at four weeks again turn out to be a statistically significant risk factor for two-year recurrence (backward elimination change in loglikelihood $\chi^{2}=$ ratio is $7.11,1 \mathrm{df}, \mathrm{p}=.008$ ).

Table 2.b shows - controlled for type of therapy - a 3.37 times higher risk to two year recurrence, if the patient's leg still has remaining varicose veins at four weeks after operation. Model $\chi_{l}^{2}=29.40$ with $2 \mathrm{df} .(\mathrm{p}<.001)$ and variance explained amounts to $31 \%$. Standardized partial odds ratios for therapy modality turns out to be 2.4 times larger than the 4 weeks remaining varicose tisk factor. 
Table 2.a. Logistic regression model tesults for l-year recurrence

\begin{tabular}{|c|c|c|c|c|c|c|c|c|}
\hline risk factor & $\mathrm{B}$ & SE. & Wald & df. & Sign. & $\operatorname{Exp} .(\mathbb{B})$ & $s t \operatorname{Exp}(\beta)$ & $\begin{array}{l}95 \% \text { C. of } \\
\operatorname{Exp}(\mathrm{B})\end{array}$ \\
\hline therapy & 2.65 & 1.08 & 6,06 & 1 & .014 & 1421 & 8.48 & $1.72-117.62$ \\
\hline 4 wh waris & 225 & 1.09 & 4.27 & 1 & .039 & 9.46 & 3.21 & $1.12-79.69$ \\
\hline constant & -.91 & 1.04 & .77 & 1 & .381 & .40 & - & \\
\hline
\end{tabular}

Backwitd elimination change in loglikelihood chi-square $\chi_{(P)}$ :

$\begin{array}{lrl}\text { thernpy: } & 10.62 & (011) \\ \text { 4 wik varix: } & 4.57 & (033)\end{array}$

\begin{tabular}{llll}
\hline Predicted (I year): & & & \\
\hline observed & recurrence & no recurtence & 16/6 \\
\hline recurrence & 13 & 0 & 100 \\
no recurrence & 36 & 47 & 56.6 \\
& & & 62.5 \\
\hline
\end{tabular}

Legend: "therapy": therapy modality $(1=$ AP; $2=$ Sclero $) ; ~ " 4$ wh varix": remaining varicose veins at 4 weeks after operation; $(0=$ no; $1=$ yes $)$

Table 2.b Logistic regression model results for 2-year recurrence.

\begin{tabular}{|c|c|c|c|c|c|c|c|c|}
\hline risk Factor & B & S.E. & Wald & df. & Sign. & Exp. (B) & st $\operatorname{Exp}(\beta)$ & $\begin{array}{l}95 \% \mathrm{Cl} . \\
\text { of } \operatorname{Exp}(\mathrm{B})\end{array}$ \\
\hline therapy & 3.44 & 1.14 & 9.13 & 1 & .003 & 31.27 & 7.91 & $3.35-291.74$ \\
\hline 4 wh varix & 3.28 & 1.54 & 4.53 & 1 & .033 & 26.57 & 3.37 & $1.30-544.78$ \\
\hline constant & -2.55 & 1.53 & 2.76 & 1 & .096 & .08 & - & \\
\hline
\end{tabular}

Backward thmbation change in loglikelhood chi-square $X_{(p)}$ :

$\begin{array}{lll}\text { therapy: } & 20.37 & (<.0011) \\ 4 \text { wh varix: } & 7.11 & (.008)\end{array}$

Predicted (2 year):

\begin{tabular}{llll}
\hline observed & recurrence & no recurrence & $\%$ \\
recurrence & 19 & 0 & 100 \\
no recurrence & 30 & 47 & 61.0 \\
& & & 68.8 \\
\hline
\end{tabular}

legend: "therapy": therapy modality (1=AP, $2=$ Sclero), "4 wh warix"; temaining varicose veins at 4 weeks nfter operation $(0=$ no; $1=y e s)$ 
Table 3. Recurrences and complications after ambulatory phlebectomy and compression sclerotherapy

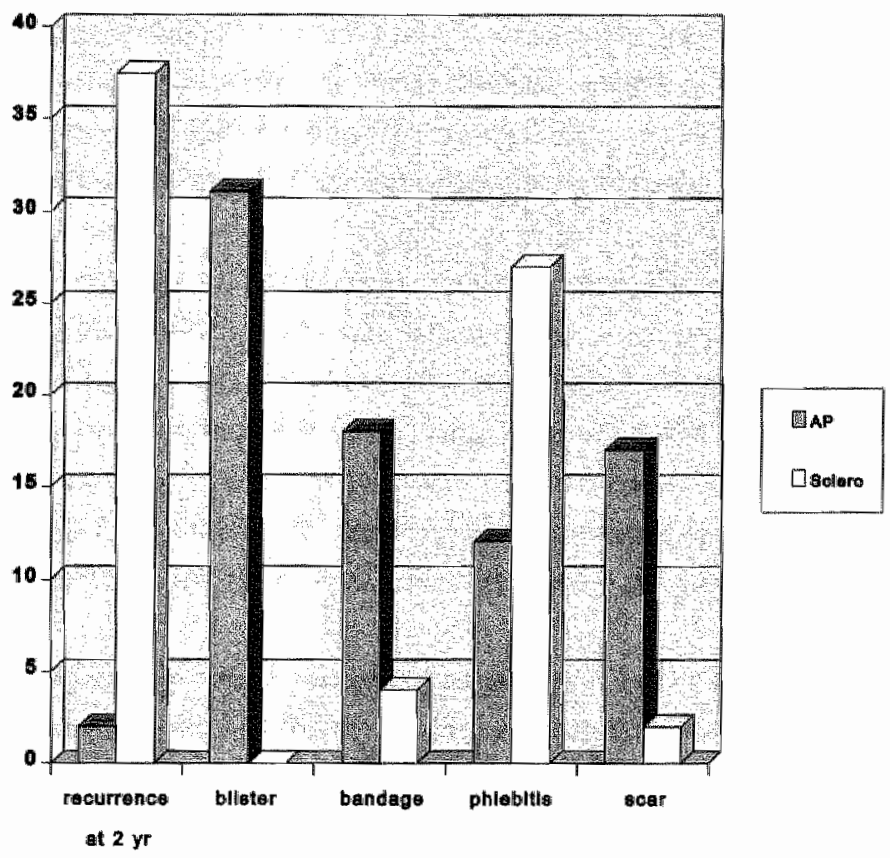

\section{Complications}

Only during the first two wecks after therapy blisters occurred and only in 15 $(31 \%)$ of the AP treated legs $\left(\chi^{2}=23.59,1 \mathrm{df}, \mathrm{p}<.001\right)$. There is no difference in hematoma for both operation modalities: this occurred in one third of the cases during the first month of follow-up, but predominantly at the two weeks control visit $\left(\chi^{2}=.00,2 \mathrm{df}, \mathrm{p}=1.000\right)$. In thirteen $(27 \%)$ of the Sclero-legs and $6(12 \%)$ of the AP-legs phlebitis was observed. The difference however was not significant $\alpha^{2}=3.28,1 \mathrm{df}, \mathrm{p}=070$ ). Teleangiectatic matting was observed only three times over the two-year follow-up period, each of the cases after AP. This was statistcally significant $\left(\alpha^{2}=4.26,1 \mathrm{df}\right.$., $\left.\mathrm{p}=.039\right)$.

Scar formation did occur mostly two weeks post-operatively, and only in AP cases: eight $(17 \%)$ and $\chi^{2}=11.82,1 \mathrm{df}, \mathrm{p}=.001$. Afflictions due to bandaging occurred more after AP $(9 ; 19 \%)$ than in Sclero-legs $(2 ; 4 \%)$ and $\chi^{2}=5.40,1 \mathrm{df}$., $p=.020$. 


\section{DISCUSSION}

The GSV can be treated with both AP and Sclero. However it is not possible to perform a proper crossectomy with these techniques. Next to the GSV the LAV vein is the largest superficial vein in the leg and it may lead to complaints if it has become varicose (Ramelet \& Monti 1999). LAV is considered to be an excellent indication for Sclero by many phlebologists (Wallois 1982). The use of ambulatory phlebectomy as an alternative therapy for LAV has been suggested in the past (Davy et all. 1985).

We realize that in this study one physician performed all therapy sessions and because of this we are cautious to generalize the results. Nevertheless with this study we have shown that ambulatory phlebectomy of $\mathrm{LAV}$ has a low recurrence rate after two years $(2.1 \%)$, which is significantly lower than after compression sclerotherapy (37.5\%). Publications on recurrence rates often have a scope of five years. Because of the impressive differences we found even only after two years we decided not to wait another three years with the publication of our results.

This study further shows that if remaining varicose veins up to four weeks are included in the two-year recurrence model, they turn out to be a statistically significant risk factor for two-year recurrence. In other words: if LAV requires three sclerotherapy sessions $(0,2$ and 4 weeks $)$ to disappear, there is a very high risk of recurrence at one or two years.

This finding has significant implications for every-day practice. Based on this study we conclude that $\mathrm{AP}$ is the treatment of choice for $\mathrm{LAV}$. If however Sclero is chosen and is unsuccessful after two treatmont scssions, wo arguc that $A P$ should be the next step.

There are no theoretical anatomical or practical reasons why these results cannot be extrapolated to other varicose veins of this caliber.

There were no major complications or adverse events over the total study period of four years. Blister formation was the most important complication during the first two weeks after AP (31\%). This is attributed to friction caused by the use of non-elastic adhesive surgical tape for the closure of the incisions made during phlebectomy. Although the use of these tapes is not directly a consequence of ambulatory phlebectomy it is inextricable bound up with this therapy. There was no significant difference in severity of complaints as a consequence of treatment for both treatment modalities $(\mathrm{p}=.41)$.

Because of their low mortality rate varicose veins seem to have a low priority when it comes to RCT. However as a result of their high morbidity rate and as a 
consequence their impact on society varicose veins play a majot role in everyday practice of general practitioners and specialists treating venous disease. Although A.P has been proven to be a good treatment option for varicose veins of different caliber's we have provided evidence of the superiority of AP in the treatment of LAV. Because of the time-consuming nature of AP physicians treating varicose veins may prefer sclerotherapy. With this study we hope to convince them that the extra-time initially spent in performing $A P$ is an investment in a lower recurrence rate, a higher rate of patient satisfaction, and probably, cost-effectiveness in the long run. 


\section{CHAPTER 5}

\section{FOOT VARICOSIS}

Roos de K-P, Neumann HAM

Muller's ambulatory phlebectomy for varicose veins of the foot

Dermatol Surg 1998; 24: 465-70.

Roos de K-P, Nieman FHM and Neumann HAM

Patient satisfaction after ambulatory phlebectomy for varicose veins in the foot.

Dermatal Surg 2002; 28: 1027-30. 



\section{1}

\section{Muller's ambulatory phlebectomy and varicose veins of the foot}

Background. Ambulatory phlebectomy is an accepted therapy for varicose veins. It has also been used for ankle and foot varicosities with succes although the anatomy of the venous system of the foot is poorly described in the literature.

Objective. To review the relevant literature on the anatomy of the veins of the foot. Also to form an opinion on safe possibilities for the treatment of foot varicosis.

Methods. The English, French, German and Dutch language literature was reviewed for anatomy and treatment for varicose veins of the foot. Fourteen patients (19 feet) were treated for varicose veins of the foot with ambulatory phlebectomy.

Results. Venous surgery, sclerotherapy and ambulatory phlebectomy have all been used for the treatment of varicose veins of the foot. The former two have resulted in serious complications. All treated patients observed excellent results. No serious side effects were seen.

Conclusions. The venous anatomy of the foot does not indicate major restrictions in the treatment of it's varicosities. Ambulatory phlebectomy is the safest and most elegant treatment option for varicose veins of the foot. Venous surgery and sclerotherapy may be used successfully in special cases. 


\section{INTRODUCTION}

Ambulatory phlebectomy has gained more and more interest among phlebologists, first in France where it was introduced in 1966 and world-wide during the past few decades (Muller 1966). It is a simple, elegant, definite, and safe treatment modality with excellent cosmetic results for the treatment of varicose veins which has been extensively described in the literature (Tritsch 1985, Goren 1991, Goren \& Yellin 1991, Neumann 1992, Fratila et al. 1993, Fligelstone et al. 1995). Because of it's safety and excellent cosmesis, it has been proposed for the treatment of varicose veins on the legs as well as for other parts of the body such as the arms, the feet, and the peri-orbital and temporal area (Constancias-Dortu \& Dortu 1991). It has also been proposed as a diagnostic tool in wenous as well as arterial disease (de Roos \& Neumann 1995).

It is a safe technique with a low incidence of side effects. However, in most cases some hematoma formation is seen. A multicentre study performed in France evaluated 36,000 phlebectomies. Most frequently encountered complications were teleangiectasias $(1.5 \%)$, blister formation $(1 \%)$, phlebitis $(0.05 \%)$, hyperpigmentation $(0.03 \%)$, postoperative bleeding $(0.03 \%)$, temporary nerve damage $(0.05 \%)$, and permanent nerve damage $(0.02 \%)$ (Gauthier 1993). More incidental complications include granuloma formation (Ramelet 1991), neuroma (de Roos \& Neumann 1994), and more recently necrobiosis lipoidica as a Koebner phenomenon on phlebectomy scars (Vion 1997).

Most important contra-indications are escape varicose veins, hemodynamic important secondary varicose veins, and hypercoagulable states. Relative contra-indications include overweight, deep venous insufficiency. Recurrent varicose veins make ambulatory phlebectomy a challenging therapy. Fibrosis due to previous scllerotherapy often necessitate multiple incisions. In angiodysplasia syndromes, like the Klippel-Trenaunay syndrome, ambulatory phlebectomy is extremely difficult due to the vulnerability of these veins (Asselman \& Neumann 1997).

It is considered to be common knowledge that treatment of varicose veins of the foot should be avoided because of the great risks involved, the most dreaded of which being acute ischemia with a possible nescessity for amputation as a result (Oesch et al. 1984, anonymus 1975, Walois 1987). These adverse events have been registerred following both compression sclerotherapy and stripping procedures (Eger et al. 1973, Liddicot et al. 1975). Other complications include venous thrombosis and pulmonary embolism. In recent years, however, there have been several publications on the use of Muller's ambulatory phlebectomy for the treat- 
ment of varicose veins of the foot and ankle region (Olivencia 1997, Muller 1990, Constancias-Dortu 1987, Tritsch 1985). As with any surgical procedure knowledge of the regional anatomy is of great importance. It is therefore astonishing to see how little has been published on this subject. Even textbooks and anatomical atlases fail to mention the venous anatomy of what is considered to be the starting point of venous teturn, namely the foot in great detail (Gardner \& Fox 1993). In their excellent monography on venous return of blood to the heart Gardner and Fox state that: "The deep veins of the foot were not even mentioned in a recent anatomical atlas of the foot and ankle (McMinn et al. 1982) or in Grant's Atkas of Anatomy (Anderson 1979) although the Adas does depict the dorsal vein of the clitoris" to illustrate the lack of interest for the venous anatomy of this region.

In this article we review the relevant literature and its implications, illustrated with our own experience on the subject. This knowledge of the venous anatomy of the foot will be the basis for successfull treatment of varicose veins in this area.

\section{PATIENTS AND METHODS}

\section{Patients}

A group of 14 patients (13 females and 1 male; aged 33-63; mean age 48) was treated for primary varicose veins of the foot ( 19 feet were treated). It was an open prospective study that included all patients from November 1996 to November 1997, and who were seen by one of the authers.

Pretreatment investigations always included Doppler ultrasound for the detection of reflux and light reflexion theography for determining calf muscle pump capacity, as measured with the venous refill time (Neumann \& Boersma 1992). In 5 patients additional Duplex scanning was performed. All major points of reflux, such as insufficiency of the sapheno-femoral junction were treated surgically first. Then the varicose veins of the entire limb were treated with sclerocompression therapy ( 13 of 19 feet) or a combination of sclerotherapy and ambulatory phlebectomy as described before (Neumann 1992). Finally, the varicose veins of the foot were treated with ambulatory phlebectomy. In this group of 14 patients, five patients had complaints of their foot varicosities (pain, problems with shoes, etc) and nine patients found the varicose veins cosmetically disturbing. 


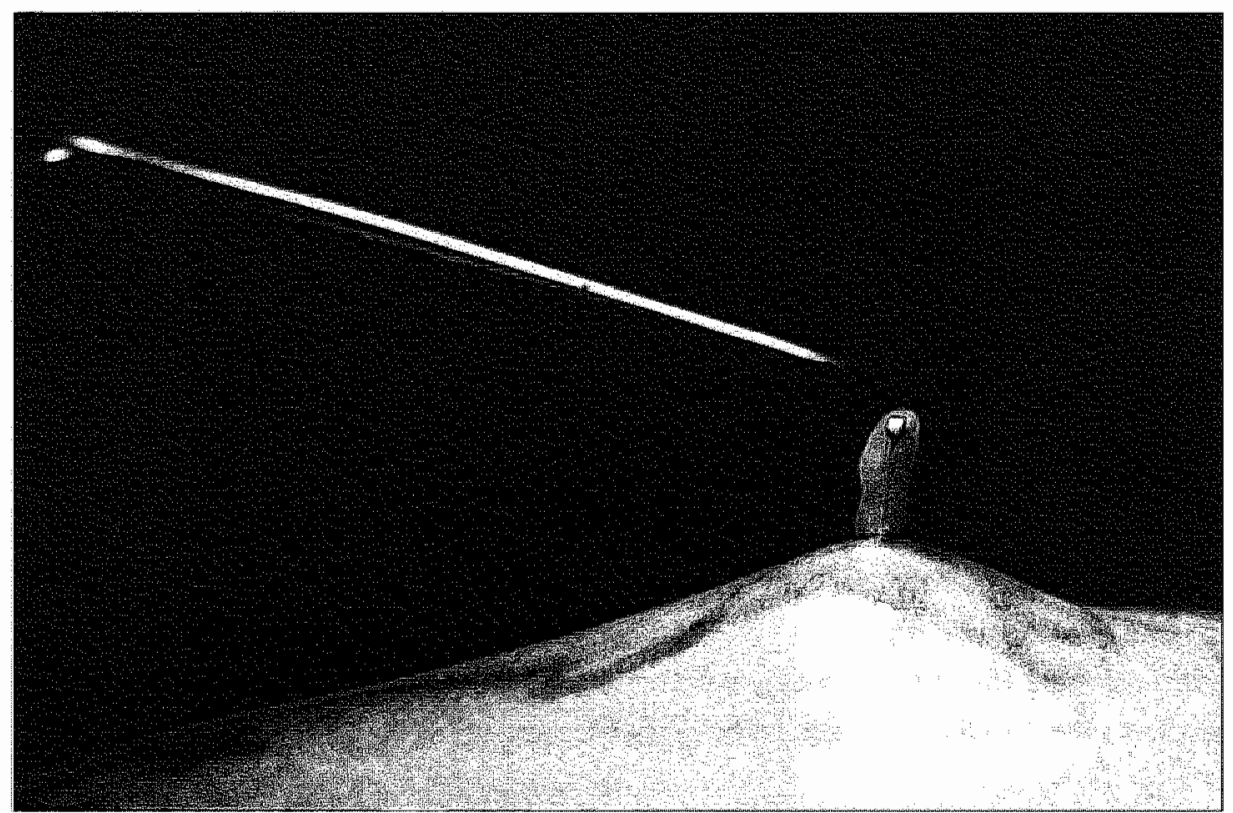

Figure 1. Foot vein grasped using a phlebectomy hook.

\section{Methods}

First the varicose vein is marked in standing position using indelible ink. "Then after placing the patient on an operating table the marked skin is anesthetised using lidocain with epinephrine. Parallel to the marking 2 -mm stab incisions are made every $5-10 \mathrm{~cm}$ through which the vein is grasped using a phlebectomy hook (figure 1). The vein is then fixed with clamps and extracted untill it will break. "This procedure is repeated untill the vein is extracted or "harvested" completcly. The incisions need no suture and can be closed by surgical tape (eg, Steristrip (ing . To prevent extensive hemorrhage bandages are applied for a period of five days after which elastic stockings are worn for another five days (Neumann et all. 1998).

\section{Literature searb}

The English, French, German, and Dutch language literature was systematical]y reviewed for anatomy and treatment of varicose veins of the foot. The relevant literature is presented. 


\section{ANATOMY}

After thorough examination of the literature as well as relevant textbooks we were surprised to find such a small number of publications dedicated to our current subject. Although the first publication dates from 1890 (Lejars 1890) and other investigators had preceeded them, van Limborgh et al. published their investigations on the communicating veins of the leg completing most of what had been done previously. They emphasize the importance of these veins in the treatment of varicosis (van Limborgh et al. 1962). To accomplish this, they dissected 25 cadaver legs and listed the communicating veins that were found in at least $18(75 \%)$ of them. There were some discrepancies in the literature between the use of terms as perforating vs communicating veins. Since not all communicating veins perforate tissue (eg, fascia) van Limborgh et al. suggest to use the former, which is nowadays widely accepted (Staubesand \& Li 1992).

Aside from their findings concerning the rest of the leg they identified four groups of communicating veins in the foot: plantar, medial and lateral marginal, and dorsal communicating vein. The first group consists of approximately 15 communicating plantar pedal veins that in part drain into the lateral plantar vein and in part into the medial plantar vein. The second group consists of six communicating veins connecting the medial plantar vein to the greater saphenous vein. The third group on the lateral side of the foot consists of eight communicating veins connecting the lateral plantar vein to the lesser saphenous vein. "The fourth and last group of communicating veins is the dorsal pedal communicating veins which can be divided into three subgroups and connect the deep veins of the foot to the greater saphenous vein.

Van Limborgh et al. (1963) also found, as would be expected, that most communicating veins in the leg have one or two valves directing blood inward from the superficial to the deep venous system. However, this did not hold true for the foot, where the valves if present direct blood ourward from the deep system into the superficial venous system. Being anatomists they did not make any statements to the clinical implications of their findings.

In the venous system many perforating veins have been identified. It is estimated that on each leg there are approximately $90-150$ perforators. Major perforators have been named: Hunter, Dodd, Boyd, Cockett, Sherman, and May are names known to most phlebologists. Less familiat is Kuster's name when it comes to communicating veins of the foot. With his co-workers he rubricated the most important communicators as we will see further on (Kuster et al. 1968). 


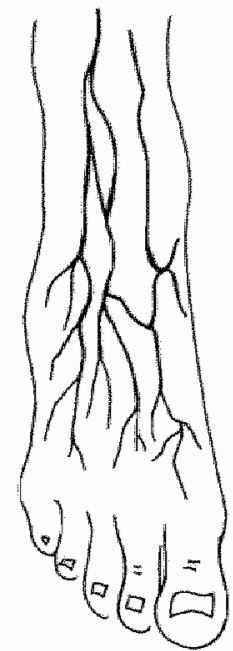

Figure 2. The thin reticular pattern of the superficial dorsal system

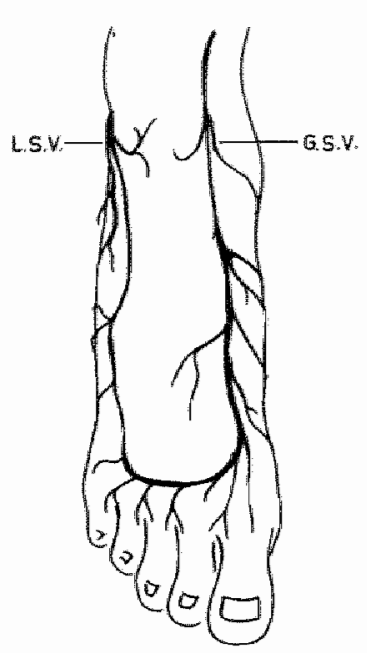

Figure 3. The dorsal arch connecting the greater saphenous wein (GSV) to the lesser saphenous vein (LSV)

In the late 1960s and early 1970s Kuster, Lofgren, and coworkers extended their stripping procedure to the elimination of dilated perforating veins on the foot and ankle in an effort to improve their result on treating patients with varicose veins (Lofgren et al. 1968). They were impressed by the many perforating veins on the foot and observed both thrombosis when veins were ligated and extensive bleeding when these veins were avulsed. These observations led them to investigate further, producing ther first extensive study on the anatomy of the foot and ankle (Kuster et al. 1968). After studying ten adult cadaver feet they were able to determine five systems:

1. The superficial dorsal system with veins normally upto 2 millimeter in diameter on the dorsal aspect of the foot which have their origin mainly in the dorsal skin of the foot. They form a reticular pattern (figure 2).

2. The dorsal venous arch connecting the greater saphenous with the lesser saphenous vein on the dorsum of the foot in a semicircular fashion parallel to the base of the toes. The arch is located between the deep and the superficial fascia and has four origins: the dorsal and lateral aspect of the toes; veins from the skin of the dorsum of the foot; veins which leave the superficial network of the sole of the foot and perforating veins that connect the deep system to the arch and both the saphenous veins (figure 3).

3. The deep venous system consists of veins that accompany the arteries and run deep to the muscles and tendons; two veins for each artery. The plantar veins 


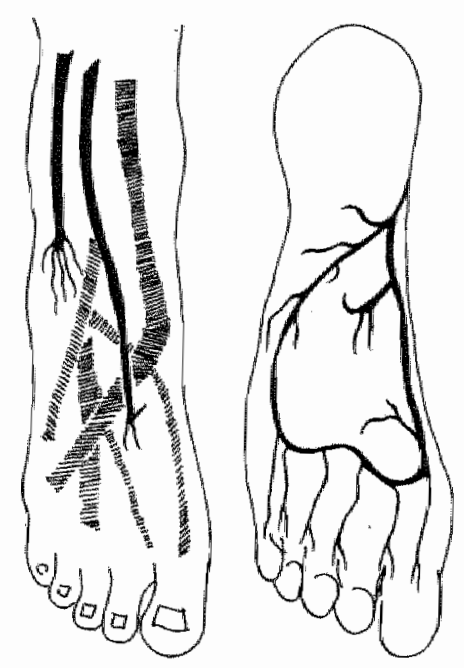

Figure 4. The deep venous system of the foot. Peroneat veins (left) and the dorsal arch (right).

unite deep to the flexor retinaculum and drain into the posterior tibial veins on the dorsal aspect of the foot. Receiving blood from plantar digital veins; from veins which drain the muscles, bones, and joints; and from veins which come from superficial plantar veins and valveless communicating veins from the saphenous system (figure 4).

4. The superficial plantar venous network consists of fine veins in the skin in the sole of the foot, the subcutaneous tissue, and in the areolar tissue formed by the superficial plantar fascia. This plexus drains into the first three systems (figure 5).

5. The communicating system. Although there are many communications among the four previous systems which need not be described in detail, there are those between the deep and the saphenous system that are considered to be important. The perforating or communicating veins that establish this connection follow a constant pattern (figure 6). Most of which perforate the fascia. Kuster et al. estimated that there are approximately six communicating veins on the medial aspect of the foot and ankle and six on the lateral aspect. For the description of the exact location of the communicating veins we refer to their excellent article (Kuster et al. 1968).

They allso found that distal to the ankle the direction of the valves was outwarcl confirming earlier findings. In adition to this, in 49 of $91(54 \%)$ of cases there 


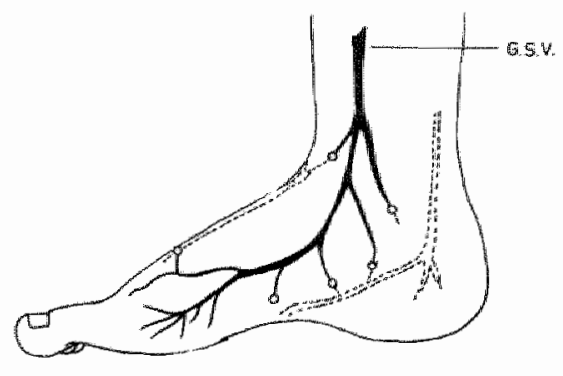

Figure 5. Medial aspect of the foot with perforators (circles) that connect the GSV to the deep venous system.

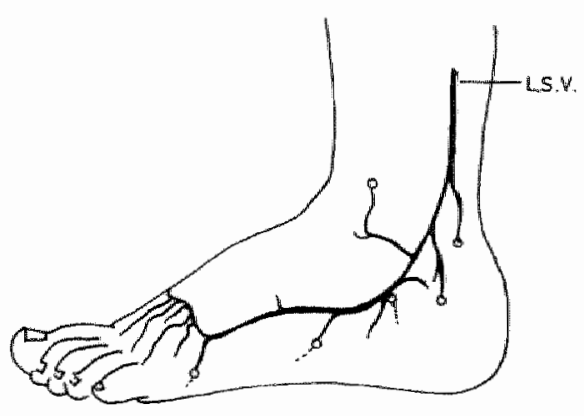

Figure 6. Lateral aspect of the foot with perforators (circles) that connect the LSV.

were no valves in the communicating veins allowing blood to flow freely in both directions.

Much of the detailed work by Kuster et al. (1968) was confirmed by other investigators adding some dynamics to it through phlebographic studies. Jacobson (1970) confirmed Kuster's supposition about the function of the superficial veins as an accessory drainage system for the deep veins of the foot. In addition, he showed that it was possible for blood to flow from superficial veins into the deep veins after occlusion of the former (Jacobson 1968). Later, Askar improved the available technique for phlebography of the foot as well as initiating criteria for the interpretation of these phlebograms (Askat et al. 1975). In a subsequent study he concluded that all the veins digital, metatarsal, and communicating are equipped with valves which allow a flow of blood towards the dorsal venous arch (Askar \& Abdullah 1975).

\section{RESULTS}

In all 19 feet, no serious side effects were observed. In three cases more than expected hematoma was formed. In one case a temporary nerve damage was observed. One patient needed a second session for a remaining varicose vessel. 


\section{DISCUSSION}

If the calf muscle pump is be considered to be the 'second heart', the feet are the atria of this heart. It is therefore nescessary to focus every phlebologist's attention to the starting point of venous return. Although there are nearly no muscles in the foot, a foot pump does exist. Incompetence of this foot pump leads to clinical signs of venous insufficiency such as pigmentation and lateron also pseodo-Kaposi (Mali-Kuiper disease) (Mali et al. 1965, Bluefarb \& Adams 1967). Finally, ulcerations may also occur.

Although investigators were somewhat surprised to find valves in the communicating veins in the foot and ankle region directed outward, it seems logical and even physiological. The large veins of the foot are situated between 'a rock and a hard place": the plantar aponeurosis and the boney structures of the foot. The aponeurosis has three functions: it provides protection for veins, arteries and nerves, it ensures attachment to the overlying skin and assists to maintain the arch of the foot. During walking the bloodvolume is compressed, forcing it to leave the veins of the deep venous system rapidly ("venous hurry"). The direction in which de pressure is developed is forward, leaving only one direction for the blood: to (through) the superficial plantar and dorsal venous plexuses: hence the direction of the valves. To put it in other words: if valves were directed inwards they would not last very long and become incompetent.

The question may be raised if we should treat varicose veins below the ankle. 'The classic notion is that there is no need for intervention if there is no disease or if there are considerable risks involved ("primam nil nocere") does not stop at the ankle. However there are some patients with serious phlebologic complaints of varicosities of the foot and ankle region that can be alleviated through simple treatment. In our opinion, therefore, treatment of varicose veins should not stop at the ankle. The complicated venous anatomy of the foot wich many parallel veins makes treatment possible in a safe way. In our study (although the number of patients is low) we proved that ambulatory phlebectomy can be used for treatment of varicose veins of the foot.

Considering the risks involved, thete seem to be few indications for sclerotherapy. The major risks being intra-arterial injection and deep thrombosis of the foot. Most reports on arterial injection concern the medial aspect of the ankle near Cocketts perforating veins and with the use of potent sclerosing fluids (sodium-tetradecyl-sulphate and iodine). There may be some place for sclerotherapy of varicose veins in this region. Although there is no current evidence, sclerotherapy may be safer if small amounts of less potent fluids 
(polidocanol) are used that are injected with little force and adequate compression afterwatds (personal observation).

We will not recommend sclerotherapy as a routine procedure for varicose veins of the foot. In fact, the venous arch of the foot is a junction between greater and lesser saphenous veins. True varicose veins of the foot are a continuation of the reflux of one or both of these veins. Isolated treatment of only the varicosity of the foot is therefore contra-indicated. A total work-up and systematic treatment from proximal to distal - is essential for good results. Based on the knowledge of the anatomy, it is clear that also varicose veins of the foot can be treated softly. Our results as well as that of Olivencia (1997) prove that. However, sclerotherapy has too many risks. Conventional vascular surgery is too rough for this delicate area.

Ambulatory phlebectomy is in our opinion and experience the treatment modality of choice. 'Treatment of this varicosity is not only for cosmetic reasons, but also for medical reasons. In case the venous return from the foot can be restored, complications like pseudo-Kaposi and foot ulceration can be avoided. In contrast to primary varicosis of the leg, a simple investigation like the LRR with high predictive value for the outcome of treatment results is lacking. With a complicated strain gauge setup measuring technique, the so-called foot pump function can be measured (Kuiper \& Brakkee 1971).

Conventional vascular surgery has been used with some success in the past. The major disadvantage, however, is that it inevitably leaves disfiguring scars.

Because of the selectivity of the procedure surgical techniques may be superior to a nonselective technique such as sclerotherapy. Ambulatory phlebectomy combines surgery with cosmesis and, because of the many seperate venous systems, alternative routes and escape possibilities it can be applied safely below the ankle. Because of its safety it can also be used for cosmetic indications. Our group of patients also show that ambulatory phlebectomy is a safe and efficient treatment modality for varicose veins of the foot.

There is essentially no difference in the technique when special regions, such as the ankle and foot, are treated. We would nevertheless advocate the initial training on other parts of the $\mathrm{leg}$, eg, the upper leg, before attempts should be made on the foot and ankle. This holds true for several reasons. First, because the skin of the foot is much thinner and much more fibrotic phlebectomy hooks get caught up in the skin. Second, because there is much less if any subcutaneous fat, there is less protection against trauma of the skin and more important underlying tissues such as tendons, tendonsheaths, reticulatum, and joints. Furthermore, there appear to be more small nerve branches readily available for the hooks to 
get entangled in. This is probably why a traumatic neuroma has been described in this region (de Roos \& Neumann 1994). As in the kneepit there is a greater risk of rupturing an artery. Moreover, there is the not unimaginable risk of grasping and possible rupturing of the tendon.

The relative safety of the procedure does not excuse the treating physician from his responsibility for the accuracy and care that has to be taken during patient selection and work up. It should furthermore be stressed that phlebectomies of the foot and ankle region need extra experience in both selection of patients and their treatment. It can be very satisfying and rewarding, however, to treat the phlebologic patient as a whole and not have to stop at the ankle. 



\section{2}

\section{Patient satisfaction after ambulatory phlebectomy of varicose veins in the foot}

Background. Ambulatory phlebectomy is an accepted therapy for varicose veins of the ankle and foot region. Although most phlebologists regard this therapy highly, little is known about patient satisfaction.

Objective. To investigate patient satisfaction and complaints as reported by the patient after ambulatory phlebectomy for varicose veins in the ankle and foot region.

Methods. A questionnaire was taken from patients who received ambulatory phlebectomy for varicose veins of the ankle and foot region between 1996 and 2000 .

Results. According to the results of the questionnaire fifty percent of patient population is not completely satisfied, mostly because of persisting pain, reported discoloration and perceived recurrence.

Conclusions. Most important factors that influence patient satisfaction are reported discoloration, persisting pain and perception of varices after surgery. To avoid misunderstandings and/or disappointments attention should be given to patient information before and after surgery. 
$98 \mid$ CHAPTER 5

\section{INTRODUCTION}

The efficiency of ambulatory phlebectomy (AMP) has been well established over the years. It has proven to be a safe and effective therapy modality for vaticose veins of most caliber's. In a review of the literature we have indicated that AMP also can be used safely for varicose veins of the feet (de Roos \& Neumann 1998). We have also demonstrated preliminary results of 14 treated patients in our clinic. Recently we evaluated the results of all patients who were treated for varicose veins of the foot between 1996 and 2000.

In our treatment strategy for varicose veins, at first major points of reflux are treated, before side branches and smaller veins. When all these varicose veins have been eradicated, varicose veins of the foot are treated. Follow-up after the final treatment session is generally five days to six weeks. During the last control visit, patients are asked, if they are satisfied about the result and if recently any adverse events had occurred. If so, this is registered in the patient's medical file. If patients indicate that they feel satisfied with the result, no further appointments are made. They are advised, however, to return if any (other) adverse events occur.

To register long-term satisfaction with the treatment undergone a survey was started. All patients who were treated with AMP for varicose veins of the foot between 1996 and 2000 in our practice were contacted by telephone to ask whether they agreed to participate in this survey. If so, they were questioned for 10 minutes using a preconstructed questionnaire. Survey items included the current health status of the foot, as seen by the patient, perceived recurrence, and complications and how these complications effect daily life.

The main question is, what determines the respondent's evaluation of the health state of the foot at the time of the survey? Is it simply the subjectively seen recurrence of varicose veins, or do one or more complications provide an explanation for a more negative evaluation of the health state of the foot? Or is it a combination of the perception of recurrence and complications reported that produces a positive or negative evaluation of the health state of the foot?

\section{PATIENTS, MATERIALS AND METHODS}

From January 1996 to December 2000 a total of 377 AMPs were performed for varicose veins. $A$ total of 53 patients were treated for varicose veins of the foot. Their mean age at first treatment was 49.2 year $(S D=10.5$ years; minimum age 
Table 1. Location of foot paricosis according to medical file.

\begin{tabular}{llllll}
\hline & location & left & right & $\begin{array}{l}\text { frequency } \\
\text { L+R }\end{array}$ & percentage \\
\hline 1 & Foot dorsum & 12 & 5 & $16^{*}$ & 30.8 \\
2 & Lateral ankle & 6 & 4 & 10 & 19.2 \\
3 & Medial ankle & 12 & 9 & 21 & 40.4 \\
4 & Medial \& lateral & 2 & 2 & 4 & 7.7 \\
5 & Foot dorsum \& ankle & 0 & 1 & 1 & 1.9 \\
& Missing & 1 & 0 & 1 & 100 \\
\hline
\end{tabular}

* one patient had the dorsum of both feet treated

Table 2. Complications according to medical file.

\begin{tabular}{llll}
\hline & complication & frequency & valid percentage \\
\hline 1 & None & 43 & 81.1 \\
2 & Significant hematoma & 2 & 3.8 \\
3 & Skin sensitivity & 2 & 3.8 \\
4 & Pain due to bandage & 1 & 1.9 \\
5 & Blister formation & 5 & 9.4 \\
& Total & 53 & 100 \\
\hline
\end{tabular}

28.7 years; maximum age 72.4 years $)$. Forty-four patients were women $\left(83^{\circ} \%\right.$; mean age 50.1 years; $\mathrm{SD}=10.6$ years $)$ and 9 were men $(17 \%$; mean age 44.7 years; $\mathrm{SD}=9.4$ [Student's $t$-test $\mathrm{p}=.169]$ ).

The medical files of these 53 patients were reviewed for the location of varicose veins that had been treated (table 1), the date of treatment, and the occurrence of complications (table 2). Of these patients, 49 could be traced and were approached for the telephone survey, which was held in November and December 2001 by a properly instructed independent interviewer. One patient declined our invitation to participate, the remainder $(n=48)$ did comply. 


\section{STATISTYCS}

For univariate categorical variables frequencies and percentages were used, and for interval variables means and standard deviations. In testing differences between interval variables the Student t-test for independent groups was applied. Pearson product-moment correlation coefficients and multiple regression analysis were applied, when ordinal categories in variables were assumed to represent an underlying normal distribution. Chi-square and Kendall's tau-b rank correlation coefficient was used for ordinal variables. All results were analyzed with SPSS-pc, version 10.0 (SPSS Inc., Chicago, IL). A p-value of less than .05 was considered to be statistically significant.

\section{RESULTS}

The mean age at being interviewed was 52.8 years $(\mathrm{SD}=10.1$ years; minimum age 34.3 years; maximum age 75.2 years). Forty patients were women $(83 \%$; mean age 53.4 years; $\mathrm{SD}=10.3$ years) and 8 were men $(17 \%$; mean age 50.0 years; $\mathrm{SD}=9.5$ years [Student's t-test $p=.393]$ ).

The mean period of treatment until the last follow-up date ("status time") was 1 year and 8 months $(S D=1$ year and 9 months; median was 11 months, minimum: 5 days, maximum: 5 years and 5 months). The mean period of the last follow-up until the survey date (November 2001) was 2 years and 4 months ( $\mathrm{SD}=1$ year and 6 months, median 2 years 1 month, minimum 2 months, maximum: 5 years and 6 months). The mean period elapsed between the first treatment session and survey date was therefore 3 years and 11 months.

One of the first questions asked was, if former patients could see "one or more varicose veins" within "the region of the foot or feet that was/were treated during past months/years." Regarding this question 20 of the 48 participating respondents (42\%) said "yes, most definitely so", $3(6 \%)$ said "yes, I do", $9(19 \%)$ said "I think so", and 16 (33\%) responded "I don't see such varicose veins". The next question was to give an evaluation of the state of health of the foot or feet that had been treated. Of the 48 respondents $4(8 \%)$ replied that the state of health was "excellent", $20(42 \%)$ said it was "good", $15(31 \%)$ said "moderately good", $6(13 \%)$ said "bad" and $3(6 \%)$ characterized it as "very bad". There is a statistically significant relationship between the evaluation of the state of health and the perception of varicose veins on/in the foot/feet: loglikelihood chi-squared is $30.63(\mathrm{df}=12 ;(\mathrm{p}=.002)$ and Kendall's $t-b$ rank correlation coeffi- 
Table 3. The patient's evaluation of the state of health of the foot at the rime of the interview, given the perception of recurrence.

\begin{tabular}{|c|c|c|c|c|}
\hline $\begin{array}{l}\text { evaluation of the result vs } \\
\text { categorized perception of } \\
\text { foot-waricosis }\end{array}$ & $\begin{array}{l}\text { sees no } \\
\text { varicose vein }\end{array}$ & $\begin{array}{l}\text { sees possible } \\
\text { waricose vein(s) }\end{array}$ & $\begin{array}{l}\text { definitely sees } \\
\text { varicose vein(s) }\end{array}$ & total \\
\hline \multirow[t]{2}{*}{ excellent tesult } & 3 & 1 & 0 & 4 \\
\hline & $18.8 \%$ & $8.3 \%$ & & $83 \%$ \\
\hline \multirow[t]{2}{*}{ good result } & 11 & 6 & 3 & 20 \\
\hline & $68.8 \%$ & $50.0 \%$ & $15.0 \%$ & $41.7 \%$ \\
\hline \multirow[t]{2}{*}{ reasonable result } & 1 & 4 & 10 & 15 \\
\hline & $6.3 \%$ & $33.3 \%$ & $50.0 \%$ & $31.3 \%$ \\
\hline \multirow[t]{2}{*}{ bad result } & 1 & 1 & 4 & 6 \\
\hline & $6.3 \%$ & $8.3 \%$ & $20.0 \%$ & $12.5 \%$ \\
\hline \multirow[t]{2}{*}{ vety bad result } & 0 & 0 & 3 & 3 \\
\hline & & & $15.0 \%$ & $6.3 \%$ \\
\hline \multirow[t]{2}{*}{ total } & 16 & 12 & 20 & 48 \\
\hline & $100.0 \%$ & $100.0 \%$ & $100.0 \%$ & $100.0 \%$ \\
\hline
\end{tabular}

Table 4. Frequencies of reported swelling, skin sensitivity, scars, discoloration and pain

\begin{tabular}{lll}
\hline complication & frequency & percentage \\
\hline swelling & $19 / 48$ & $39.6 \%$ \\
skin sensitivity & $21 / 47$ & $44.7 \%$ \\
scars & $1 / 46$ & $2.2 \%$ \\
discoloration & $23 / 48$ & $47.9 \%$ \\
persisting pain & $8 / 48$ & $16.7 \%$ \\
\hline
\end{tabular}

cient turns out to be $-0.53(\mathrm{ASE}=0.088, \mathrm{p}<.001)$ (table 3). The latter coefficient means that the more definitively varicose veins are perceived, the lower the state of health as evaluated by the respondent (the less definitely these veins are perceived, the higher state of health).

Along with the respondent's perception of the recurrence of varicose veins, the interviewer also asked about the patient's perception of complications common to these varicose veins. Table 4 shows the frequencies of presence of swelling, loss of skin sensitivity, scars, and discoloration of skin. Almost $40 \%$ saw swelling, $45 \%$ said they felt a diminishing of skin sensitivity in the area operated upon, $2 \%$ 
Table 5. Resulte of regression analysis: dependent variable: evaluation of "foor health" (ranging from 1: "excellent" to 5: "very bad result"), Variance explained: 0.505.

Unstandardized Coefficient Standardized Coesficient

\begin{tabular}{llllll} 
Model & $\mathrm{B}$ & Std error & $\beta$ & $\mathrm{t}$ & Sign \\
\hline (constant) & 2.719 & 0.332 & & 8.196 & 0.000 \\
$\begin{array}{l}\text { perception of recurrence } \\
\text { of varicose vein }\end{array}$ & -0.220 & 0.096 & -0.288 & -2.292 & 0.027 \\
reported discoloration & 0.749 & 0.239 & & & \\
reported pain & 0.744 & 0.314 & 0.371 & 3.128 & 0.003 \\
\hline
\end{tabular}

Note: addition of other complaints such as swelling, skin sensinvity or scars did not add information to these results

saw a scarring, and $48 \%$ reported a discoloration of the foot skin. "The respondents were then asked, if the operated area still felt painful. Nlmost $17 \%$ ( 8 respondents) said it still felt painful at the time of the interview.

To answer the main question raised in the introduction, an inspection of the statistical associations between the evaluation of the state of health and perceptions of varicose vein recurrence and complications may shed some light on this matter. If the evaluation of the state of health can be seen as an interval scale, a regression analysis will provide the relative importance of either reported recurrence or complications to predict this scale.

Table 5 provides the results of a forward selection regression analysis. Variance explained by the regression equation amounts to 0.505 using perception of varices recurrence, reported discolotation of the foot skin and reported pain as the only statistically significant predictors. So, if respondents at the time the interview did perceive varicose veins, their evaluation of the state of health was significantly lower than that of respondents who saw no varicose veins at all. Next to this, if respondents reported to see discoloration of the foot skin in the area they were operated, they evaluated the state of health as significantly lower. And finally, if respondents also said they (still) felt pain in the foot at the area operated upon, they evaluated the state of health also significantly lower.

Next, patients who reported to see varicose veins were asked, if they considered this recurrence as a nuisance. Of the 32 respondents reporting to see varicose veins 14 or $44 \%$ considered this as an irritating nuisance, 9 or $28 \%$ considered it as a nuisance, 1 or $3 \%$ said it was a mild nuisance and 8 or $25 \%$ said it did not 
bother them at all. The Pearson correlation coefficient between the evalluation of the state of health and the reported burden or nuisance in everyday life for all 48 respondents is $0.551(\mathrm{p}<0.001)$. That is: the more the state of health is considered to be lacking, the more varicose veins are felt to be a nuisance (and vice versa).

If respondents reported to see varicose veins again, they were also asked to consider the possibility of being treated again. Of the 32 respondents 2 or $6 \%$ said "no/never" to this, 1 or $3 \%$ sairl to be "indecisive" at this point, 12 or $38 \%$ said "yes, maybe, but later on", 11 or $34 \%$ said "sure, but not right now" and 4 or $13 \%$ said they wished to be treated "right now". Two respondents $(6 \%)$ said they could not make up their minds on this matter. If the question was rephrased to choose for the same operation technique again in case of recurring varicose veins, the 48 respondents replied as follows : 4 or $8 \%$ said "no", 2 or $4 \%$ said "I don't think I will", 9 or $18 \%$ said "yes, maybe I would", 29 or $59 \%$ said "sure, I would do so" and 4 respondents or $8 \%$ said they did not have an opinion on this.

\section{DISCUSSION}

Treatment of varicose veins of the foot in an ambulatory setting is a facility which can be performed without any risk. In recent history there have been several reports on complications after AMP (Ramelet 1997, Oivencia 1997). Although there has been a great variation in reported adverse events, there seems to be a general agreement among phlebologists that AMP is a safe and effective procedure. To date there are no prospective studies on recurrences after AMP. Rivlin reported a 10 -year recurrence rate of $7 \%$ in 1,993 operated limbs using the 'multiple cosmetic phlebectomy technique (Rivlin 1975). Fratila et al. (1993) state that $A M P$ is "a very effective way to of completely and permanently removing all varicose veins".

AMP is also reported to enhance cosmetic appearance, and in close response to the individual patient's desires a phlebologist can operate to his or her satisfaction on the eventual results (de Roos \& Neumann 1998),

In $20 \%$ of the cases treated in our clinic post-operarive complications had occurred and standard procedures have been followed to deal with these problems. Information on post-operative complaints that may occur was provided to all patients prior to the operation and care was given to assure that patients were satisfied with the cosmetic results. 
In this survey patients were asked about their opinion on the (long term) results of their foot operation. Because of the nature of this study neither the exact location of the varicose veins the respondents reported could be verified by the authors, nor their relationship to the area that had been treated. Therefore the recurrences as reported by the patients $\left(66^{\circ} \%\right)$ are not necessarily "real" recurrences but constitute a subjective result (i.e.: as perceived by the patient).

Forty percent or more said to see either swelling, discoloration or indicated that they felt diminished skin sensitivity. Only one patient (2\%) reported to see residual scars in the foot.

With AMP varicose veins are permanently eradicated. However when new varicose veins do occur in the same region patients tend to regard these as a failure of treatment, if they are not sufficiently informed about this possibility.

Over the years it has become more and more important to prepare patients for the possible occurrence of complications and to provide them with information on the risks involved in the procedure. After the procedure patients are asked, if they are satisfied with the results of the operation.

Based on the results of this study we argue that in informing the patient (verbally and in writing) more attention should be given not only to what complications may occur, but also to what in the eye of the patient are the most important complaints after a certain procedure. In the case of AMP: discoloration, pain and "recurrences". To enhance the quality of information given to the patient and to avoid misunderstandings and/or disappointments the provider of care should base his/her patients education (also) on the priorities of problem solving patients report to adhere to, before treatment and most definitively after treatment. Although patients perceive "recurrent" varicose veins of the foot to be a nuisance, the fact that $85 \%$ of them still would like to be treated again with AMP is nevertheless very encouraging. 


\section{CHAPTER 6}

\section{SPECIAL INDICATIONS AND LOCATIONS}

Roos K-P de, Neumann HAM.

Vein biopsy; a new indication for Muller's phlebectomy.

Dermatol Surg 1995; 21: 632-4.

Roos K-P de, Neer PAFA wan, Go IH, Neumann HAM.

Non leg varicose veins and ambulatory phlebectomy;

a special technique for special cases.

(submitted) 



\section{1. \\ Vein biopsy;}

\section{a new indication for Muller's phlebectomy}

\section{INTRODUCTION}

In the dermatologic practice surgical techniques have to be used in order to obtain material for histologic verification of the diagnosis. As chronic venous insufficiency very often tends to induce to skin lesions, dermatologists are frequently confronted with venous diseases. The incidence of venous disease among adult population is calculated by Widmer as one out of eight adults (Widmer 1981). In close correlation to venous diseases special syndromes and angiodysplasia's are seen. In some of them the diagnosis can only be established by histological examination of the veins or smaller vessels (table 1) (Leu \& Leu 1993). Recently Corcos et al. published the results of 399 venous diagnostic biopsics and discussed the clinical applications of those biopsies (Corcos et al. 1993). So also for dermatologists it is of clinical interest to become familiar with an easy, quick and safe technique to harvest a small peace of subdermal vessel.

In the last two decade more attention is drawn to a safe and effective form of permanent treatment for varicose veins (Muller 1966, Hararap 1985, Neumann 1992). This technique, the Ambulant Minisurgical Phllebectony (AMP), was developed in the mid-1950's by Robert Muller a Swiss dermatologist (Muller 1966, Neumann 1992). This technique and its indications has been extensively described in this journal (Hararap 1985, Tretbar 1990, Neumann 1992). There is no need for profylaxis against thrombosis and leaves excellent cosmetic results. The operation is performed under local anaesthesia in an outpatients clinic (Neumann 1992). Although most varicose veins can be treated with this safe and elegant technique, special indications include varicose veins on the dorsal aspect of the foot, around the ankle (Muller 1990) and in the popliteal fossa. Contraindications for AMP are severe arterial occlusive disease, lymfedema, insufficient mobility and varicose veins located in severely inflammed areas or with dematosclerosis (Fratila et al. 1993). In our opinion this technique can also be used as simple method to obtain sufficient material for histopathologic with 
excellent cosmesis. To our knowledge this is the first report of the use of AMP as a technigue for wein biopsy.

\section{THE MICROSURGICAL VEIN BIOPSY}

In some venous diseases vein biopsies have to be performed (Corcos et al. 1993)leaving relatively large incisions and subsequent scars. Since pathologists only need a small portion of a vein to make their conclusions and diagnosis no elaborate attempt should have to be made to harvest large sections of a vein. We proved that a section of about $10 \mathrm{~mm}$ is enough to enable pathologists to come to the diagnosis. Therefore the use of the principles of AMP should be sufficient to obtain adequate material for proper (immuno/histochemical) examinations of subcutaneous vessles. Harvesting of teleangiectasia's with AMP have recently been discribed (Ramelet 1993). By using this technique the dermatologist offers his patient the possibility of a cosmetic and medical method for a subcutaneous vessel biopsy.

Histological examination of smaller vessels, vein and teleangiectasia, can contribute to an accurate diagnosis and a better understanding of the underlining histopathological proces.

\section{TECHNIQUE}

First the biopsy place is carefully marked with indelible ink unaffected by sterile cleaning solutions. The area is then anaesthetised with $1 \%$ lidocain with or without epinefrine according to the preference of the surgeon. A single mini-incision is then made in the centre of the laesion just lateral to the mark with No.\#11 scalpel placed in a needlcholder (Hegar, $15 \mathrm{~cm}$ ). With a phlebectomy hook the vein is grasped (figure 1) and fixed with mosquito forceps and if necessary isolated with the help of a phlebodissector (Varady 1988). When the expected amount of vein is teased out it is ligated with resolvable suture ( $\mathrm{eg}$ Vicryl 5-0) and desected (figure 2). The incision as in normal AMP needs no suture. A single Steristrip is all that is needed. Since the vein is ligated there is also no need for compression. 'This modified technique is therefore applicable in almost any part of the body. The part of the vein that has been harvested is hardly traumatised and be used for routine histology. 
Table 1. Indications for wein biopsy.

\begin{tabular}{|c|c|c|}
\hline Type of vessel & Discase & Location \\
\hline $\begin{array}{l}\text { Vein } \\
\text { predominandy or } \\
\text { exclusively }\end{array}$ & $\begin{array}{l}\text { Phlebitis saltans } \\
\text { Venous insufficiency } \\
\text { Bockenheimer's syndrome }\end{array}$ & $\begin{array}{l}\text { - Extremities, superficial veins } \\
\text { - Lateral on the thorax } \\
\text { - Disseminated in larget and smailer veins } \\
\text { and sometimes in arteries } \\
\text { - Veins of the lower extremities } \\
\text { - Diffuse of the body }\end{array}$ \\
\hline $\begin{array}{l}\text { Vein } \\
\text { sporadic }\end{array}$ & $\begin{array}{l}\text { Morbus Boeck } \\
\text { Wegener"s and Churg-Stratuss } \\
\text { granulomatosis } \\
\text { Catscratch disease }\end{array}$ & $\begin{array}{l}\text { - disseminated, esp. in cerebral weins } \\
\text { - sporadic in periferal veins } \\
\text { - sporadic in periferal veins }\end{array}$ \\
\hline Arteries and veins & $\begin{array}{l}\text { Morbus Bürger } \\
\text { Morbus Zeek }\end{array}$ & $\begin{array}{l}\text { - disseminated in medium size vessels } \\
\text { - disseminated in small vessels }\end{array}$ \\
\hline
\end{tabular}

Modified after Leu \& Leu (1993)

Diffuse genuine phlebectasia or Bockenheimer's syndrome is characterized by more or less progressive venous ectasia without arteriovenous anastomoses in a circumscribed area of the body, mostly of the upper extremity. Usually the phlebectasia is limited to the suprafascial venous system, although (subfascial) deep veins may be implicated (Bockenheimer 1907, Hulsmans et al. 1993). Histologic examination of ectatic veins can confirm the diagnosis.

\section{CASE}

A 35-year-old woman was referred in 1993 for a second opinion about her vascular lesions localized on the right arm, that were suspected to be a Klippel-Trenaunay syndrome. The mother of this patient noticed bluish patches on the right elbow and on the right shoulder of her daughter when she was 8-9) months of age. At first, these patches were considered to be port-wine stains, for which radiotherapy was performed. Afterwards new lesions developed. At age 12 phlebectasia connecting the different bluish patches became apparent. There were no motor limitations of the affected limb. When she woke up in the morning after having slept on the affected arm, she sometimes complained about pain in the right elbow radiating to the ipsilateral hand and shoulder or about sensations of heaviness. 


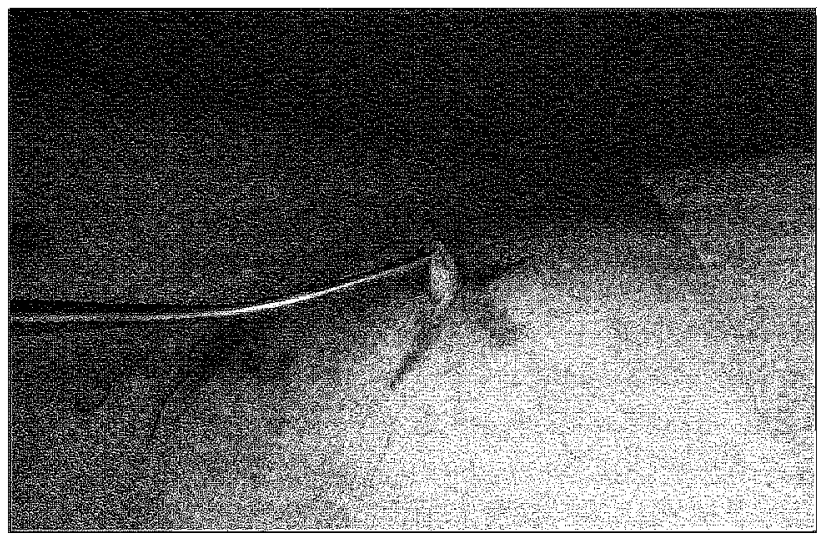

Figure 1. Vein is grasped with phlebectomy hook

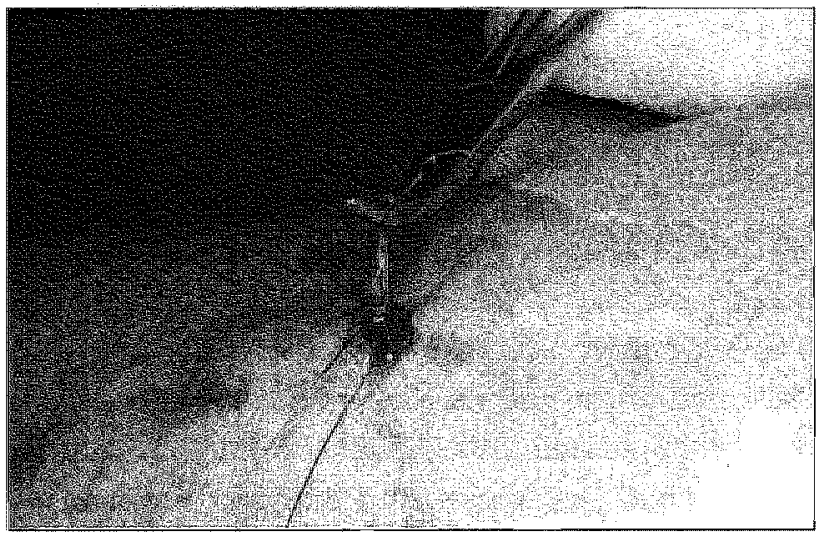

Figure 2. Vein is ligated with resolvable suture.

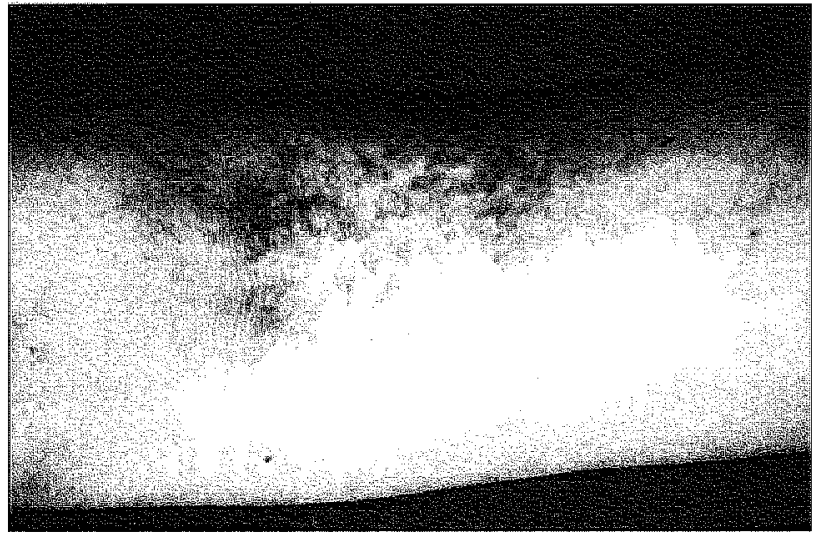

Figure 3. Physical examination revenls linear phlebectasia. 
Physical examination of the right arm revealed linear phlebectasia running from the dorsal aspect of the wrist over the volar aspect of the lowet arm to the lateral aspect of the upper arm and the dorsal aspect of the shoulder (figure 3). In the course of this phlebectasia various patches of venous sinusoids were observed. No bruits or thrills were noted. A macule consisting of fine capillary telangiectasias was present on the wrist. Port-wine stains were absent. Patches with atrophy, hypo- and hyperpigmentations in the fold of the right elbow and on the dorsal aspect of the right shoulder as a consequence of the previous radiotherapy were noted. There were no differences in length and circumference of the upper limbs.

Radiography of the left and right arm excluded the presence of either intraosseous translucencies, indicative for vasculat destruction of bone, or of cortical erosions, or of enchondromas. No differences in length of the long bones or hands were noted. Examination by echo Doppler duplex scanning demonstrated a normal vena brachialis. At the height of the elbow reflux was heard over the vena cephalica by proximal compression and by distal decompression. Multiple phlebectasias were visualized by this technique. In the ones located on the dorsal aspect of the upper arm and on the wrist no reflux was heard. Arteriovenous anastomoses were absent. Minisurgical phlebectomy according to Muller was performed. Histologic examination confirmed the diagnosis Bockenheimer's syndrome.

\section{CONCLUSION}

With this method we think we are able to harvest more than enough material for histologic diagnosis with little or no discomfort to the patient and excellent cosmesis. 

6.2 .

Non leg varicosis and ambulatory phlebectomy;

a special technique for special cases

Summary. Ambulatory phlebectomy has been an accepted therapy for leg varicose veins for many years. It has also been used successfully for veins and varicose veins on other parts of the body. The successful application of this technique is illustrated with four especially selected cases. Each location with its specific challenges and possible pitfalls. 


\section{INTRODUCTION}

Over the years ambulatory phlebectomy (AP) has become a standard treatment option for the treatment of varicose veins. (Muller 1966). For many phlebologists it is a simple, elegant, definitive and safe treatment modality with excellent cosmetic results which has been extensively described in the literature. Because of its safery and excellent cosmesis it has been proposed for the treatment of varicose veins on the legs as well as for other parts of the body such as the arms, the feet and the peri-orbital and temporal area (Constancias-Dortu \& Dortu 1991, de Roos \& Neumann 1998). It has also been proposed as a minimal invasive diagnostic tool in venous as well as arterial disease (de Roos \& Neumann 1995), and has been used for the removal of subdermal implants (Lam \& Tope 1997). In this article we report the treatment of non-leg veins in four different cases to illustrate our opinion that ambulatory phlebectomy $(A P)$ is a safe and efficient therapeutic modality for special cases.

\section{CASE 1}

In 1998 a 45 year old patient was treated for a solid basal cell carcinoma on her left temporal region. During the operation at the request of the patient, attempts were made to isolate a cosmetically disturbing vein at the lateral border of the incision. These attempts failed. Five months after the operation although the scar had healed with excellent cosmetic result the vein was still very prominent (figure 2.1). The visible part of the angular vein was then successfully removed with $A P$. Two months after the last operation the result was still excellent (figure 2.2) and to date (four years later) there have been no recurrences of either basal cell carcinoma or the facial vein.

\section{CASF 2}

In September 1996 a fifty-year old patient presented herself with progressive pain in both forearms. She wotked as an usherette at a local theatre and because of this work she was used to wear elastic armbands to hold up her sleeves. Recently she noticed the appearance of dilated veins on both her arms. These veins started to become painful. There was no (family) history of thromboembolic or venous disease. She never had surgety on her upper extremi- 


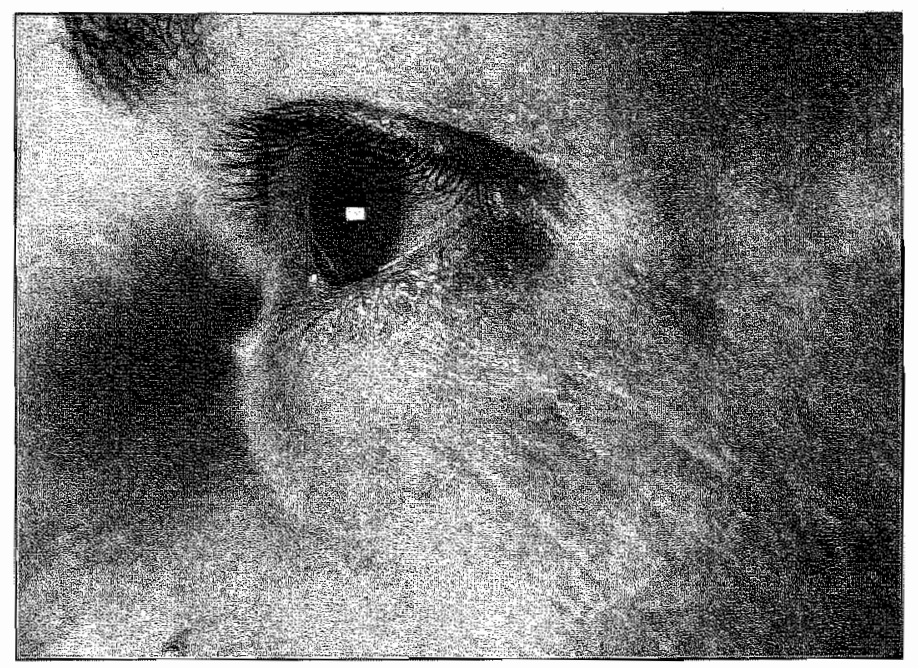

Figure 1 visible angular vein (case 1)

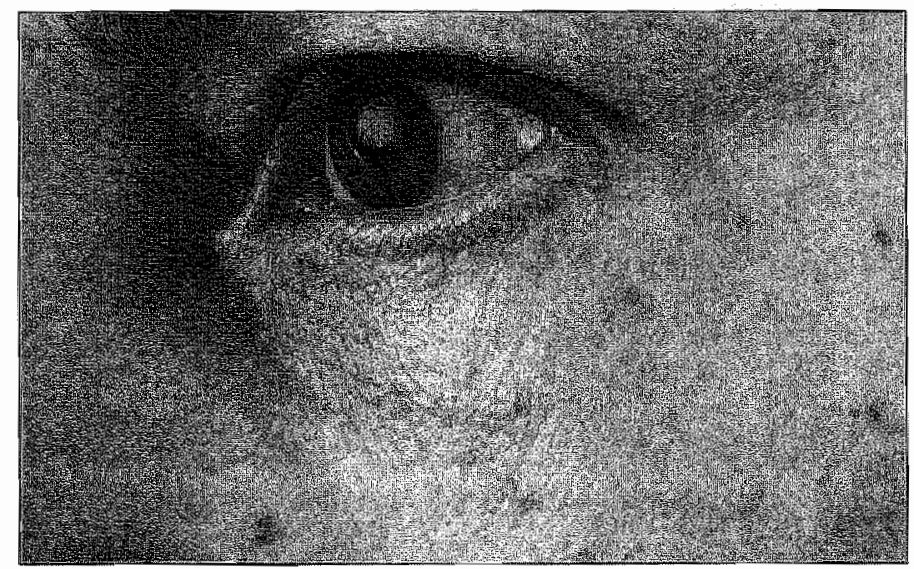

Figure 2 two month after $A P$ (case 1)

ties. Doppler investigation revealed no spontancous flow through the apparent ectatic veins. Upon proximal compression there is some reflux. Phlebography showed dilated veins on both her lower arms (figure 3). There were no signs of obstruction or phlebitis. AP of the distal section of the cephalic veins was performed first to her left arm and after this was successful and her complaints had disappeared her right arm was treated also. She was advised to refrain from wearing her armbands and to date there has been no recurrence and she is free of complaints. 


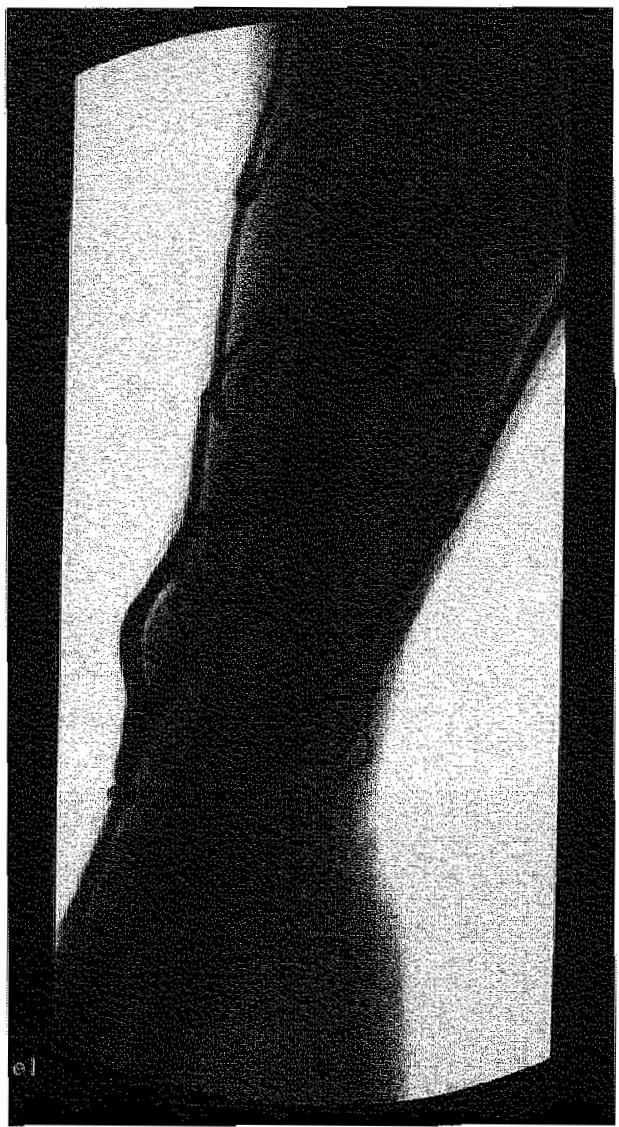

Figure 3 Phlebography of the forearm (case 2)

\section{CASE 3}

A 40-year old female patient complained of a varicose vein in the right gluteal area. She had developed this varicose vein twelve years earlier during a pregnancy. Recently the varicose vein started to become painful, especially during menstruation. She never had treatment for varicose veins nor had she any history of tromboembolic disease. Duplex ultrasonography of the superficial and deep venous system of her legs and the gluteal area revealed reflux only in the visible vatix. This varicose vein was located in the region of the lower gluteal perforator vein (figure 4). There was no reflux in other superficial or deep venous structures of the leg or gluteal area. AP was performed and the varicose vein was removed completely (figure 5). The patient was relieved of her symptoms, and to date there has been no recurrence. 


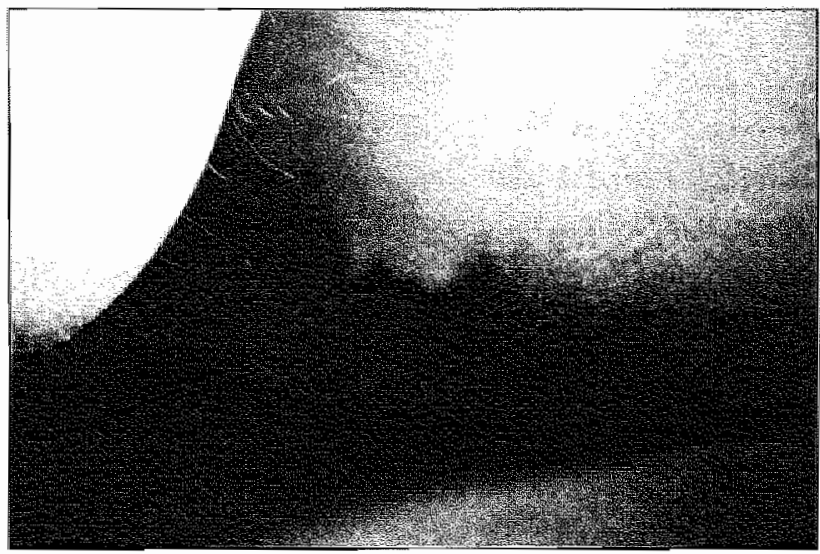

Figure 4. Gluteal varicose vein before treatment (case 3)

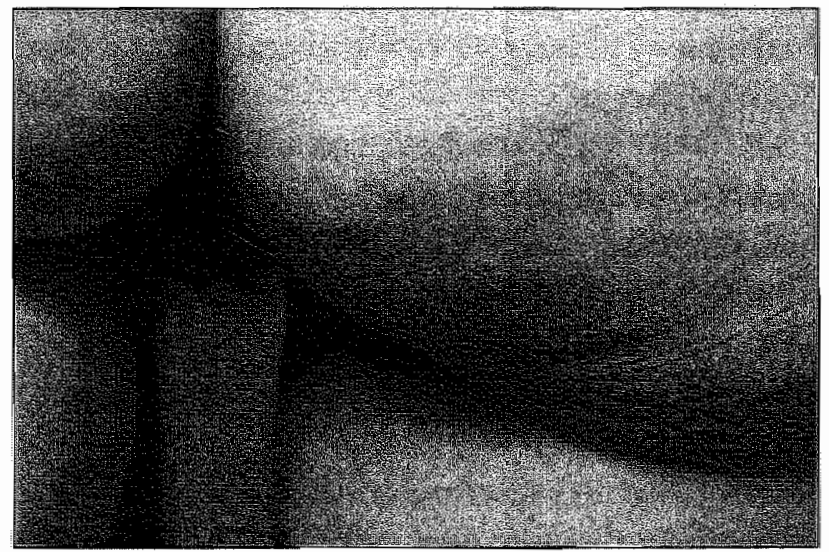

Figure 5 Gluteal varicose vein after treatment (case 3)

\section{CASE 4}

A 46-year old male patient presented himself with varicose veins over the left part of his scrotum. Although he had no complaints he insisted on the removal of this varicosity because he felt it did not belong there. The patient was in good health and had never been treated for venous disease. Complete venous workout of the patients legs - including Duplex ultrasonography and photoplethysmography - was normal. AP of the dilated parts of the scrotal veins was successfully performed. At a two month post-treatment follow up visit there were no signs of any scrotal varicosis. 


\section{ANATOMY}

To refresh basic anatomic knowledge of the venous flow in the four specific locations that have been introduced above an overview is presented.

The superficial wenous system of the head and face consists of a network of venules and veins that drain into three major veins. In the temporal region venules drain into the superficial temaporal vein which in turn drains into the superficial jugular vein.

In the occipital region the veins and venules drain into the occipital wein which in turn drains into the suboccipital venous plexus. The third major vein is called the angular vein in the paranasal and cheek area and more distally: the superficial facial wein. This vein drains into the internal jugular vein. Two side branches of the angular vein collect venous blood around the eyelids: the superior and inferior palpebral veins. Both may become dilated and visible with age. For some patients this becomes a cosmetic problem especially because the dilated vein can give the impression of tiredness or even a "black eye".

The venous system of the arm can be divided into two systems: the superficial and the deep venous system. The superficial system consists of the ceppalic vein which collects blood from the dorsal metacapal veims of the hand and drains into the sublawial wein but also has a connection with the basilic vein in the cubital area (medial cubital vein). In this connecting vein a third vein enters the venous system: the medial antebracbial vein.

The deep venous system of the arm consists of radialand the whar vein into which the palmar digital veins drain. The ulnar and radial vein join just above the elbow to form the bracbial wein.

Venous retum of the male scrotum consists of with several strotal veins which drain into the internal pudendal vein which in turn drains into the internal itiac vein through the gluted weins. "The female equivalent of the scrotal veins are the labial veins. There is no connection with the plexus vesicalis in men or plexus uterovaginalis in women.

The superficial reticular veins in this region drain either into the inferior gututeal wein or into the intemal pudendal vein. Both veins in turn drain into the internal illiac vein. In this area there are however three groups of gluteal perforator veins: the swperior, mnidginted and lower ginteal perforator weins (Caggiati et al. 2002). 


\section{TECHNIQUE}

Standard operating procedure for $\mathrm{AP}$ of varicose leg veins consists of marking the targeted varicose vein with indelible ink. Then the projected incision sites are infiltrated with lidocain $1 \%$. A minute incision $(1-2 \mathrm{~mm})$ is made parallel to the vein and a phlebectomy hook is inserted through this incision. When the search for the vein has produced the vein it can be fixed and removed with clamps. When all the veins have been removed the incisions ate closed with Steriestrip (3M, St Louis, USA) and a compression bandage is applied (Neumann et al. 1998). Patients are advised to walk after the procedure and are able to resume all normal daily activities immediately. Bandages are removed after five days and elastic hosiery has to be worn for another five days.

When other (non leg) varicose veins are treated however the technique has to be modified according to the specific lacation. Phlebectomy of facial veins is very challenging. The movement of the hook should be very subtle before a minute vein can be grasped. When attempts are made to grasp the vein it is possible to accidentally hook on to part of the periocular muscles. Although during clinical inspection the vein is very visible and often cosmetically disturbing, when grasped during the procedure it is only a (fraction of a) millimeter in diameter. It then has to be fixed with small clamps (e.g. baby-mosquito) and harvested very delicately, after which the treated area is bandaged with some compression if possible.

When dealing with varicose veins on the scrotum there is also a possibility of entanglement. The phlebectomy hook may get caught in the external spermatic fascia which is situated between skin and tunica dartos and the fascia of the cremaster muscle. This fascia has the same color and texture as the vein. Palpation will help to differentiate between these two.

Except from the different location there is essentially no difference in technique between ambulatory phlebectomy for leg or arm varicose veins. The same holds true for the gluteal area.

An integral part of $\mathrm{AP}$ for leg varicose veins is compression after therapy. For AP of arm vessels there is no adjustment necessary, for gluteal veins only simple bandaging is possible and for scrotal veins a suspensory bandage is the bandage of choice. For facial veins Steriestrips ${ }^{13}(3 \mathrm{M})$ can be used; and some minimal form of compression with cotton wool rolls (cotton rolls as used by dentists). Bandages are removed after five days and in our opinion no further compression is needed. 


\section{DISCUSSION}

Ambulatory phlebectomy has proved to be an efficient, safe and elegant treatment modality for varicose veins. Vessels of all caliber's can be treated and there are special indications such as foot varicosis, varicose veins in the popliteal fossa were ambulatory phlebectomy probably is the best choice. Most important contra-indications include escape varicose veins, hemodynamic important secondary varicose veins and hypercoagulable states. Relative contra-indications include overweight, deep venous insufficiency and pregnancy.

Dermatologists who have been trained in phlebology ate very familiar with the venous anatomy of the lower extremities. There is little need for knowledge of the venous anatomy of the face, the arm, or even the gluteal and scrotal area in every day phlebologic practice. When attempts are made to remove veins from other parts of the body however special attention has to be paid to the anatomical situation to avoid adverse events, especially nerve damage.

The first and the last case both patients were concerned about the appearance of the vein in question. The first patient because people repeatedly asked here if she had bumped into something because of her black eye. The last patient because he thought "it" (the varicose vein) did not belong there.

The second case introduced a patient with painful veins on her forearms due to the use of elastic bands. Because there were no signs of acclusion of the deep system - the radial, ulnar, and brachial veins were open - the painful section could be removed without any complications. Because varicose veins in the upper extremities do not occur as often as vaticose veins on the legs radiological evaluation should be considered, especially if there is insufficient explanation for the appearance of these vein. Another reason for this evaluation may be that in contrast to varicose veins on the legs where there are many veins alternative routes and escape possibilities for venous blood flow, the arms lack these collaterals. The third case demonstrates a patient also with a painful varicose vein in the gluteal area. An area where varicose veins seldom occur. Probably because the major gluteal muscle is covered with a firm fascia. In this patient, since other varicose veins could be excluded, local weakness of this fascia may have contributed to the development of this particular varicose vein.

In all presented cases ambulatory phlebectomy was the treatment of choice. In all cases this treatment was successful. Compression scletotherapy may be considered as an alternative to AP. In our view in the presented cases this is not an alter- 
native because of the risk of uncontrolled flow of the sclerosing fluid into other veins and subsequent possible occlusion of veins (cases 1,2 and 4).

Recently Green published a non-comparative case study in which fifty female patients were successfully treated for periocular veins with sclerotherapy (Green 2001). There is however no evidence in the literature that sclerotherapy is a safe procedure for or scrotal veins. Furthermore because of the location it is very difficult to apply the necessary compression (cases 1,3 and 4). With ambulatory phlebectomy only the targeted vein is treated and only mild compression is needed for a tellatively short period of time.

In recent years the authors have used ambulatory phlebectomy for special cases, but when reviewing the English, French and German literature we could only find a few articles that describe ambulatory phlebectomy for the treatment of facial veins (Vergereau \& Trauchessec 1993, Weiss \& Ramelet 2002) and veins of the hand (Vin 2001). Because of our special interest in ambulatory phlebectomy we would like to illuminate the use of this technicue for non-leg varicose veins. We recognize that there are other possibilities such as laser treatment or even sclerotherapy for facial and other varicosity's (Goldman et al, 1993, Bowes \& Goldman 2002). From our personal experience we should like to illustrate the possibilities and possible pitfalls in the treatment of non-leg varicose veins because we believe that with sufficient expetience and the proper materials it should be possible to successfully broaden the horizon for many phlebologists. 



\section{CHAPTER 7}

\section{COMPLICATIONS}

Roos K-P de, Neumann HAM.

Traumatic neuroma; a tare complication following Muller's phlebectomy.

J Dermatol Surg and Oncol 1994; 20: 681-2.

Roos K-P de, Neumann HAM.

Hematomas are underrepresented in studies on complications

of ambulatory phlebectomy.

Letter to the editor. Dermatol Surg 2002; 26: 544-5.

Bullens-Goessens YIJM, Roos K-P de, Kockaert MA, Neumann HAM.

Survenue d'un vitiligo après phlébectomie ambulatoire.

Phlébologie 2002; 55:275-7. 



\section{1. \\ Traumatic neuroma; a rare complication following Muller's phlebectomy}

Background. Complications following ambulatory surgical phlebectomy are rare, and to our knowledge, traumatic neuromas have never been reported.

Objective. To present a case of traumatic neuroma in a 48 -year-old woman after ambulatory minisurgical phlebectomy.

Metbods. The ambulatory phlebectomy as described by Muller.

Results. In a 48-year-old woman who developed persisting nodules after phlebectomy, histopathology confirmed the clinical diagnosis of traumatic neuroma. 


\section{INTRODUCTION}

The ambulatory minisurgical phlebectomy (AP) or Muller's ambulatory phlebectomy (Muller 1966) has been extensively described in this journal (Hararap 1985, Tretbar 1990, Neumann 1992). The incidence of complications following Muller's ambulatory phlebectomy is low (Gauthier 1993). In a recently published multicentre study evaluating 36.000 phlebectomies, telengiectasias where the most common $(1.5 \%)$ complication. Other complications included pigmentation $(0.03 \%)$, blister formation (1\%), flebitis $(0.05 \%)$, postoperative bleeding $(0.03 \%)$, and neural damage (temporarely $[0.5 \%]$ and persistent $[0.02 \%]$ ) (Gauthier 1993). Other than Ramelet's publication on a patient with a rare complication of AP (silicotic granuloma) (Ramelet 1991), there are no reports of nodular eruptions arising after AP. We present a complication that to our knowledge has never been reported, and have teviewed the literature.

\section{CASE PRESENTATTON}

A 48-year-old woman presented with 20 year history of varicose veins, for which she had been treated previously in a phlebologic center elsewhere. She had no history of oral thrombosis, flebitis or erysipelas. Her venous complaints consisted of pain and especially premenstrual swelling of her legs for which she used rutosides. No other medication was used. On physical examination the left saphenous vein was palpable including the saphenous crosse and side branches. Light reflexion theography showed a venous tefill time of 10 seconds which normalised after complete occlusion of the superficial venous system. With additional duplex sonography there were no signs of deep venous insufficiency. Both crosses were insufficient. After ligation of the crosses her varicose veins were treated with sclerotherapy. The remaining varicose veins in the ankle region were treated with ambulatory minisurgical phlebectomy and subsequent compression therapy.

After six months she still complained about a persistent nodule in the ankle region at the site where AP was performed (figure 1). There was no numbness or loss of skin sensitivity in that region. Excisional biopsy of the nodule revealed normally developped epidermis with orthoketatotic horny layer. The underlying dermis consisted of collagen tissue with strands of hyperplastic neural tissue (fig.ure 2). Additional staining with S-100, Vimentine, and epidermal membrane antigen (Ariza et al. 1988, Theaker et al. 1988) confirmed the diagnosis traumatic 


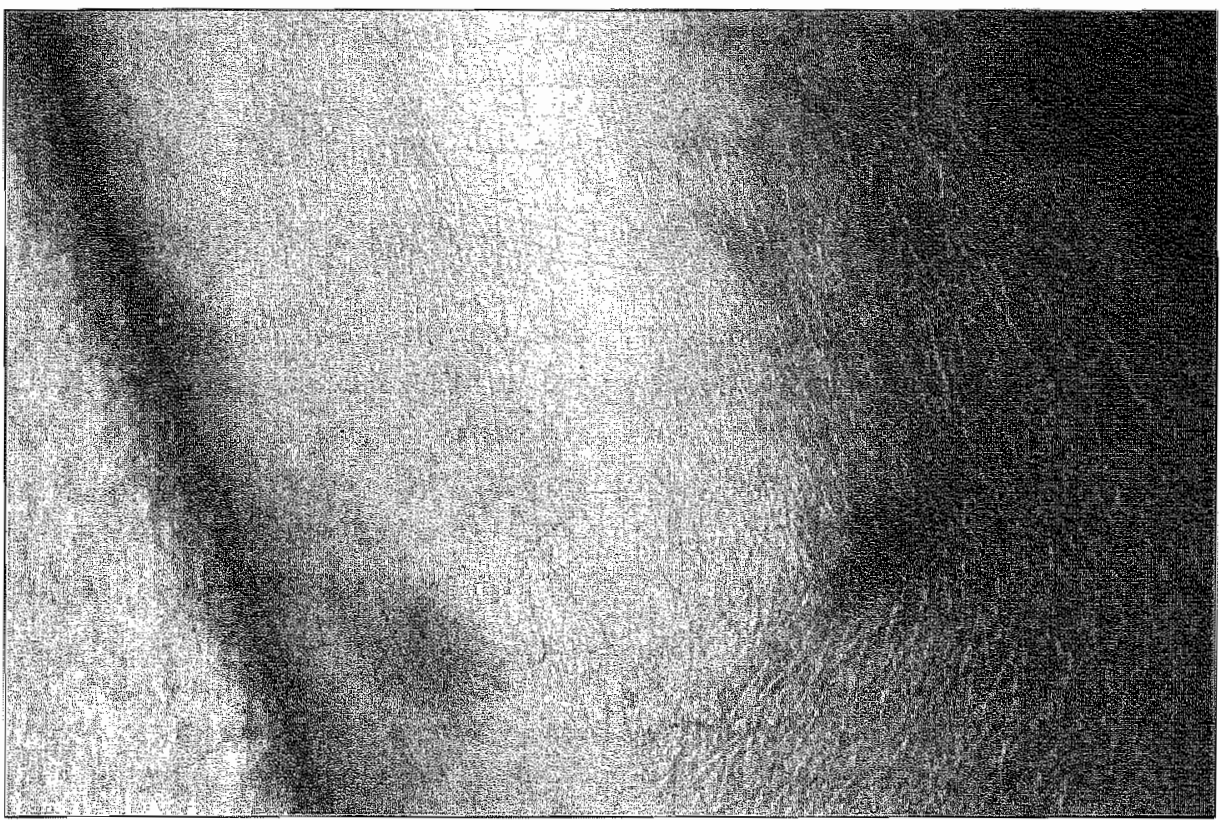

Figure 1. Persistent nodule at site of AP

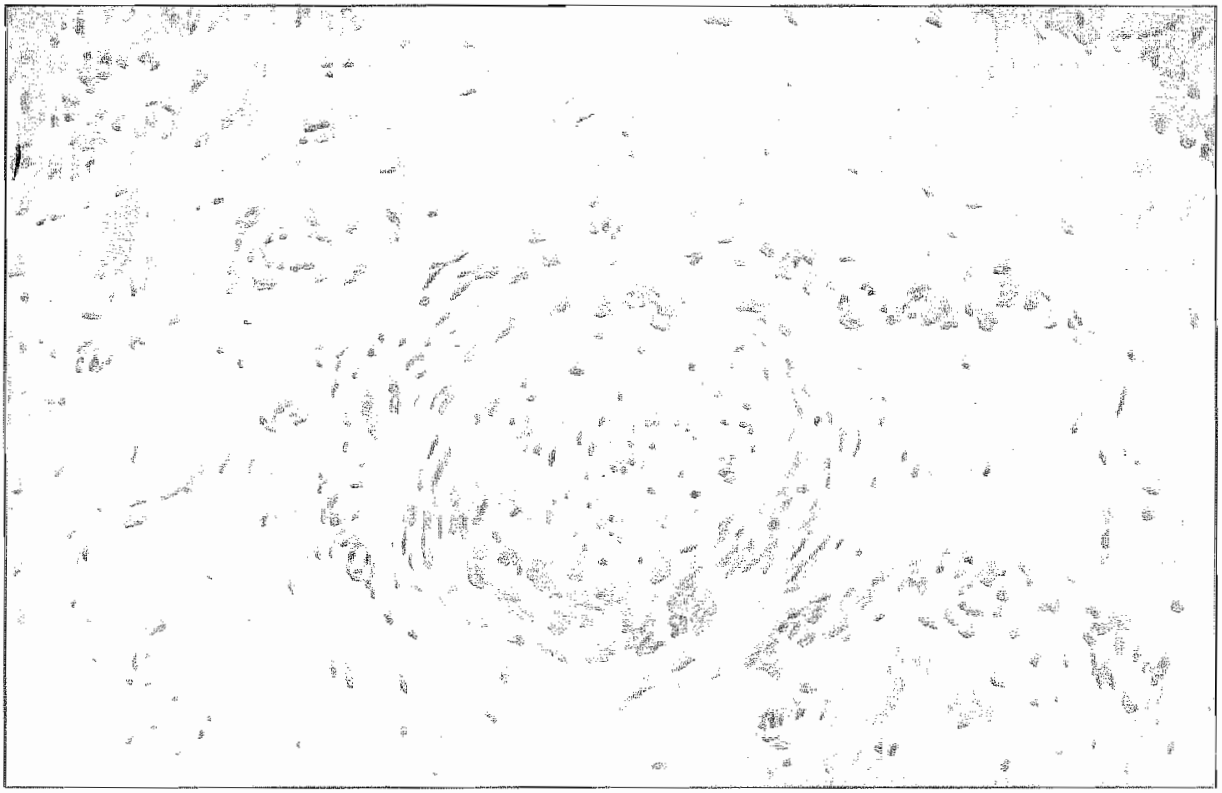

Figure 2. Underlying dermis consisting of collagen tissue with stands of hyperplastic newal tissuc (H\&E, 400x) 
neuroma. There was no recurrence after complete excision of the tumor nor was there loss of skin sensitivity distal to the neuroma.

\section{DISCUSSION}

Traumatic neuromas include the amputation neuromas and the so-called rudimentary supernumerary digits. The latter are asymptomatic smooth or verrucous papules that are found at the same site as true supernumerary digits, that is, at the base of the ulnar side of the fifth finger. They arise as a result of either postnatal destruction of a supernumerary digit or its autoamputation in utero (Shapiro et al. 1973). Amputation neuromas are very sensitive to pressure and may be painfull.

When a nerve is partially or completely severed, the axons distal to the point of transection undergo wallerian degeneration, whereas the axons and Schwann cells of the proximal stump proliferate. If there is interposition of the tissue between the two segments ( $\mathrm{eg}$, due to scarring) or if the distal segment is lost (eg, by amputation), axons and Schwann cells will still grow out of the proximal stump but will fail to reach their target and form a disorganized tangle of nerve twiglets extending into the surrounding soft tissue, thus forming a traumatic neuroma. On histologic examination it consists of multiple small nerve fasciculli enmeshed in dense bundlles of collagen. Each fascicullus is ensheathed by multiple lamina of perineural cells. There is wide variation in the size of the axons (Waggener 1966). Although the bundles of nerves show no capsule in some instances, a capsule composed of perineurial cells and collagen can be found in most instances (Lever \& Schaumburg-Lever 1990). The pain associated with traumatic neuromas may be caused by contraction of the scar tissue leading to nerve compression or ischemia. As a diagnostic tool therefor infiltration with $1 \%$ lidocain can be used to confirm the diagnosis. Treatment can be conservative or surgical; the latter aims either at preventing axonal growth or at isolating the nerve from injury (Abrecht \& From 1993). In our patient there was no recurrence of the neuroma after excisional biopsy. Although of course in theory traumatic neuromas can occur following neural damage by AP this to our knowledge is the first report of this complication. 
7.2 .

Hematomas are underrepresented in studies on complications of ambulatory phlebectomy 


\section{TO THE EDITOR}

General complications of varicose vein surgery include recurrence, hemorrhage and hematoma formation, damage to deep weins and arteries, nerve damage (saphenous and sural nerve), wound necrosis, lymphedema and lymphatic pseudocysts, wound necrosis, and unsightly scars (Browse et al. 1999). With the use of ambulatory phlebectomy, wound necrosis, unsightly scars, and infection do not occur. In a recent review by Ramelet post-operative hemorrhages were reported in $0.3 \%-4.3 \%$ and major hematomas in $0.1 \%-2.45 \%$ of cases (Ramelet 1997). The incidence of - not further specified - hematomas was reported in 1 of 1000 cases by Olivencia (1997a).

In light of our experience with ambulatory phlebectomy, we have serious doubts on the way in which the occurrence of hemorrhage and hematoma formation is teported.

In our phlebologic practice we notice hemorrhage (escape of blood from a ruptured blood vessel) in $<1 \%$ of cases, especially when bandages shift immediately (up to 24 hours) after phlebectomy. Hematomas (extravasation of blood), however, seem to occur much more often than reported in the literature. This is why we addressed this problem for both sclerotherapy (Neumann et al. 1998) and ambulatory phlebectomy (Tazelaar et al. 1999).

Recently we examined 100 cases of ambulatory phlebectomy and found that hematomas occurred in almost all cases $(98 \%)$.

In order to compare publications, in the future a distinction should be made between hemorrhages, which in our view are real complications, and hematomas, which are an inevitable consequence of "state-of-the-art" performed ambulatory phlebectomy.

Kees-Peter de Roos, MD

H.A. Martino Neumann, $M D, P h D$

Maastricbt, The Netherlands 
7.3

Unforeseen vitiligo after ambulatory phlebectomy

Summary. We saw a patient with vitiligo lesions on the leg, on the same spot where an ambulatory phlebectomy was performed. 



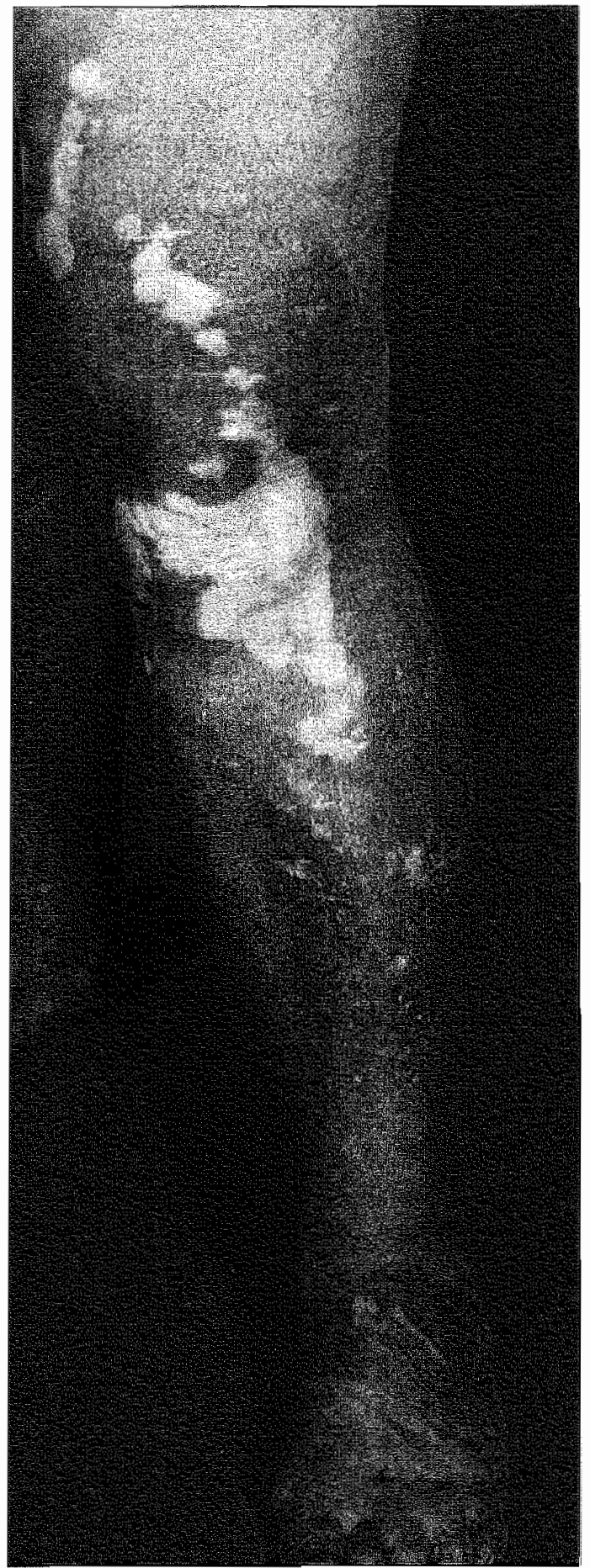

gure 1. Vitiligo after ambulatory phlebectomy 


\section{ADDITIONAL INVESTIGATIONS}

\section{Labaratory analyisis}

No hematologic or immunologic abnormalities. Especially no evidence of thyroid disease.

\section{Histopatbology}

A relatively narrow epidermis with a multilayered cornifying squamous cell epithelium and orthokeratosis. In the basal layer there is an absence of melanocytes. Furthermore a perivascular and lymphohistiocytic infiltrate which spreads into the subcutis. Immunohistochemical investigation revealed only a few $S 100$ positive melanocytes at the border of the biopsy. These findings supported the diagnosis: vitiligo.

\section{DISCUSSION}

This relatively frequent and acquired depigmentation of the skin is caused by the disappearance of melanocytes. The prevalence of this disorder is 1 to $2 \%$, equally distributed between man and women. There is a positive family history in nearly 30 to $40 \%$ of patients. Recent publications show an association with HLA-class II genes in patients suffering from vitiligo (Zamani et al 2001). The first lesions often develop before the age of 20 and for the better part present as symmetric over the body; segmental distribution has been observed. An assaciation with thyroid disease, hypoparathyroidism, diabetes mellitus, Addison's disense, pernicious anemia, myasthenia gravis, alopecia areata, lichen sclerosis and morphea has been described.

Although there are several theories the etiology of vitiligo is unknown. The fact that circulating antibodies and lymphocytes have been found around the margins of vitiligo lesions suggests an auto-immune process. To this date it is unclear if this is a cellular or a humoral immune response. The fact that melanocyte specific CD8 $+\mathrm{T}$-cells frequently appear suggest ideas more and more in the direction of a cellular immunity (Palermo et al. 2001).

A neurogenic theory suggests that dermal nerve endings release an upto now unknown substance which is toxic to melanocytes.

The so-called "self-destruct theory" suggests that melanocytes destroy themselves because of a defect in a protective mechanism that removes toxic melanin precursors. 


\section{CONCLUSION}

In spite of a well conducted initial interview in search of other conditions, to the patient the pre-existing disturbance was to insufficient for her mention. For those who concern themselves with viriligo it is a well known fact that it may occur as a result of the so-called Köbner phenomenon. However this is the first time vitiligo has appeared unforeseen not only around the incisions but also in the venous section.

This complication has not yet been described after ambulatory phlebectomy. It may well be that the trauma inflicted by the needle during the administration of the local anesthesia, the dissection or the eradication of the varicose vein has resulted in the Köbner phenomenon. "There is also the possibility that the injection of the lidocain - a neuro-active substance has provoked vitiligo. We hope to have demonstrated with this case report that certain disorders can be caused by ambulatory phlebectomy through the Kobner phenomenon. The occurrence of psoriasis or lichen planus after ambulatory phlebectomy therefore is possible. 



\section{CHAPTER 8}

\section{IMPLEMENTATION}

Roos K-P de, Neumann HAM.

Flebectomie op schapenpoten; het lange-termijneffect van praktische instructie.

Medisch Contact 2001; 56: 1382-4.

Roos K-P de, Neumann HAM.

Flebologie in de dermatologische praktijk; een landelijke enquêre.

Ned Tijdschr Dermatol Venereol 2002; 12: 194-7. 



\section{1. \\ Phlebectomy on sheep legs; \\ the long term effect of practical instruction}

\section{SUMMARY}

The effect of a workshop, in which a new technique for the ambulatory treatment of varicose veins was introduced, was evaluated after five years.

After five years one in three participants still applies this labor-intensive technique.

More than 35 percent of the respondents indicated that because of lack of time in their practice they were not able to implement this new technique.

Because care for dermatological patients increases and becomes more labor-intensive and because training capacities for dermatologists are limited, the introduction of new treatment modalities such as ambulatory phlebectomy, will become increasingly difficult.

The organization of a practical workshop is a time-demanding task. The need for education has to be investigated beforehand. Investigation afterwards, as was the case with the participants of a phlebology workshop five years before, revealed the success rate of the course. In this case it was high.

Preceding the annual meeting of the Dutch Society of Dermatology and Venereology on the first Friday afternoon of January 1994 a continuing-education course was given to Dutch-speaking dermatologists. It concerned the introduction of an in our country relatively new technique for the ambulatory removal of varicose veins under local anesthesia: ambulatory phlebectomy. This technique, introduced in the mid-sixties by Robert Muller (1966), a Swiss dermatologist, combines a high rate of efficiency with a splendid cosmetic result. 
Table 1. Indications for ambulatory phlebectomy.

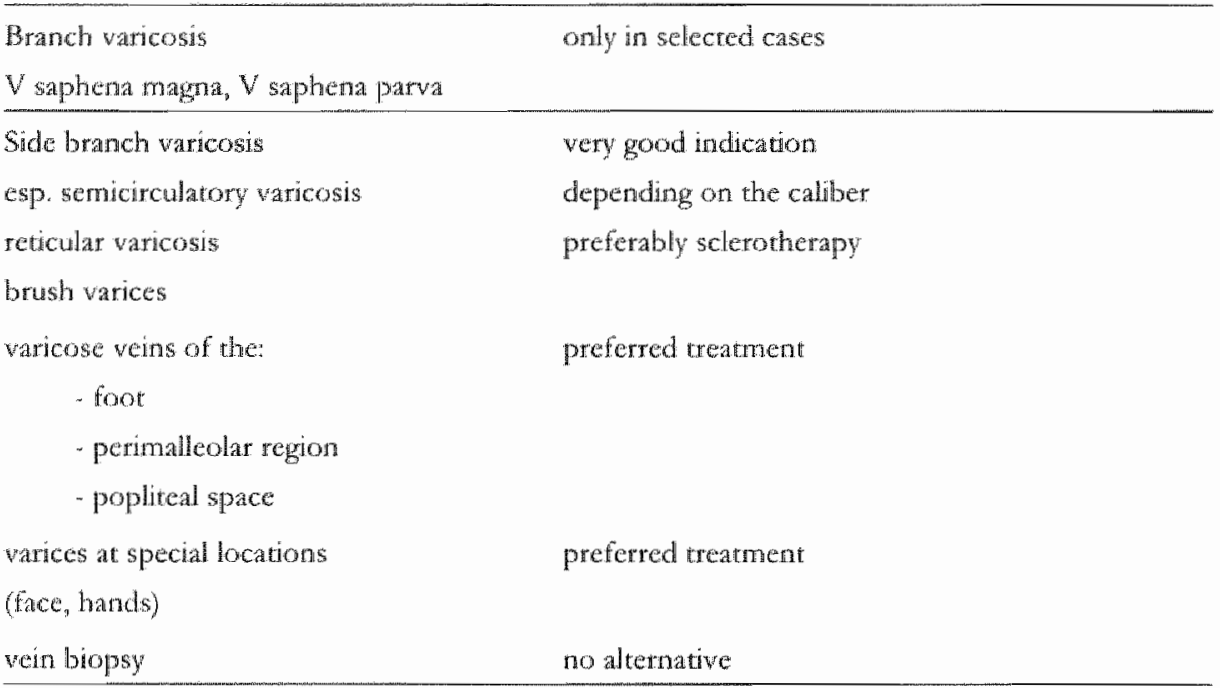

\section{HOOK UP BLINDLY}

Prior to treatment patients are analyzed in a way that is common practice for phlebological patients (de Roos \& Neumann 1993). Through closely defined criteria patients are selected for this treatment (Neumann \& de Roos 1994). While the patient is standing upright the affected varicose vein is marked off and the covering skin is infiltrated with a local anaesthetic. Then, at regular intervals, the dermatologist makes 2 to $3 \mathrm{~mm}$ incisions. Using veneretraction- or phlebectomy hooks he "blindly" hooks up the affected varicose vein through the insertion opening (figure 1) and fixes it with artery clamps. The fixed varicose vein subsequently will be harvested (figure 2). Concluding the surgery the treated area is cleaned and after sticking wound plasters (Steriestrip ) it will be bandaged with a compressive bandage. After five days the bandage will be removed in the hospital. During another five days the patient has to wear elastic stockings (Neumann et al. 1998).

However this technique is more labor-intensive than compression therapy, which dermatologist often use as standard therapy, its postoperative period is much shorter (ten days of compression). Besides the general ones there are several specific indications for this technique (table 1). 


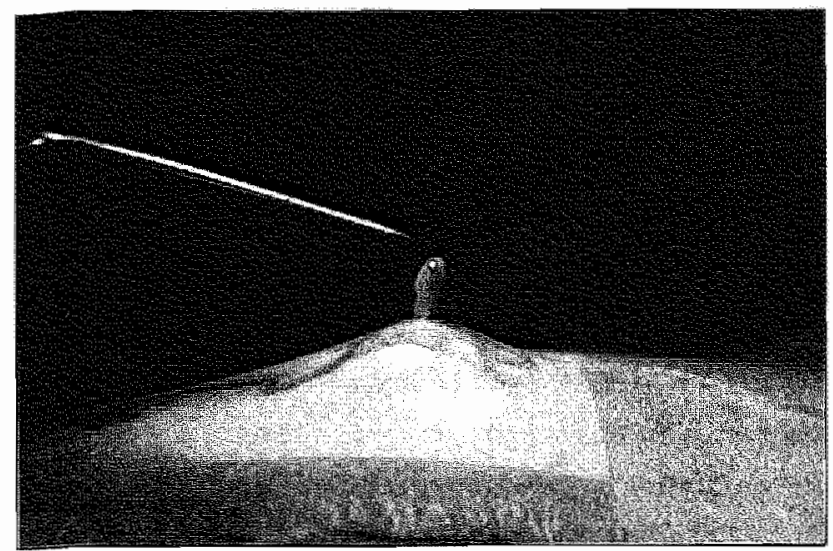

Figure 1. The grasping of the varicose vein.

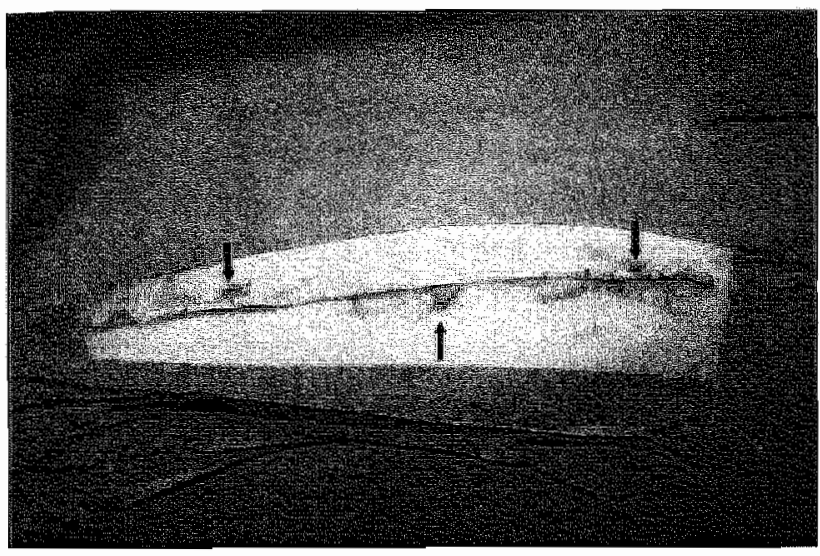

Figure 2. Completely removed waricose vein; the incisions are indicated with artows.

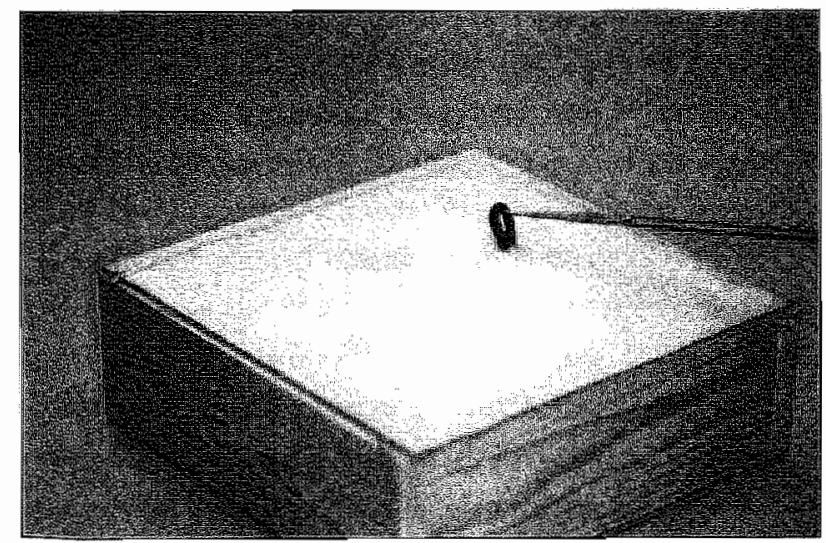

Figute 3. The used wooden model, the waricose ven' is hooked. 
At first the technique only was used in Switzerland and France. At the end of the eighties dermatologists in the Netherlands also became interested, although on a small scale. The indications are recorded in the table.

In order to enlarge the interest in the technique to a broader dermatological/ phlebological public, a workshop was organized. The afternoon was split up in a theoretical and practicall part. During the theoretical part several speakers successively presented a historic review, the anatomic backgtound, the wotk-up and selection of patients, the technique of phlebectomy, the post-operative treatment and the possible complications.

During the practical part of the afternoon the participants were given the opportunity first to have a dry run, applying the techmique to a laboratory model (figure 3) and after that to the veins in the legs of dead sheep.

The number of enrolments for the first workshop were far too many. For this reason another course was organized in April of the same year.

\section{MULTIPLE-CHOICE}

Continuing education especially is the responsibility of the professional group. The organizers have to invest a lot of time, energy and financial means. To objectify the efficiency of such a continuing education, the participants were inquired five years after the course. As far as we know, this is the first time that a continuing education of a professional group of medical specialists has been evaluated and described after a number of years.

Using the list of names and addresses of the Dutch Society of Dermatology and Venereology all participants had been located and phoned up (November-December 1999). The workshop had 46 participants. Two participants who recently had been retired and two participants living and working in Belgium were not approached. The remaining 42 participants, working in the Netherlands, all could be reached by phone and all of them were willing to take part in the inquiry.

The inquiry consisted of four multiple-choice questions with the possibility to make comments on each question.

To the question 'Why did you attend the workshop?' 10 participants (23.8\%) answered that they wanted to be kept informed of new developments. Fourteen participants $(33.3 \%)$ answered that they wanted to learn this new technique to use it in practice and 18 participants $(42.8 \%$ ) mentioned both reasons. 
The question whether the workshop at that time came up to their expectations 37 $(88.1 \%)$ of the questioned participants answered affirmatively. To two participants $(4.8 \%)$ the workshop did not come up to their expectations and two participants had no answer to the question. One participant (2.4\%) answered that only part of the workshop came up to his expectation. Subsequently it was noted that 3 times $(7.1 \%)$ practicing on patients was missed.

To the question whether the participants had practiced the acquired knowledge, 23 of the 42 participants $(54.7 \%)$ answered with 'yes'; $15(35.7 \%)$ did this immediately after the workshop and $8(19.1 \%)$ after additional education. Nineteen participants $(45.2 \%)$ did not practice the acquired knowledge. Most of them (15 $-35.7 \%$ ) mentioned lack of time as the main reason. Only one participant thought that the technique was too labor-intensive. One participant mentioned both factors as a reason. Other factors why the technique had not been used, were that 'the general surgeon does the surgery' (once) and the lack of life-patients during the workshop (once). One participant mentioned not to practice phlebology.

To get an impression of the extent of the technique, the last question asked how many phlebectomies on average were being performed five years after the workshop. A third (14) of the participants mentioned to perform a phlebectomy regularly, while $28(66.6 \%)$ answered that they did not perform it (anymore). Eleven respondents regulatly performed - on average 4 to 5 times a month - an ambulatory phlebectomy, two only rately and one only three times a year.

\section{RET'URN}

Education and continuing education of colleagues is a meaningful and responsible task that gives a lot of satisfaction, especially if you go by the good response immediately after the continuing education is finished. We were interested in the return of the course we had organized five years earlier. An optimal starting point was that all participants still could be located and all participants working in the Netherlands we called answered the inquiry.

Three-quarter $(14+18)$ of the questioned persons mentioned that the reason why they participated the workshop was that they wanted to learn a new rechnique that could be used in practice. This indicates that the workshop at that time provided the demand for continuing education in phlebology.

The used laboratory model functioned well. To most of the participants (88.1\%) the workshop came up to their expectations and was highly appreciated. 
It is common knowledge that phlebectomy is a labor-intensive technique. We regard it as a high return that after five years one out of three participants still uses this rechnique. Apart from that, this percentage is almost equal to the percentage $(35.7 \%)$ that started to use the technique without continuing education immediately after the workshop. Including thereupon the participants who did have additional continuing education ( $54.7 \%$ ), the return is even higher.

A concerning observation during our inquiry is that more than 35 percent of the respondents cannot implement this new treatment modality in their practice due to lack of time. Since there is a growing demand for dermatological care which is getting more and more labor-intensive (Beljaards et al. 2001), because education capacities are limited, and partly due to the long waiting periods, the introduction of new treatment modalities such as ambulatory phlebectomy, will become increasingly difficult.

Specifically for the workshop we developed a model that made the technique perceptive and in which the participants could make a dry run (figure 3 ). The technique also had been tried out on different kind of cadavers in order to find an animal model that corresponded to reality as much as possible. Sheep legs appeared to comply the most. Although personal teaching never can be replaced by it, the practical instruction duting a workshop or course is an important first step. After the course many participants felt themselves sufficiently equipped to use the technique in practice. In our opinion this is safe, especially if at the beginning one only is limited to side branch varicosis.

Despite the effort and preparation, the organisation of continuing education such as an intensive and focused on practice course certainly is worthwhile. Our inquiry shows that the return can be high even after five years. Handling an exercise model that can be used in practice, as well as the theoretical interpretation of several speakers, contributed to the quality and return of this course. 


\section{2 \\ Phlebology in dermatological practice; \\ a national survey}

\section{SUMMARY}

Seventy-five percent of respondents always use Doppler to analyse phlebologic parients; $80 \%$ sometimes use Duplex ultrasound. Almost $95 \%$ can offer sclerocompression therapy; $44 \%$ ambulatory phlebectomy. $93 \%$ of dermatologists work in cooperation with a surgeon, in which all surgical phlebological interventions can be offered to patients. Among respondents there is a great need for phlebological training.

In the Netherlands phlebology is practiced by dermatologists as well as by surgeons. Although not a certified specialism, phlebology is a definite part of the education of both disciplines. The more it is remarkable that so little is known about the availability of phlebological techniques and therapy in general practice. However, it is supposed that in general dermatological practice a lot of time is invested in diagnostics and the treatment of varicose veins.

To gain a clear understanding on the nature and dimension of phlebological care by dermatologists and the demand for education of phlebological subjects, we decided to perform an inquiry among all periphery-working dermatologists. The co-operation between the surgeon and the dermatologist as well as the phlebological therapeutical arsenal of the surgeon with whom the dermatologist is working was stated. Also some general information of the Dutch dermatologist and his practice was collected. 
$146 \mid$ CHAPTER 8

\section{METHODS}

In September 2000 , referring to the membership list of the Dutch Society of Dermatology and Venereology, all periphereworking dermatologists had been asked to fill out an inquiry form. In first instance 137 out of 242 inquiries had been returned. After another six weeks those 105 members who did not return the form received a reminder. A frer that 30 members still filled out and returned the inquiries after which the total tesponse became (167/242) $69.0 \%$. The inquiries anonymously were processed and evaluated (SPSS-pc, version 9.0 (SPSS-inc, Chicago, Illinois, USA)).

\section{RESULTS}

\section{General information}

In three of the returned inquiry forms the respondents indicated that they recently had retired and in one inquiry form nothing was filled out besides age and sex. These inquiries were not used and therefore 163 incjuiry forms could be used for the analysis. The results of the general information are recorded in table 1. Out of 163 respondents $31 \%$ were female (51/163). The mean age of all respondents was 48 years; women were on average 4.9 years younger than men (significant $\mathrm{p}<0.01$ ) The mean number of ptactice years was 14.4 years; women on average had worked 3.2 years less as a dermatologist than men. On average the Dutch dermatologists wotked 0.85 fte (full time equivalent), women 0.73 fte and men 0.91 fte.

Of the respotudents $91 \%$ appeared to work intramurally. It should be noticed however that where someone had filled out intra- as well as extramural this was indicated as intramural. Twenty-two respondents $(13.7 \%)$ worked on their own, while the others $(86.3 \%$ ) worked in some form of partnership (emplloyment or free establishment). The extent of the partnership varied from two to six with an average number of fte's of 2.51 .

\section{Specific information}

The inquiry had been mailed in September, because then in most hospitals the production output figures of the previous year are known. Nevertheless, a large number of dermatologists did not have the asked information at their disposal, 
information on Dutch dermatologists

\begin{tabular}{|c|c|c|c|c|c|}
\hline & $\begin{array}{l}\text { Percen- } \\
\text { tage }\end{array}$ & $\begin{array}{l}\text { Mean age } \\
\text { (spreacl) }\end{array}$ & $\begin{array}{l}\text { Experience } \\
\text { (spread) }\end{array}$ & Adherence & Nexp patients \\
\hline & $31 \%$ & 44.3 yrs $(33-62)$ & $12.0 \mathrm{yrs}(1-30)$ & $101.445(n=22)$ & - \\
\hline & $69 \%$ & 49.2 yrs $(35-62)$ & 15.4 yrs $(1-30)$ & $106.517(n=71)$ & * \\
\hline & $100 \%$ & 47.8 yrs $(33-62)$ & 14.4 yrs $(1-30)$ & $105.317(n=93)$ & $2,465(n=137)$ \\
\hline 2) & $14 \%$ & 513 yrs $(38-62)$ & 17.4 yes $(6-27)$ & $96.875(n=8)$ & $3,013(n=15)$ \\
\hline 9) & $86 \%$ & $47.2 \mathrm{yrs}(33-62)$ & 14.1 yrs $(1-30)$ & $106.11 \|(n=85)$ & $2,397(n=122)$ \\
\hline \multirow[t]{2}{*}{ ) } & $91 \%$ & $47.8 \mathrm{yrs}(33-62)$ & $14.3 \mathrm{yrs}(1-30)$ & $106.272(n=90)$ & $2,467(n=1,25)$ \\
\hline & $9 \%$ & 49.5 yrs $(39-62)$ & $15.3 \mathrm{yrs}(4-27)$ & $75.000(n=2)$ & $2,637(n=10)$ \\
\hline
\end{tabular}

jondents had information about the number of new patients they 1999, 66\% about the number of sclerocompression patients 660 left or right) and somewhat more than half (56\%) about the ? phlebological patients.

rmation the average adherence (filled out by 93 out of 163 responumber of new patients $(137 / 163)$ and the number of new vatients $(91 / 163)$ was calculated per fte (table 2.1). Regarding the nce for the various categories (male, female, solo, partnership, amural), only small differences were observed. The mean number per 1.0 fte was 2,465 and the mean number of new phlebological $13(12 \%$ of the total number of new patients).

nswers to phlebological questions are recorded. Behind each item lacking answers is mentioned berween brackets. The percentages per item over the number of given answers.

of dermatologists always use a Doppler during the diagnosis of aricose veins (question 1). Only two percent never use it. More sm use a plethysmograph (d-PPG of LLR), while more than one $\approx$ it. The use of echo-Doppler of Duplex equipment also has shed, because only $9 \%$ never apply those techniques on new atients.

f the dermatologists can offer sclerocompression therapy to vatients (question 2), although this does not mean that all ques- 
148 CHAPTER B

Table 2. Answers to the phlebological questions

1. On new phlibological patients the following examinations are performed:

\begin{tabular}{llll}
\hline Doppler $\left(3^{*}\right)$ & never: $2 \%$ & sometimes: $23 \%$ & always: $75 \%$ \\
Phoroplethyomography (13) & never: $36 \%$ & sometimes: $53 \%$ & always: $11 \%$ \\
Echo-Doppler (Duplex) (6) & never: $9 \%$ & sometimes: $7 \%$ & always: $12 \%$ \\
\hline
\end{tabular}

2. The treatment modalities in my practice are:

\begin{tabular}{lll} 
Sclerocompression (3) & yes: $94 \%$ & no: $56 \%$ \\
Ambulatory phllebectomy (1.0) & yes: $44 \%$ & no: $56 \%$ \\
Echosclerosis (15) & yes: $3 \%$ & no: $97 \%$ \\
\hline 3 Do you work rogether with a & yes: $93 \%$ & no: $7 \%$ \\
surgeon?: (3) & & \\
Joint surgery hours: (3) & yes: $17 \%$ & no: $83 \%$ \\
\hline
\end{tabular}

4. The treatment modalities of the surgeon in my hospitall ate:

\begin{tabular}{llll} 
Crossectomy (6) & yes: $99 \%$ & no: $1 \%$ & not known: $<1 \%$ \\
Stripping (7) & yes: $99 \%$ & no: $1 \%$ & not known: $<1 \%$ \\
Cryostripping (19) & yes: $19 \%$ & no: $73 \%$ & not known: $8 \%$ \\
Convolutectomy (9) & yes: $96 \%$ & no: $3 \%$ & not known: $1 \%$ \\
Ambulatory phlebectomy (15) & yes: $26 \%$ & no: $62 \%$ & not known: $12 \%$ \\
Sclerocompression (11) & yes: $75 \%$ & no: $25 \%$ & not known: 0 \\
\hline
\end{tabular}

5. Do you or does someone in your partnership want to be educated in phlebological subjects?

Lecture (17) yes: $62 \%$ no: $32 \%$ not known: $6 \%$

Subject:

Workshop (13) yes: $69 \%$ no: $26 \%$ not known: $5 \%$

Subjoct:

Training by a colleague (22) yes: $44 \%$ no: $45 \%$ not known: $11 \%$

* Number of laching answers is shown per item between brackets.

tioned dermatologists also use it themselves. Some indicated that someone else of their partners carries out the further treatment. Forty four percent of the dermatologists have disposal of ambulatory phlebectomy. Only $3 \%$ can treat patients with echosclerosis.

More than $90 \%$ of the dermatologists work in co-operation with a surgeon and $17 \%$ also have joint surgery hours (question 3). In question 4 information was asked about the treatment modalities of the surgeon who they work together 
with. Almost all surgeons who work in co-operation with dermatologists perform classical varicose vein surgeries such as crosse-ectomies, stripping procedures and convolutectomies. Also, according to the dermatologists, $75 \%$ of the surgeons perform compression sclerotherapy and one quarter perform ambulatory phlebectomy. It should be mentioned that to this question a noticeable number of dermatologists did not give an answer (12\% do not know, 15 times no answer). Nineteen percent of the surgeons perform cryostripping, although here again, compated with other questions, relatively many ( $8 \%$ ) filled out 'do not know' and 19 times no answer was given.

Finally the dermatologist were asked about their demand for education. Sixty two percent of them wanted a lecture about a phlebological subject. The mentioned subjects were ambullatory phlebectomy (17 times), Duplex (13), echosclerosis (10), "update" (5), phlebological diagnostics (3) and cryostripping (2). Once compression therapy, Doppler, indications for therapy and laser therapy were mentioned.

Almost $70 \%$ of the dermatologists demanded a workshop. The mentioned subjects were echosclerosis (7 times), "update" (7), phlebological diagnostics (6), Duplex (5), cryostripping (4), ambulatory phlebectomy (4) and deep venous thrombosis (2). A number of subjects was mentioned only once: lymphedema, photoplethysmography, postthrombotic syndrome, subfascial endoscopic perforantectomy surgery, wound covering, co-operation with a surgeon, Giacomini vein en gastrocnemic muscle insufficiency.

\section{DISCUSSION}

In our opinion the inquiry has succeeded in $1 \mathrm{ts}$ aim. The response of around $67 \%$ was sufficiently high and we got a better view of the phlebological practice of the Dutch dermatologist. Our inquiry showed that $31.3 \%$ of all periphere-working dermatologists are female. Recent research showed that the percentage of women among medical specialists of the observing disciplines is about $24.4 \%$; for the cutting specialisms this percentage is $15.3 \%$ (van der Velden et al. 2001). The percentage of women in our profession group is thus considerably higher. The significant difference $(p<0.01)$ in age between men and women in our inquiry could be explained because in recent years more and more women had a professional education and according to that the intake of new dermatologists has shifted in favour of the female part of our profession group. "The average practical experience as a dermatologist for women is twelve years, while for men 
this is 15.4 years, which confirms this statement. Deducting the age with the number of practicall years you get the age at which the dermatologist started his/her practice. From this we may conclude that on average women are younger when they finish training than men.

From the table above we also can conclude that the dermatologist who works on his own on average is older than his colleague who is working in pattnership. This difference is not so evident for the extra- or intramurally working dermatologist.

Regarding the mean calculated adherence, only marginal and non-significant differences can be observed. The mean adherence was calculated at 105,317. The average number of new patients per 1.0 fte was 2,465 and the average number of new phlebological patients was 297.

In general one could suggest that Doppler investigation for detecting reflux in de Long Saphenous Vein is completely reliable. Regarding the Short Saphenous Vein Doppler-examination is considered to be satisfying as long as there is no reflux. If this is the case, additional examination has to be carried out with Duplex (Coleridge Smith 2001). Regarding the diagnostic possibilities, the Dutch dermatologist is well equipped, as the inquiry reveals.

Almost every practice can offer its patients sclerocompression therapy. More than two fifth of the dermatologists also can offer ambulatory phlebectomy, which does not mean though that also two fifth of the dermatologists carry it out themselves. Nevertheless this percentage can be called high. The treatment modality however is not new, but only since 1999 added to the management education regulations (Twishondelijk Opleidings Reglement) of the Society.

A recently published inguiry by phone among dermatologists who attended a workshop about this subject 5 years before, shows that almost one third of them always perform ambulatory phlebectomy. It also shows that the most important obstacle to implement the technique is the great amount of time one has to invest and the labor intensive character of the technique itself (de Roos \& Neuman 2001). Together with the information of this inquiry the conclusion can be made that instruction and systematic education can be an effective formula to the introduction of a new treatment modality.

The Dutch dermatologists also appear to have a great demand for education. They are clearly interested in this speciality according to the wide range of subjects brought up spontaneously by the respondents. Also more than forty percent of the respondents want to be professionally trained by a colleague. 
he inquiry reveals interesting information about the phlebological arsenal of the 4 rgeon. One has to be careful however, because in fact the information was Ven indirectly. Nevertheless it is evident that throughout the Netherlands the tandard surgical phlebological equipment is available. In almost every case the lematologist has, due to the care of the surgeon, access to crosse-ectomy, striping and convolutectomy, whether or not in the form of ambulatory phleectomy.

The results of this inquiry for the first time gave us an insight into the nature and he extent of phlebological care by dermatologists. The phlebological part in Jermatological practice with $12 \%$ of the new patients is high. In practice this Teans that the spent time is comparatively higher because diagnostics and treatment of a phlebological patient meed more time than those of a general dermatological patient. On the same time the frequency factor of these patients is higher.

There also is an overview of important essential information such as age, sex, size of practice and extent of partnership. This information not only is interesting and relevant to periphery-working dermatologists, but also to policymakers. After all, with this information it will be easier to adjust the planning of care- and education to daily practice. 

CHAPTER 9

\section{GENERAL DISCUSSION AND SUMMARY}



Ater taking the patient history an inventory has to be made to cstimate the atent of the venous problem. If there are only brush veins and reviculat waricose eins there is no need for treatment unless these veins are cosmetically disturbing to the patient. If the patient complains about fatigue, heaviness or cramps LAR tray reveal early venous insufficiency. If plethysmography indicates a venous refilling time of 20 seconds or more there still is no medical indication for therapy. If this VRT is shorter than 20 seconds adjuvant sereening for deep wenous insufficiency is in place. This may be done by measuring the Ambulatory Venous Pressure, which is still considered the golden standard. If there tre no hemodynamic disturbances treatment is optional and dependant on the patient's wishes. If there are hemodynamic disturbances these will have to be corrected. Further investigation with a Doppler instrument is optional.

Some patients will present themselves with either Great or Short Saphenous Vein varicosis or varicosis of one of the side branches. These veins warrant further analysis. The first part should be through Doppler investigation. If SF-or SP junctions are competent therapy should be either CST or AP. If a reflux is detected in the SF junction this should be corrected through ligation and tremoval or obliteration of the GSV. If with a Doppler reflux in the knee pit (SP junction) is detected, this has to be confirmed with Duplex ultrasound. In cases of real reflux this can be treated with echo-guided SCT. First one has to be certain that there is no reflux in the poplited mein (PV). In cases of incompetent PV adjuvant investigations will have to determine the AVP. If the AVP is normal AP or CST is the best therapy option. If the AVP is to high CT is the best option.

Chapter three explores the possibilities of compression therapy for both sclerotherapy and ambulatory phlebectomy. In the first study one hundred patients (120 legs) were treated for varicose veins of different calibers with CST. A special technique was used to make the firm cotton wool rolls which were placed over the treated areas. Additional compression was given by a combination of a class I medical compression hosiery and a class II compression hosicry. Patients were screened after therapy and side effects were noted. Furthermore in twelve patients the pressures directly underneath the cotton wool roles was measured. The mean interface pressure of all measuring sensors under these cotton wool rolls was measured to be $84 \mathrm{~mm} / \mathrm{Hg}$ (range: $68-122 \mathrm{~mm}$. $\mathrm{Hg}$ ) with the additional use of compression with a class I and a class If medical compression stocking. By using these long cotton wool compression rolls, the compression 
part of compression sclerotherapy becomes more effective and much easier to perform. Accurate fixation of these rolls however is paramount. This study proves the great effectiveness of a cotton wool roll compression right at the place of treatment.

The second study in this chapter describes the use of compression after CST and AP. The aim and mechanism of compression therapy is analyzed and clinical implications are discussed. Because of the possibility of blood loss from the ruptured part of the remaining vein some form of compression has to be applied after ambulatory phlebectomy. When firm cotton wool rolls as described in part one of this chapter are used the extravasate is pushed to the area just beside the rolls. Therefore $7 \mathrm{~cm}$ broad foam compression pads are proposed after which the treated area is bandaged using $10-\mathrm{cm}$ broad adhesive tape. Over the bandage a compression class II hosiery is worn during the day to prevent edema formation in the distal "non-compressed" areas. There is no consensus in the literature. on the duration of compression. Based on empirical evidence we advise five days of the combination and five subsequent days with oniy compression hosiery. The use of these broad compression pads after AP reduces hemorrhage and seems to enhance resorption of tesidual blood.

There is a surprisingly limited number of prospective studies on the effect or efficacy of surgery, compression sclerotherapy, and ambulatory phlebectomy. Hobbs and Rutgers provided evidence that the success of CST and surgery alone is limited. Side branch varicosities have been the best indication for CST. The poor long term result of CST however is the main reason to initiate the prospective tandomized trial presented in chapter four. Ninety-eight legs with lateral accessory (semicirculatory) varicose veins were randomly allocated to either CST or AP. Eighty-two patients were included of whom sixteen were included with both legs. Two patients were lost to follow up. One recurrence occurred in the AP group at one and none at two years. In the CST group twelve recurrences at one year $(p<.001)$ and eighteen at two years $(p<.001)$ occurred. Some complications occurred significantly more in the AP group: blisters, telengiectatic matting, scar formation and bruising from bandaging. There was no significant difference in severity of complaints as a consequence of treatment for both treatment modalities $(p=.41)$.

Our results show for the first time that AP is significantly more effective than CST for the treatment of varicose veins of the legs. Recurrence rates are significantly lower than for CST therapy. If varicose veins persist 4 weeks after com- 
pression sclerotherapy, it can be argued that to reduce the risk of future recurrence $\mathrm{AP}$ should be considered as the better treatment option.

The first part of chapter five explores the theoretical background for the trentment of varicose veins of the foot. AP is an accepted therapy for varicose veins which has also been used for ankle and foot varicosities. After reviewing the relevant literature on the anatomy of the veins of the foot no indications were found that the venous anatomy of the foot holds major restrictions in the treatment of its varicosities. Venous surgery and compression sclerotherapy may be used successfully in special cases. Subsequently fourteen patients (19 feet) were treated for varicose veins of the foot with AP. All treated patients observed excellent results. No serious side effects were seen. AP is therefore a safe and elegant treatment option for varicose veins of the foot.

To shed a light on the patients view we initiated a survey. We investigated patient satisfaction and complaints as reported by the patient after AP for varicose veins in the ankle and foot region using a questionnaire. According to the results of the questionnaire fifty percent of the interviewed patient population is not completely satisfied. Most important factors that influence patient satisfaction are reported discoloration, persisting pain and perception of varicose veins after surgery. A disturbingly high number of patients $(66 \%)$ reported to see recurrences after AP. These recurrences are not necessarily "real" recurrences but constitute a subjective result (i.e.: as perceived by the patient). With AP varicose veins are permanently eradicated. However when new varicose veins do occur in the same region patients tend to regard these as a failure of treatment, if they are not sufficiently informed about this possibility.

Based on the results of this study we argue that in informing the patient (werbally and in writing) more attention should be given not only to what complications may occur, but also to what in the perception of the patient are the most important complaints after a certain procedure. In the case of AP: discoloration, pain and "recurrences". To enhance the quality of information given to the patient and to avoid misunderstandings and/or disappointments the physician should base his patients education (also) on the priotities of problem solving patients report to adhere to, before treatment and most definitively after treatment. Although patients perceive "recurrent" varicose veins of the foot to be a nuisance, the fact that $85 \%$ of them still would like to be treated again with $\mathrm{AP}$ is nevertheless very encouraging. 
Chapter six first describes a new indication for AP: a method to harvest a (varicose) vein for histological investigation. A case report of a patient with suspected Bockenheimers syndrome is presented. With the use of AP a varicose veins was harvested and histological examination confirmed the diagnosis. Using this technique fundamental histological studies can be performed to differentiate between primary varicose veins (e.g. Klippel-Trenaunay syndrome or Bockenheimer's syndrome) and secondary varicose veins.

The second part of this chapter gives detailed information on several other locations where AP can be applied. In theory there is no limitation to what part of the body this technique can be applied as long as there is proper knowledge on the anatomical structures adjacent to the vein that has to be removed. This is instructed through four case reports on patients with varicose veins on the face, the arms, the scrotum and the buttocks. AP is a safe and effective technique for removal of non-leg veins.

Every treatment option has the possibility of failure. A complication can be seen as a failure of therapy and may be unforeseen or even inevitable is some cases. In chapter seven first a report is given of a very rare complication: a traumatic neuroma. After disruption of a sensory nerve the axons distal to the point of transection undergo wallerian degeneration, whereas the axons and Schwann cells of the proximal stump proliferate. If scar formation prohibits reconnection of the two the proximal part may still grow out of the stump and form a disorganized tangle of nerve twiglets extending into the surrounding soft tissue, thus forming a traumatic neuroma.

A second case report describes the possibility of a pre-existing dermatosis to appear in an area where a varicose vein has been removed with AP. It has been teporred earlier that after other surgical procedures pre-existent dermatoses may be triggcred: the so-called Köbner phenomenon. However this is the first rime vitiligo has appeared unforeseen, not only around the incisions of AP but also in skin covering the venous section that has been removed. This complication has not yet been described after AP. It may well be that the trama inflicted by the needle during the administration of the local anesthesia, the dissection or the removal of the varicose vein has triggered this phenomenon in the reported patient. There is also the possibility that the injection of the lidocain - a neuro-active substance has provoked vitiligo. AP can instigate a Kobner phe- 
nomenon as is demonstrated with this case report. The exacerbation of psoriasis or lichen planus after ambulatory phlebectomy therefore is possible.

In a letter to the editor we convey our concerns about the apparent low incidence rates of hematomas in review articles on the complications after $A$ P. Based on our experience and previous studies we state that this is a side-effect inherent to the rechnique which should not be registered as a seldomly seen complication. A distinction should be made however because hemorthages are also reported in the literature, sometimes combined with hematomas. Hemorthage is a more severe loss of blood mostly due to inadequate bandaging and should be considered a real complication needing further action from the physician (i.e. renewal of the bandage or thrombectomy).

Education and continuing education of colleagues is a meaningful and responsible task that gives a lot of satisfaction, especially if one relates to the good response immediately after this education is finished. We were interested in the return of a training course we organized in 1.994. Chapter eight states the results of this survey held among Dutch dermatologists who attended a workshop on AP five years earlier. The majority of attendees were satisfied about the way this workshop came up to their expectations. About one in three still uses this technique despite the fact that they believe it is time consuming. More than $35 \%$ of respondents were not able to implement this newly acquired technique. Lack of time, in part because of growing waiting lists, is the main reason. Since there is a growing demand for (more labor-intensive) dermatological care and because education capacities are limited, the introduction of new treatment modalities such as $A P$, will become increasingly difficult.

To gain a clear understanding on the nature and dimension of phlobological care by dermatologists and the demand for education of phlebological subjects, we decided to perform an incuiry among all periphery-working Dutch dermatologists. The majority of respondents (91\%) work intramurally and $86.3 \%$ work in some form of partnership with other dermatologists. On average the Dutch dermatologist works 0.85 fte (full time equivalent), women 0.73 fte and men 0.91 fte. The mean number of new patients per 1.0 fte was 2,465 and the mean number of new phlebological patients was 303 , which is $12 \%$ of the total number of new patients per year.

Amost all respondents use Dopplet to analyze their phlebologic parients; $80 \%$ of them sometimes use Duplex ultrasound. Almost $95 \%$ can offer compression 
sclerotherapy; $4 \% \%$ ambulatory phlebectomy. Ninety-three percent of dermatologists work in cooperation with a surgeon, in which all surgical phlebological interventions can be offered to patients. Among respondents there is a great need for phlebological training.

The results of this inquiry for the first time gave us an insight into the nature and the extent of phlebological care by dermatologists. The phlebological part in dermatological practice with $12 \%$ of the new patients is high and in concordance with our own findings (chapter one). The amount of time spent on phlebological patients is comparatively larger than the time spent on a general dermatological patient because diagnostics procedures as well as treatment options in phlebology are more time consuming. In practice this means that phlebological patients are more time consuming than patients with a general dermatological problem.

\section{WHERE TO END?}

As stated time and again ambulatory phlebectomy is an elegant, efficient and efficacious technique to remove unwanted (varicose) veins. It has been proven to be more effective than compression sclerotherapy in cases of side branch varicosis and therefore probably also in other varicose veins. It is also proven very effective in varicose veins of the foot although in our opinion compression sclerotherapy can also be used here because there are no anatomic restrictions. Patient satisfaction is relatively poor although the majority of patients would choose this technique again.

With the material harvested with exery ambulatory phlebectomy session histologic studies can be done without the necessity of adjuvant investigation (i.e.: biopsy). This technique can even be used to harvest part of the temporal artery in cases of suspected arteritis temporalis. This would lead to less visible scars without compromizing material for the histopathologist.

New techniques such as laser therapy and minimal invasive endoscopic modalities may arise on the horizon for patients with varicose veins but ambulatory phllebectomy remains a method for the permanent removal of varicose veins that requires some skills, some practice, and only a small investment for equipment before starting with this procedure. With the proper appreciation from both patients and physicians, as well as proper reimbursement from the government this forty-year old rechnique may have an even more excellent furure. 


\section{CHAPTER 10}

\section{SAMENVATTING}


William Babcock (1872-1963) kan worden gezien als de gtondlegger van de modeme flebologie. Hij zag het belang van het adequat verwijderen van de insufficiënte $v$ Saphena. Tournay kan wel gezien worden als de grondlegger van de modeme sclerocompressie therapie doordat hij een sclerosans combineerde met compressietherapie. Fegan zorgde voor nieuwe impulsen voor deze modaliteit toen hij de zogenaamde "empty vein technique" introduceerde om zo het contact tussen vene en scierosans te verbeteren. Robert Muller (2 september 1919) voegde ambulante flebectomie aan het therapeutisch arsenaal toe omdat hij ontevreden was over zijn initiele resultaten na sclerocompressie therapie en de lelijke litrekens na chirurgie.

Het eerste hoofdstuk geeft een historisch overzicht en een hypothese over de mogelijke oorsprong van spataders als ook een definitie van deze aders. Vervolgens worden ongepubliceerde gegevens gepresenteerd om de parameters voor de doclen van dit proefschrift aan te geven.

Gedurende een jaar (april 1997 - april 1998) werd van alle patiënten die een afspraak hadden gemaakt voor een flebologisch probleem, geregistreerd. Er werd cen onderscheid gemaakt tussen 'nieuwe' patiënten (nooit eerder behandeld voor spataders) en 'oude' patiënten (laatste behandeling tenminste twee jaar geleden). Met behulp van deze inventarisatie kon worden berekend dat 11,9\% van alle nieuwe patiënten zich presenteen met spataders. Het merendeel van deze patiënten, oud en nieuw, heeft grote varices, hetzij v Saphena Magna (GSV), v Saphena Parva (SSV) of zijtak varices. Omdat flebologische pateenten meer tijd vergen voor analyse en behandeling is de impact op de tijd die de dermatoloog te besteden heeft veel groter. Men heeft berekend dat een dermatoloog ongeveer twintig procent van zijn tijd besteed aan problemen die gerelateetd zijn aan flebologie. Het introduceren van een nieuwe techniek, die in eerste instantie veel tijd vergt, in een dermatologische setting is zeer moeiljik. Wanneer deze techniek daarentegen minder recidieven veroorzaakt en meer tevreden patiënten oplevert, zal dit op de lange termijn eerder tijd opleveren.

De beperkingen van laser behandeling voor varices zoals die werden beschreven in de publicaties waarop hoofdstuk twee werd gebaseerd, zijn dramatisch veranderd. Door de verbeteringen van moderne lasermachines is deze modaliteit momented warschijnlijk de beste behandelingsoptie voor 'teleangiectatic matting'. Daarnaast rijn lasers en IPL succesvol ingezet bij de behandeling van een steeds grotere diversiteit aan varices en teleangiectasieën. Langere golflengtes en pulsduur als ook geavanceerdere koeling zijn de belangtijkste doorbraken 
Seweest. Dit hoofdstuk beschrijt tevens een 'work-up' procedure voor patienten thet varices. Een beslisboom voor diagnostische verrichtinger en behandeling wordt aangereikt.

Na het afnemen van de anamnese wordt het flebologische probleem geinventariseerd. Wanneer er alleen bezemrijs en reticulaire varices zijn is er geen noodzaak re behandelen tenzij deze voor de patiënt cosmetisch storend zijn. Wanneer de patiënt over vermoeidheid, zwar gevoel in de benen of krampen klaagt, kan een LRR beginnende veneuze insufficiëntie aan tonen. Indien de plethysmografie een veneuze herwullingstijd (VRT) weergeeft van 20 seconden of meer is er geen medische indicatie woor behandeling. W/anneer de VRT korter is dan 20 seconden is anvullende screening voor diep veneuze insufficientie geindiceerd. Dit kan door het meten van de Ambulante Veneuze Druk, hetgeen nog steeds wordt beschouwd als de gouden standaard. Indien er geen hemodynamische afwijkingen zijn, is de behandeling facultatief en afhankelijk van de wensen van de patiënt. Indien er hemodynamische afwijkingen zijn dienen deze te worden gecorrigeerd. Aanvullend onderzoek met behulp van een Doppler instrument is facultatief.

Soms presenteren patiënten zich met varices in het verloop van de v Saphena Magna of Parva dan wel van een van de zijtakken. Deze verdienen verdere analyse. Eerst zal door middel van Doppler-onderzoek moeten worden vastgesteld of de sapheno-femorale en parvo-popliteale crosse sufficient is. Behandeling is dan ambulante flebectomie (AP) of sclerocompressie therapie (CST). Indien er reflux wordt geconstateerd in de SF crosse dient deze te worden geligeerd en de GSV te worden verwijderd of geoblitereerd. Indien met Dopplet onderzoek een reflux in de knieholte (SP crosse) wordt geregistreerd, dient dit te worden bevestigd door middel van Duplex onderzoek. In die gevallen van daadwerkelijke reflux kan dit worden behandeld door middel van zogenaamde echosclerose. Eerst dient men een reflux in de v poplitea (PV) uit te sluiten. In gevallen van insufficiënte PV zal men de AVP moeten bepalen. Bij een normale AVP kan de behandeling geschieden door middel van AP of CST. Wanneer de AVP te hoog is, is compressie therapie de beste optie.

Hoofdstuk drie onderzoekt de mogelijkheden van compressie therapie voor zowel sclerocompressie therapie als ambulante flebectomic. In de ecrste studic werden honderd patiënten ( 120 benen) met varices van verschillend kaliber behandeld door middel van sclerocompressie therapie. Een speciale technick 
werd grebruikt om een stevige wattenrollen te maken die op de behandelde gebieden werd bevestigd. Additionele compressie werd gegeven door middel van cen combinatie van klasse I en II elastische kousen. $\mathrm{Na}$ de behandeling werden de patiënten gescreend en werden bijwerkingen geregistreerd. Bovendien werd bij twaalf patiënten de druk direct onder de watten rol gemeten. De gemiddelde gemeten druk onder alle druksensoren onder de wattenrollen in combinatie mer de additionele compressie kousen (klasse I en II) was $84 \mathrm{~mm}$ Hg (spreiding: 68 $122 \mathrm{~mm} \mathrm{Hg}$ ). Door gebruilk te maken van deze lange wattenrollen wordt het compressieve deel van de sclerocompressie therapie veel effectiever en eenvoudiger te tealiseren. Nauwkeurige fixatie van deze rollen is echter uitermate belangrijk. De studie bewijst de grote effectiviteit van stevige wattenrollen precies op de plaats van behandeling.

De tweede studie in dit hoofstuk beschrijft het gebruik van compressie na sclerocompressie therapie en ambulante flebectomie. Doel en mechanisme van compressie therapie wordt geanalyseerd en de klinische implicaties worden besproken. In verband met het mogelijke bloedverlies vanuit het geruptureerde deel van de resterende varix is er enige vorm van compressie noodzakelijk na ambulante flebectomie. Wanneer de stevige wattenrollen zoals beschreven in deel een van dit hoofdstuk worden toegepast, wordt het extravasaat naar het gebied direct naast de rol gedrukt. Vandaar dat het voorstel wordt gedaan om $7-\mathrm{cm}$ brede schuimpelottes aan te brengen na de behandeling, die worden gefixeerd met behulp van $10-\mathrm{cm}$ brede kleefpleister. Daarover wordt overdag een klasse lI elastische kous gedragen om oedeemvorming in het distale, niet behandelde deel, tegen te gatan. Er is in de literatuur geen consensus over de duur van compressie. Gebaseerd op empirische gronden adviseren wij de gecombineerde compressie gedurende vijf dagen gevolgd door vijf dagen elastische kous. Het gebruik van deze drukpelottes na ambulante flebectomie vermindert hematoomvorming en lijkt de resorptie van resterend bloed te verbeteren.

Er is een opvallend beperkt aantal prospectieve studies naar het effect of de doeltreffendheid van chirurgie, sclerocompressie therapie of ambulante flebectomie. Hobbs en Rutgers leverden het bewijs dat het succes van sclerocompressie therapie en chirurgie alleen slechts beperkt is. Zijtak varicose zijn altijd de beste indicatie geweest voor SCT. De slechte resultaten op lange termijn zijn echter de belangrijkste reden geweest on een prospectieve gerandomiseerde studie te starten die in hoofdstuk vier wordt beschreven. Achtennegentig benen met varicose van de laterale accessoire vene (semicircularia varicose) werden gerandomiseerd 
voor ambulante flebectomie dan wel sclerocompressie therapie. Er werden tweëentachtig patiënten geïncludeerd van wie zestien met beide benen. Twee patiënten konden niet worden vervolgd. In de ambulante flebectomie groep ontstond een recidief na een jaar en geen na twee jaar. In de CST groep ontstonden twaalf recidieven na één $(p<0,001)$ en achttien na twee jaar $(p<0,001)$. Sommige bijwerkingen traden significant meer op in de A.P groep zoals: blaren, teleangiectatic matting, littekens en klachten als gevolg van de verbanden. Er was geen significant verschil in de ernst van de klachten als gevolg van de behandeling $(p=0,41)$. Onze resultaten tonen voor het eerst aan dat AP significant effectiever is voor de behandeling van zijtakvaricose dan CST. Het aantal recidieven is significant lager dan bij CST. Indien het scleroseren van zijtakvaricose na twee pogingen niet succesvol is, dient men te kiezen voor een andere behandeling. Ambulante flebectomie is dan een goede keuze.

Het eerste deel van hoofdstuk vijf onderzoekt de theoretische achtergrond van de behandeling van varices aan de voet. AP is een geaccepteerde therapie voor varices die ook wordt toegepast voor enkel en voetvarices. Onderzoek van de relevante literatuur over de anatomie van het veneuze stelsel van de voet leverde geen aanwijzingen op dat deze belangrijke beperkingen voor de behandeling ervan met zich meebrengt.

Veneuze chirurgie van sclerocomptessie therapie kunnen succesvol worden gebruikt in speciale gevallen. Vervolgens werden veertien patiënten (19 voeten) behandeld woor voetvarices door middel van AP. Bij alle patiënten werden excellente resultaten geboekt.

Er werden geen serieuze bijwerkingen waargenomen. $A \mathrm{P}$ is derhalve een veilige en elegante behandelingsoptie voor voetvarices.

Om de zienswijze van de patiënt te belichten werd een enquête gestart. Wij onderzochten de tevredenheid van de patiënt en de eventuele klachten zoals deze door de patiënt werden gerapporteerd. De resultaten van de enquête laten zien dat de helft van de geinterviewde patiënten niet geheel tevreden is over de behandeling. De belangrijkste factoren die de patiënttevredenheid beinvloeden zijn: gerapporteerde verkleuringen, aanhoudende pijnklachten, en de waargenomen recidieven. Een verontrustend aantal patiënten rapporteert het zien van recidieven na AP. Deze recidieven zijn niet noodzakelijkerwijs 'echte' recidieven maar vormen een subjectief resultaat. door middel van AP worden varices permanent verwijderd. Wanneer de patiënt vooraf niet wordt geinformeerd over de mogelijkheid dat in hetzelfde gebied opnieuw varices kunnen ontstaan, wordt dit door 
de patiënt ervaren alsof dit het gevolg van het mislukken van de operatie. Gebaseerd op deze resultaten stellen wij dat bij het mondeling en schriftelijk informeren van de patiënt niet alleen voldoende aandacht gegeven wordt aan alle mogelijke complicaties, maar ook aan wat in de ogen van de patiënt meest belangrijke klachten kunnen zijn die na een bepaalde behandeling kunnen optreden. In het geval van AP is dat: verkleuringen, pijn en "recidieven". Om de kwaliteit van de informatie aan de patiënt te vergroten maar ook om misverstanden en/of teleurstellingen te voorkomen zou de behandelaar de patiënteninformatie mede moeten baseren op de problemen die volgens de patiënt zouden moeten worden verholpen. Dit is wan belang woor de behandeling maar zeker na de behandeling. Alhoewel pariënten aangeven deze recidieven als vervelend te ervaren is het feit dat $85 \%$ van hen zich, indien nodig, weer op deze manier zouden willen laten behandelen zeer bemoedigend.

Hoofdstuk zes beschrijft allereerst een nieuwe indicatie voor AP: een methode om een varix te oogsten voor histologisch onderzoek. Er wordt cen casus gepresenteerd van een patiënte die verdacht werd van het syndroom van Bockenheimer. Met behulp van de AP wordt een deel van een varix geoogst waarna histologisch onderzoek de klinische diagnose bevestigd. Met deze methode kan fundamenteel histologisch onderzoek worden verricht om te differentieren primaire (bijvoorbeeld Syndroom van Klippel Trenaunay, of Bockenheimer) en secundaire varices.

Het tweede deel van dit hoofdstuk geeft gedetailleerde informatie over verschillende gebieden waar A.P kan worden toegepast. Er is geen theoretische beperking in de gebieden die kunnen worden behandeld door middel van AP, zolang er voldoende kennis is van de anatomische structuren in de nabijheid van de te behandelen vene. Dit wordt toegelicht aan de hand van vier casus van patiënten met varices in het gelarat, de armen, het scrotum en de nates. AP is een veilige en effectieve techniek voor het verwijderen van varices en venen op plaatsen anders dan aan de benen.

Iedere behandelingsmodaliteit bergt de mogelijkheid in zich te mislukken. Een complicatie kan worden gezien als het falen van de behandeling, kan onvoorzien zijn en zelfs onvermijdelijk. In dit hoofdstuk zeven wordt eerst een zeldzame complicatie beschreven: het traumatisch neuroom. Wanneer sensibele zenuwvezels worden geruptureerd zal het distale deel zogenaamde Walleriaanse degeneratie vertonen terwijl de axonen en Schwann cellen van het proximale deel zullen 
prolifereren. Indien littekenvorming een nieuwe verbinding in de weg staat kan uit het proximale deel de proliferatje doorgaan waardoor een ongeorganiseerde kluwen van zenuwtwijgies ontstaat dat zich in het omliggende weefsel uitbreidt. Hierdoor ontstaat het traumatisch neuroom.

Een tweede casus beschrijft de mogelijkheid dat een pre-existente dermatose kan ontstaan in een gebied waar eerder een varix is verwijderd met behulp van AP. Het is eerder in de literatuur beschreven dat een chirurgische ingreep een pre-existente dermatose kan luxeren: het zogenaamde Köbner fenomeen. Het is echter voor het eerst dat vitiligo onverwacht optreed niet alleen rond de incisies maar ook in her gebied waar de varix is verwijderd. Het is voot het eerst dat dit is beschreven na AP. Mogelijk dat het trauma als gevolg van de infiltratieanesthesie, de dissectie of het verwijderen van de varix dit fenomeen heeft veroorzaakt bij de gepresenteetde patiënte. Ook zou het toedienen van lidocaïne, een neuro-actieve stof, de vitiligo heeft veroorzaakt. Met deze casus is de mogelijkheid van het Köbner fenomeen na AP aangetoond. De exacerbatie van huidziekten als psoriasis en lichen planus na AP behoort daarmee ook tot de mogelijkheden.

In een brief aan de redactie spreken wij onze bezorgdheid uit over de kennelijk lage incidentie van hematomen na AP. Gebaseerd op onze ervaring en eerdere studies stellen wij dat dit een bijwerking is die inherent is aan de behandeling en geen zeldzame bijwerking. Er zou niettemin een kanttekening gemaakt moeten worden omdat in de literatuur bloedingen soms in combinatie met hematomen worden gerapporteerd. Bij bloedingen is er een uitgesproken bloedverlies, doorgaans als gevolg van inadequaat verbinden en zou moeten worden beschouwd als een echte complicatie die ingrijpen van de arts noodzakelijk maakt (zoals: opnieuw aanleggen van het verband, thrombectomic).

Onderwijs en nascholing van collega's is een belangrijke verantwoordelijke taak die veel voldoening geeft vooral wanneer men afgat op de reactie direct na de scholingsactiviteit. Wij waren geïnteresseerd in het rendement van een nascholing die wij in 1994 hadden georganiseerd. Hoofdstuk acht geeft de resultaten wan de enquête weer die werd gehouden onder Nederlandse dermatologen die vijf jaar eerder een workshop over AP hadden bijgewoond. Het merendeel van de deelnemers was teyreden over manier waarop deze workshop voldeed aan hun verwachtingen. Ongeveer cenderde past de geleerde techniek nog steeds toe ondanks het feit dat men vindt dat het een tijdrovende techniek betreft. 
Meer dan $35 \%$ van de respondenten was niet in staat deze pas geleerde techniek te implementeren in de praktijk. Gebrek aan tijd, deels door de toegenomen wachtlijsten wordt als belangrijkste oorzaak opgegeven. Vanwege de groeiende vraag naar (meer arbeidsintensieve) dermatologische zorg en omdat onderwijscapaciteit beperlkt is zal de introductie van nieuwe behandelingsmodaliteiten zoals AP in toenemende mate bemoeilikt worden.

Om een meer helderheid te verschaffen over de aatd en dimensies van flebologische zorg door dermatologen als ook de behoefte aan onderwijs over flebologische onderwerpen, werd besloten een schriftelijke enquête te verrichten onder alle perifeer werkende Nederlandse dermatologen. De meerderheid van de respondenten $(91 \%)$ werkt intra-muraal en $86,3 \%$ werkt op een of andere manier samen met andere dermatologen. Gemiddeld werkt de Nederlandse dermato$\operatorname{loog} 0,85$ fte (full time equivalent), vrouwen 0,73 fte en mannen 0,91 fte. Het gemiddeld aantal nieuwe patiënten per 1,0 fte was 2.465 en het gemiddeld aantal nieuwe flebologische patiènten was 303 , hetgeen $12 \%$ van het total aantal nieuwe patiënten per jaar betekent.

Vrijwel alle respondenten gebruiken Doppler om hun flebologische patiënten te analyseren; $80 \%$ gebruilst soms Duplex. Bijna $95 \%$ heeft sclerocompressie therapie in het pakket; 44\% ambulante flebectomie. Drieënnegentig procent van de dermatologen werkt in samenwerking met een chirurg, waarbij alle chirurgisch flebologische therapieën kunnen worden aangeboden. Onder de respondenten is er een grote vraag naar flebologische onderwijs.

Deze enquête biedt voor het eerst een beter inzicht in de aard en uitgebreidheid wan de flebologische zorg door Nederlandse dermatologen. Het flebologisch deel vas de dermatologische zorg, $12 \%$ van het aantal nieuwe patienten, is groot en komt overeen met de resultaten uit onze eigen praktijk (hoofdstuk 1). De hoeveelheid tijd die aan flebologische patiënten moet worden besteed is groter dan de tijd die aan algemene dermatologische patiënten moet worden besteed omdat de diagnostische procedures als ook de behandelopties in de flebologie veel tijdrovender zijn. In de praktijk betekent dit dat flebologische patiënten veel tijdrovender zijn dan algemene dermatologische patiënten. 


\section{WAAR EINDIGT DIT ALLES?}

Zoals keer op keer is angegeven de ambulante flebectomie is een elegante, efficiënte en doeltreffende techniek om ongewenste (variceuze) venen te verwijderen. Het is bewezen meer effectief dan sclerocompressie therapic in gevallen van zijtak varices en daarmee waarschijnlijk ook bij andere varices. Het is bewezen zeer effectief te zijn bij de behandeling van voetvarices, hoewel wij van mening zijn dat in deze gevallen sclerocompressie therapie eveneens toegepast zou kunnen worden, vooral omdat er geen anatomische restricties zijn. De patienttievredenheid is relatief slecht hoewel het merendecl van de patiënten deze techniek weer zou kiezen.

Bij iedere ambulante flebectomie komt materiaal beschikbatr waarmee histologische studies zouden kunnen worden uitgevoerd. Waarschijnlijk kan deze techniek eveneens worden gebruikt om een biopsie te verrichten bij verdenking op arteriitis temporalis. Ook hier zou cen minder zichtbaar litteken het gevolg kunnen zijn.

Nieuwe technieken zoals laser therapie en minimaal invasieve endoscopische modaliteiten mogen dan aan de horizon gloren, de ambulante flebectomie blijft een methode voor de permanente verwijdering van varices die enige vaardigheid, wat oefening en slechts een kleine investering voor material behoeft voordat men met deze techniek kan starten.

Met de juiste waardering van zowel patienten als artsen, als ook een adequate vergoeding van de overheid zou deze veertig jaar oude techniek wel eens een uitstekende toekomst tegemoet kunnen gaan. 

CHAPTER 11

REFERENCES 
Adhikan A, Criqu MH, Worll $V$, Denenberg fo, Fronek $A$, Langer RD, Klauber $\mathrm{M}$ (2000). The epidemiology of chronic venous diseases. Fhebology $15 ; 2$-18.

Mrecht S, Fom 1. (1993). Nooplasias and hyperplasias of neural and muscular orgin In: Dernawagy in general medicine. Fitzpantek TB, Eisen AZ, Wolff Ko, et al (eds). Fourth edition; wol $1: 1272$.

Alen $V$, Ryan DW, Lomax $N$, Murray $A(1993)$. Accumcy of interface pressure measurement systems. J Biomed Eng 15: $344-8$.

Anderson JE (1979), Grant's atlas of anatomy. Seventh edn. Batrimore.

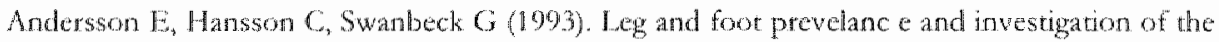
peripheral arterial and venous circulation in a randomised elderly population; An epidemiolog.. ical survey and clinical investigation. Acta Derm Venereol (5tockly) 73:57-61.

Anonymus (1960) Fabricius ab Aquapendente (1537-1619) preceptor of Haryey (editorial) JAMA 198: 1989.

Anwnymus (1975). From our legal correspondent. Hazards of compression sclerotherapy. BMJ $714-5$.

Anonymus (2000). Praktikanalyse 1909 Dermatologie, Sint Joseph ziekenhuis. Prismant, Utrecht.

Ariza A, Bilban J M, Rosai (1988). Immunohiscochemical detecrion of epithelial nuembrane antigen in normal perineural cells and perineuroma. Am I Surg Parhol 12 (9):678-83.

Arnoleli CC (1957). The aethology of primary varicose weins. Dan Med Bui 4, 102-7.

Ascher $\mathrm{E}$, Jacob $\mathrm{T}$, Hingorani A, Tsemckhin B, Gunduz Y (2001). Expression of molecular mediators of apoprosis and their role in the pathogenesis of lowerextremity waricose veins. I Vasc Surg 33: 1080-6.

Askar $O$, Abdullah $S$ (1975). The veins of the foot surgical anatomy and its relation to disorders of the venous return from the fooc. \Cardiovase Surg 16: 53-63.

Askar O, Kassem KA, Aly SA (1975). The venographic pattern of the foot. J Cardiovase Surg 16 : 64-70.

Assclman AH, Neumann HAM (1997). Ambulatory phlebectomy in patents with the syndrome of Kolippel-Trenanay. Scripa Phlebologica 5: 52-3.

Baccaglini U, Spreaficn G, Castoro C, Sortentino, $\mathrm{P}(1996)$. Scletotherapy of vaticose veins of the lowe limbs. Consensus paper. North American Sociery of Phlebology. Dematol Surg 22 883.9.

Baccylin U, Patsch H, Sacens, en al, (1996). Sclerotherapy of waricose veins of the lower limbs. Consensus papar. Scope on Phicbol I ymphol 1:4-17.

Baker DW (1988). Principles of Doppler and Duplex Uitrasound Instruments. In: Felix WR Jr. Non-invasive diagnosis of peripheral vascular disease. New York. Raven Press.

Batter M, Cibbons A (2001). Another emissary from the dawn of humanity. Science 293, 187-8.

Bartolo $\mathrm{M}$ (1992). Inupact socio économique des maladies veineuses en ltalie. Phalebologic 45: $423-31$.

Bdjards RC, Rows K-P de, Kerkhof PCM vat de, Faber WR, Neuman HAM (2001). Het veranderde profiel van de huidarts. Medisch Contact 56: 422-5.

Bemmelen van PS, Ramshorst wan B, Eikelboom BC (1992). Photoplethysmography reexamined: lack of correlation with duplex scanning. Surgery 112 . 544-8.

Bergan 1] (2002). Advances in venous surgery: SEPS and phlebectomy for chronic venous insufficiency. Dermatol Surg 28: $26-8$. 
M, Neumann HAM, Berrety PJM (1993). La lipodermosclérose et l'épaisseur dermale. sogte 46,25-31.

A, Adams LA (1967). Arteriovenous malformation with angiodermatuts. Stasis demamulating Kaposi's disease. Arch Dernatol 96: 176.

ner Ph (1907). Uber die genuine difruse phlebectasie der oberen Extremität. In: hriff für Georg Eduard wan RindAleisch. Leipzig 311-88.

Goldman MP (2002). Sclerotherapy for reticular and telangiectatic veins of the face, and chest. Dermatol Surg 28: 46-51.

LW, Stonebridge PA, Callam M), Walker Al, Allan PL, Beggs I, Ruckley CV (1993). rent varicose viens:assessment of the saphenofemonal junction. Br J Surg 81(3): 373-5. IPM, Büller HR, Heijboer H, Huisman MV, Rijk M de, Jagt H, Cate JW ten (1997). mised rrial of effects of compression stockings in patients with symptomatic proximal urombosis. Lancer 349: 759-62.

1 (1969). History of wenous research. IFEE Transactions on Biomedical Engineering $236-47$.

, Burnand KG, Irvine AT, Wilson NM (eds) (199\%). Diseases of the veins. Oxford, in, Arnold. pp. 145-62:

Gabreva JJ, Garcia-O Imedo MA (2001). Sclerosants in microfoam. A new approach in sgy. Int Angiol 20: $322-9$.

Bergan JJ, Gloviczki P, Jantet $G$, Wendell-Smith CP, Partsch H (2002). Nomenclature veins of the lower limbs: an international interdisciplinary consensus statement. I Vasc 6: $416-22$

1) European Committee for Standardization. Adopted European Prestandard. ENV : 2001: medical compression hosiery.

Chua JJ (2002). Endovenous laser photocoagulation (EVLP) for varicose veins. Lasers AED. $31:$ (4) $257-62$.

.x Perrin M (1994). Venous valwe repair: early resulits in fifty-two cases. J Vasc Surg 19. 3.

I, Elias SM, Keagy B, Kolvenbach R, Leahy AL, Marston W, Pannier-Fisher F, Rabe F, SA (2002). Powered plntebectomy (Trivex?) in treatument of varicose veins. Ann Vasc 6: 488-94.

an (1993). Valves in warteose veins and external compression studied by angioscopy. ology $8: 116-9$.

imith PD (2001). Invesugation of Venous Disease. Phlebology $16: 6-11$.

Malouf GM, Stacey MC (1995). The Australian polidocanol (acthoxysklenol) study. $s$ at 2 years. Dermatol Surg 21: $337-8$.

s-Dortu 1, Dortu IA (1991). Indications de la phlebectomie ambulatoire. Phlébologie $671-81$.

s-Dottu I (1987). Indications therapeutiques de la phlebectomic ambulateite. ologie 40(4): $853-8$.

- Willis PW, Keller $\rrbracket B$ (1973). Venous thromboembolism and other venous disense in the aseh community health study. Circulation 48: 839-46.

Procacei $T$, Peruzzi GP, Dini S (1993). Neue histopathologische Beobachtungen bei opathien der Beine. Plalebol 22; 5 -8. 
E, Kreysel HW (1993). Percataneous minisurgical phlebectony. Semin Dermatol zzi A (2002). Sclerosing foam in the treatment of varcose veins and teleangiectasias: analysis of safery and complicarions. Demarol Surg $28: 11-5$.

Fox RH (eds.) (1993). The return of blood to the heart; venous pumps in health $\therefore$ 2nd rev edition. London, John Libbey \& Company.

3). Adverse incidents and complications. In: Dortu J, Raymond-Martimbeau Peds. y phlebecwomy/Phlébectomie ambulatoire. Houston, Texas: PRM Editions:

n, Brakkee AJM, Kuiper JP (1992). Non-invasive measurement of venous muscle tion in the supine position. Phlebologie. 7: 146-9.

atel $A$, Fileta $B$, Chang $A, B$ arnes $S$, Flagg $A$, Kidwel $M$, Villavicensio $J L$, Rich $N M$ icose veins possess greater quantities of MMP-1 than normal veins and demonnal wariation in MMP-1 and MMP-13. I Surg Res 106: 233-8.

987). Sclerotherapy for superficial wenules and telcangiectasies of the lower extrematol Clin 5:369-79.

Veiss RA, Brody HJ, Colemann III WP, Fitzatrick RE (1993). Treament of facial ia with sclerotherapy, laser surgery, and/or elecrodessication: a review. J Dermat I. 19: 899-906.

ed.) (1995). Sclerotherapy; treatment of varicose and teleangiectatic leg veins. St sy-Yearbork Inc.

Imiry S (2002). Closure of the greater saphenous vein with endoluminal radioftermal heating of the vein wall in combination with ambulatory phlebectomy: 50 th more than 6-month follow-up. Dermatol Surg 28: 29-31.

!002). Treatment of varicose and teleangiectatic leg veins: double blind prospective e trial between aethoxysclerol and sotradecol. Dermatol Surg 28: 52-5.

Venbrux AC, Magee C (2000). Percutaneous deployment of a valved bovine jugular swine venous system: a potential treatment for venous insufficiency. I Vase Interve $231-6$.

- Primary varicose weins: hemodynamic principles of surgical care; the case for the stab exulsion technigue. WASA 20:365-8.

AE (1991). Ambulatory stab evulsion phlebectomy for truncal varicose weins. Am 1. $66-74$.

1. Sclerotherapy for the permanent eradication of varicose veins; theoretical and msiderations. J Am Acad Dermatol 38: 461-75.

- Removal of periocular veins by scletotherapy. Ophtalmology 108: 442-8.

E, Lechner W (1977). Einteiturg der Stammvarikose der Vena saphenan magna in 4 lebol u. Proctol 6: 116 .

Spezielle Diagnostik der primären Varikose. Demeter, Gräfelfing.

15). Cosmetic variectony. I Denmatol Surg Oncol 11: 873-8.

lillard RW, Petrerson K, Johansen K (1987). Gravitational hemodynamics and vention in the gitaffe. Nature 329,59-60.

TW, Silwerstein MD, Mohr DN, Lohse CM, Petterson TM, O'Fallon WM, Melton Trends in the ioncidence of venous stasis syndrome and venous ulcer: a 25 year based study. J Vasc Surg 33: 1022-7. 
assy SM, Danniell MB, De Bakey ME (1975). Inadvertent femoral artery stripping: ut. Surgery $77: 318$.

Banga DA, Meijerink $\mathrm{CJH}$, Laigies J HH (1962). De venae communicantes van het rijdschr Geneestad 106: 415-20.

ers TT, Lofgren $\mathrm{KA}$, Kuster $\mathrm{G}$ (1968). The venous walves of the foor and ankle. ol Obstet 107: 289-90.

- Hewitt GP (1999). The evolution of human speech: the fole of enhanced snrrol. Am J Phys Anthropol 109, 341-63.

er JP, Hamers AA (1965). Acro-angiodermatitis of the foor. Arch Dermatol 92 :

188). Rationelle Diagnostik in der phebologischen Praxis. Hautarat 39:193.

sitta MM, Guenini P, Abeni D, Stillo F (2002). Reversible cardiac arrest after sclerotherapy of peripheral venous malformation. Dematol Surg 26: 153-5.

futchings RT, Logan BM (1982). Colour atlas of foot and ankle anatomy. London. cal.

195). Applied Logistic Regression Analysis, vol 100 in Series: Quantitarive ApplicaSocial Sciences, a Sage University Paper, Thousand Oaks, Callifomia 91320, USA,

ePalma RG, Kabnick IS (2002). Endovascular obliteration of saphenous teflux. at study. J Vasc Surg 35: 1292-4.

Surgical instruments in Greck and Roman times. Chicago: Ares Publ; p 56-8, 87-8,

LRR und invasive Venendruckmessung: Vergeleich der Methoden anland von ssung. In: May R, Stemmer R, red. LRR: Die Licht Reflections Rheography. 'erimed.

. Traitement des varices par la phlébectomie ambulatoire. Bull Soc Fr Phiéb 19:

La phlébectomie ambulatoire. Phlébologie 31: 273-8.

Traitement des varices du pied par la phlebecromic ambularoire. Phlébologie 43

Jfson V, Tsikonova I, Keren D, Barmeir E, Yeshurun D (2000). Pulsarile venous $y$ in severe tricuspid tegurgitation: does pulsatility ptotect against complications of ase Angiology 51: 231-9.

RJ, Boné C(2001). Endovenous Laser: a new minimally invasive method of treatricose veins - prelimmary obserwations using an 810 num diode laser. Dermatol Surg

sson $\mathrm{E}$, Eklof B (1986). High tie with sclerotherapy for saphenous vein insuffibology 1: 113 .

fruist D, Lindhagen A (1994). Venous and non-wenous leg ulcers: clinical history ance in a population study. Br J Surg 81: 182-7.

jutist D, Lindhagen A (1996). The prevalence of chronic lower-limb ulceration has estimated: results of a validated population questionnaire. Br J Surg $83: 255-8$.

(1988). Flebologie in kort bestek. Mijdrecht: Zyma - Nederland.

Broek MJTB yan den (1991). Increased collagen IV layer in the basal membrane capillaries in severe chronic insufficiency. VASA 20:26-9. 
ampanelli $R_{0}$ Garbelli $S$, Mantovani $S$, Lantelme $E$, Brazzelli $V$, et al. (2001). Specific c T lymfocyte responses against Melan-A/MART1, ryrosinase and $g$ ploo in vitiligo by of major histocompatibility complex/peptide tetramers: the role of cellalar immunity iopathogenesis of vitiligo. J Invest Dermatol 117:326-32.

980). Besserbare und nicht besserbare chronische venöser Insuffuzienz. Vasa. 9: 165. 184). Do we need firm compression srockings exerting high pressure? Wasa 13 (1): 52 .

991). Compression therapy of the legs. \Dermatol Surg Oncol 17: 799-805.

187). How giraffes prevent oedema. Nature 329; $13-4$.

an Urk $H$, Wittens $\mathrm{CH}$ (1997). Efficacy of subfascial endoscopy in eradicating perfosins of the lowet leg and its correlation with the venous ulcer healing. J Vasc Surg 26:

ostek P, Grimatud JP, Prokopowicz SC (1999). Autogenous walve reconstruction techis post-thrombotic reflux. Ann Vasc Surg 13: 339-42.

der, Lambers JCCA, Wersch JW], Koehler PJ (1994). Reversible ischacmic neurologcit after sclerotherapy of varicose veins Lancet 343: (8894): 428 .

(1964). Discases of the veins. Wortld Health Organisation, internal communication. A/109.64.

in GS (1981). A random controlled trial of two forms of compression bandaging in nt sclerotherapy of varicose veins. I Surg Res 31:440-5.

(1991). Muller phlebectomy; A new phlebectomy hook. J Dermatol Surg Oncol 17:

1 (1991). Une complication rare de la phlébectomie ambulatoire: le granulome we. Phlébollogie 44: 865-71.

(1993). Die Behandlung der Besenreiservarizen: Indicationen der. Phlebecromie nach Phlebologie 22:163-7.

(1997). Complications of Ambulatory Phlebectomy. Dermatol Surg 23: 947-54.

, Monri M (1999). Phlebology, the guide. Elsevier - Amsterdam pp. 993-4.

inmaa $A$, Perala J, Ohtonen P, Heikkinen $T$, Wiik $H$, Karjalainen P, Haukipuro $K$, IT (2002). Endovenous obliteration versus conventional stripping operation in the It of primary varicose veins: a randomized controlled trial with comparison of the Vasc Surg 35: $958-65$.

1998). Evaluation of the long-pulse dye laser for the treatment of lcg telcangiectasias. al Surg 24: $737-40$.

lobson RW, Wright CB (1978). In: Venous Problems, Bergan J), Yas JST. (Iids.) , Yearbook Medical Publ. Inc.

giev M (eds.) (1995). Ambulatory phlebecromy; a practical guide for treating varicose losby-Yearbook Inc. St Louis USA

5). The surgical cure of primary varicose veins. Br J Surg 62:913-7.

- Neumant HAM (1993). Treatment of waticose weins; The Maastricht perspective in ggy. Practická Aebologie 1:5-11.

- Neumann HAM (1994). Tramatic neuroma: a rare complication following Muller's tomy. J Dermatol Surg Oncol 20: 681-2.

$\therefore$ Neumann HAM (1995). Vein biopsy; a new indication for Muller's phlebectomy. of Surg 21: $632-4$. 
- Maresceux J, Furderer $\mathrm{Ch}$ (1980). Die Kompressionsbehandung der unteren itäten speziell durch Kompressionsstrümpfe. Hautarzit 31: 355.

Gabler S, Partsch H (1989). Indikations gerechren Bestrumfung - Messung der ? Pumpfunkrion. VASA 18:35-9.

¿van Gent WB, Pierik EG, Wittens CH (2001). Endoscopic versus open subfascial of incompetent perforating veins in the treatment of venous leg ulceration: long tem ap. J Vase Surg 33: 1028-32.

Lazar J, Elias S, Marchand P Hefner R (1982). Surgical treatment of post-phlebitic ne with vein valye transplant. Am J Surg 144:221-4.

Jias SM, Yacobucci GN, et al (1986). Indications and results of vein valve transplant. I rasc Surg 27: 163.

Neumann HAM (1996). Macrosclerotherapy and compression. 1 .n: Ambulatory TreatE Venous Disease. Goldman MP, Bergan J1, eds. St Louis: Mosby, pp 105-12.

, Neumann, HAM, Roos $\mathbb{K}-\mathrm{P}$ de (1999). Long cotton wool rolls as compression ars in macrosclerotherapy for varicose veins. Dermatol Surg 25:38-40.

avezzi A. Frullini A (2001). Preliminary experience with a new sclerosing foam in the nt of varicose veins. Dermatol Surg 27: 58-60.

, Gatter KC, Puddle J (1988). Epithelial membrane antigen expression by the rium of periphenal nerve and in peripheral nerve tumors. Histopathology 13 (2): 171-9. (1990). The Muller technique of stab-avulsion segmental varicose vein resection. I ol Surg Oncol 16:94.

985). Indikationen zur operatieven Therapie von Krampfadern. Hautarzt 36: 218-21. (1988). Mikrochirurgische phlextraction nach Varady in der Varizenchirurgie. tionales Diskussionsblatt 1:8-9.

(1993). Erfahnungen met der minichingischen Operationstechnik in der chirurgie. Phlebologie 22: 200-5.

der, Eekhof JAH, Walma EP et al (1993). NHG-Standaard Varices. Huisarts en chap. $36: 23$ min.

. van der, Hingstman L, Nienoord-Buré, Berg M.M. van den (2001). Vragen atanbod 2000-2010. Nivel/Prismant. Utrecht.

V, Neumann. HAM (1993). Photoplethysmography in the diagnosis of superficial valvular incompetence. (Letter). Br J Surg 80:1213-4.

4, Verhacgh MEJM, Neumann HAM et al. (1993). Adhesion molecule cxpression in leg ulcers. WASA 22: 213-8.

V, Kley AMJ van der, Neumann HAM (1994). Digital photoplethysmo-graphy and Jecron rheography; a clinical comparison. J Dermatol Surg Oncol 20: 470-3.

4, Neumann HAM (1996). Effects of medical elastic compression stockings on interssure and edema prevention. Dermatol Surg 22: 876-71.

4, Daamen E, Neumann HAM (1997a). Short stretch versus clastic bandages: effect of d walking. Phlebology 26: 19-24.

W, Pronk $G$, Neumann HAM (1997b). Pressure differences of elastic compression ss at the ankle region. Dermatol Surg 23: 935-9,

1 (1997). Clinical aspects of compression therapy. Thesis, Mastrichr.

, Trauchessec JM (1993). Phebectomie esthétique au niveau de la face. J Med Lsth et arm 78: 89-94. 

183

DANKWOORD

Neuchateit le
Robert Muller

9. nue du Sayan

Tólaphone 038/25, 66 25

$\mathscr{E} 28.6 .73$

Mon cher Caypios,

c'ase aver plaisit

que is wents envarie.

in tiré - í poure at d'aubres plens récents.

conelialomeres

Rlueen 
Allereerst ben ik dr Robert Muller, dermatoloog te Neuchâtel, Zwitserland, veel dank verschuldigd omdat hij aan de wieg heeft gestaan van een elegante en effectieve technick om varices definitief te behandelen. Zonder hem geen ambulante flebectomie en dus zonder hem ook geen proefschrift over dit onderwerp.

In 1993 was ik, als voorbereiding op de eerste workshop over dit onderwerp, op zoek naar zijn cerste publicatie. Een schriftelijk verzoek om een kopie werd vrijwel direct door hem beantwoord met een originele afdruk van zijn eerste publicatie uit 1966 als ook kopieën van verschillende recentere publicaties van zijn hand. In 1994 ging dr Muller met pensioen.

Twee jaar eerder, in 1992, was professor Neumann als nieuwe opleider in Maastricht aangetreden. In dat jaar was hij met zijn bekende voortvarendheid begonnen mij deze, zeker voor Maastricht revolutionaire, techniek bij te brengen. Niet alleen ik, maar beel Nederland moest van deze methode kennis nemen en de beste manier was het organiseren van een workshop. Bij gebrek aan live patiënten zouden wij onze toevlucht moeten nemen tot een (dier-)model. Zo kwam het dat ik in de avonduren allerlei kistjes heb zitten timmeren, in de weer ben geweest met schuimrubber (met dank aan het Maastrichts Rubberhuis) en met rubberslangen, maagsondes en catheters om aders na te bootsen. Zo kwam het ook dat ik deze techniek op kadavers van diverse diersoorten heb mogen uitproberen: het werd het schaap. Mede door de praktische opzet werd de in januari 1994 gehouden workshop "Ambulante Flebectomie" een succes. Later dat jaar werd de workshop herhaald. Het feit dat er door de Ramadan nauwelijks meer (betaalbare) schapenpoten te krijgen waren, haalde bijna een streep door de rekening. Na mijn vertrek uit Maastricht in 1994 benaderde professor Neumann mij anderhalf jaar later met de vraag of ik geen zin had om daar "aan de rand van de Peel" wat onderzoek te doen naar de behandeling van spataders. Als ik daar wat voor voelde moesten wij maar cens afspreken in Asten, zijn toenmalige woonplaats. Zo werden op een donderdagavond in februari 1996 te Asten, onder het genot van een Bourgogne van veel oudere datum, de plannen gesmeed die ten grondslag liggen aan het ontstaan wan dit proefschrift.

Beste Martino, ik wil je danken voor je altijd weer stimulerende ideeën (en opdrachten), je tomeloze enthousiasme en inventiviteit op momenten dat het even tegen zat, voor de kansen die je voor mij hebt gecreêerd, maar vooral voor je vriendschap.

De praktijk warar in in 1994 in Veghel/Uden terechtkwam was een gespreid bed met twee enthousiaste collega's die zorg en zorgen voor, hoog in het vaandel bleken te hebben staan. Mariëtte van der Wegen-Keijser wil danken voor haar hulp voor het verwerven van patiënten voor de semicircularia trial. 
Mijn maat Frank Bruins ben ik zeer veel dank verschuldigd. Beste Frank, vanaf het allereerste begin heb jii er, samen met Bridget, voor gezorgd dat wii ons in Uden thuis konden voelen. Toen ik begin 1996 het idee opperde om "wat onderzoek" te gaan doen kon ik direct op jouw onvoorwaardelijke steun en medewerking rekenen. Ook toen ik later een tijdje 'free lance' staflid wilde worden in Maastricht was dat voor jouw vanzelfsprekend. Bedankt voor je wriendschap en voor het plezier dat wij samen beleven. Thanks mate!

Het goed functioneren van medisch specialisten ligt voor een groot deel aan henzelf. Het optimaal functioneren van deze professionals daarentegen kan alleen wanneer zij worden omgeven door andere professionals. Het werk van dit bulppersoneel zorgt ervoor dat de medisch specialist niet hulpeloos maar vlekkenloos zijn werk kan doen. Vooral dat laatste kan bij een dermatoloog nogal eens lastig kan zijn. Annemarie, Ans, Carla V, Carla dL, Christine, Dianne, Heidy, Martha, Miat, Sandra en Sevgi dank voor jullie inzet, interesse en hulpvaardigheid (als ik weer eens een paar honderd dossiers nodig had om 'even' iets na te kijken) door de jarten heen.

Ook de staf, het secretariaat, de polikliniekmedewerkers en de arts-assistenten in het Maastrichtse, waar ik na een korte afwezigheid werkelijk weer met open armen ontvangen werd, mogen in dit dankwoord niet ontbreken. Bedankt voor jullie gezelligheid, jullie bezorgdheid wanneer het weer weereens te slecht was voor de motor en alles wat ils in die drie jaar van jullie heb geleerd. Ik mis dic dinsdagen.

Een speciaal woord wan dank ben ik Lieneke van der Vleuten verschuldigd. Beste I.ieneke hartelijk dank voor jouw jarenlange ijver om de patiëntengegevens van onze praktijk (hoofdstuk 1 ) in te voeren in een bruikbaar computerbestand. Je ziet het was toch niet voor niets.

Wanneer je als onderzoeker cienkt dat het onderzoek gedaan is en er alleen nog wat formules op los gelaten moeten worden is daar: dr F.H.M. Nieman, statisticus. Beste dr Nieman, hartelijk dank voor de vele uren die u aan mij heeft besteed en de subtiele manier waarop u mij er steeds fijntjes op gewezen heeft dat dokters geen verstand hebben van patiëntenonderzoek. Bedankt ook woor de vakkundige wijze waarop u mij wegwijs hebt willen maken in het ondoorgrondclijke terrein van de statistiek.

De leden van de beootdelingscommissie prof. dr J. Drukker, prof. dr W.R. Faber, prof. dr P.M. Steijlen en dr J.C.J.M. Veraart wil ik danken voor de tijd en energie die zij in de beoordeling van het manuscript hebben willen steken. Dr Robert Weiss thank you not only for your willingness to be part of the review 


\section{ICULUM VITAE}

de Roos werd geboren op 2 februari 1960 te Sneck. Hij behaalde het ploma in 1978 aan het Stedelijk Lyceum en HAVO. Het ma werd in 1981 aan het Sint Maartenscollege, eveneens te behaald. Na deze uitgebreide en gedegen vooropleiding mocht hij vilitaire dienstplicht vervullen. Hij deed dat eerst in Amersfoort op de erve Officieren Cavalerie, waarna hij zijn parate tijd diende als comin het verkenningspeloton bij het Garde Regiment Fuseliers Prinses id: Lkol G. Schenk) te Schalkhaar. Na zijn beeddiging tot officier in 182 begon hij met de studie geneeskunde en behaalde hij her in oktober 1988. Tijdens zijn studie was hij student-assistent bij de 1 Medische Sociologie (84-85) en Huisartsgeneeskunde (85-87).

tiode als AGNIO te hebben gewerkt op de afdeling Algemene van het academisch ziekenhuis Maastricht (hoofd: Prof. dr G. naakte hij, op zoek naar meer diepgang, de overstap naar de afdeling gie. Eerst als AGNIO en vanaf 1 mei 1990 in opleiding (hoofd: Prof. $\therefore$ van de Staak, vanaf 1 januari 1992: Prof. dr H.A.M. Neumann).

4 vestigde hij zich als dermatoloog in her Sint Joseph ziekenhuis te Ins: Ziekenhuis Bernhoven) in associatie met F.G. Bruins. Daarnaast 1996 lid van het Concilium Dermatologicum et Venereologicum, was meer secretaris van de Commissie Operatieve Dermatologie 1) en bestuurslid van de International Society for Dematologic Sur$-2002)$.

; 1990 getrouwd met Denise van Gasselt en vader van Bart (12) cn 


\section{BIBLIOGRAPHY}

\section{Book}

Beljaards R.C. en Roos, K.P. de. Cosmetische Dermatochirurgie. 2000, Belvedère, Overveen.

\section{Chapters}

Neumann HAM, Roos K-P de. Cardiovasculaire middelen en anticongulantia. In: Th. van Joost en DP Bruynzeel (eds). Huidafwijkingen door Geneesmiddelen. 1995; Glaxo, Zeist.

Roos K-P de. Hechttechnieken. In: RC Beljaards, HAM Neumann (eds) Oncologische Dermatochirurgie. 1996; NVDV, Utrecht.

Roos $\mathbb{K}^{\mathrm{P}} \mathrm{P}$ de. De ellips. In: RC Beljaards, HAM Neumann (eds) Oncologische Dermatochirurgie. 1996; NVDV, Utrecht.

Roos K-P de, RC Beljaards. De wigexcisie. In: RC Beljaards, HAM Neumann (eds) Oncologische Dermatochirurgie. 1996; NVDV, Utrecht.

Roos K-P de, Rosweide FG, Koopman RJJ. Instrumentarium en inrichting. In: RC Beljaards, HAM Neumann (eds) Oncologische Dermatochirurgie. 1996; NVDV, Utrecht.

Roos $\mathbb{K}$-P de. De ambulante flebectomie. In: Neumann, Tazelaar, Wittens (eds.). Leerboek Flebologie. 2003 Lemma, Utrecht.

Roos K.P de, Neumann HAM. Lymfoedeem. In: Neumann, Tazellaar, Wirtens (eds.). Leerboek Flebologie. 2003 Lemina, Utrecht.

\section{Other publications}

De Graaff E, Drop MJ, Post GJ, Roos K-P de. Carriërevoorkeuren en entree op de arbeidsmarkt van Maastrichtse basisartsen, Ned. Tijdschr. Geneeskd. 1987; 131: 1677-8.

Douwes, EA, Roos K-P de, Hamulyák, K. Patiënte met huidnecrose bij sintrom-mitis gebruik. Tromnibus 1992; 20: 7-9. 
Roos K-P de, Neumann HAM. Treatment of varicose veins; The Maastricht perspective in Phlebology. Praktická Flebologie, 1993; 1: 5-11.

Mutsaerts KJGM, Roos K-P de, Punt C, Tordoir JHM, Beysens AJMM. Het gebruik wan transdermaal nitroglycerine ter voorkoming van complicaties bij langdurige perifere infusen. Ziekenhuisfarmacie. 1993; 9: 89-93.

Koedam MI, Roos K-P de, Hulsmans R-FHJ, van Breda Vriesman PCJ. Granulomatose van Wegener beperkt tot de huid. Ned Tijdschr Dermatol Venereol 1994; 4:94-6.

Roos K-P de, Neumann HAM. Traumatic neuroma; a rare complication following Muller's phlebectomy. J Dermatol Surg and Oncol 1994; 20: $681-2$

Neumann HAM, Roos K-P de. Microchirurgische ambulatoire flebectomic. Ned Tijdschr Dermatol Venereol 1994; 4: 343-9.

Roos K-P de, Neumann HAM. Vein biopsy; a new indication for Muller's phlebectomy. Dermatol Surg 1995; 21: 632-4.

Roos K-P de, Koedam MI, Neumann HAM. Het niet genezende ulcus; wees bedacht op plaveiselcelcarcinoom van de huid. Ned. Tijdschr. Geneeskd 1996; 140: 529-31.

Roos K-P de, Neumann HAM. De hechting; het sluitstuk? Ned Tijdschr Dermatol Venereol 1996; 6:106-10. (Letter 1996; 6: 215).

Alkemade H, Lucker G, Roos K-P de, Steijlen P, Kerkhof PCM van de. Systemische en lokale bijwerkingen door lokale corticosteroid-therapie van psoriasis. Ned Tijdschr Dermatol Venereol 1996; 6:211-3.

Roos K-P de. Complicaties in de dermatochirurgie, preventic en behandeling. Ned Trdschr Dermatol Venereol 1997; 7: 32-4.

Roos k-p dc. Semicirculatory varicosis: tributary vein treatment. Phlebol Digest $1997 ; 0 ; 6-9$.

Roos K゙-P de, Neumann HAM. Muller's ambulatory phlebectomy and varicose veins of the foot. Dermatol Surg 1998; $24: 465-70$.

Neumann HAM, Roos K-P de, Veraart JCMJ. Muller's ambulatory phlebectomy and compression. Dermatol Surg 1998; 24: 471-4. 
Tazelaar DJ, Neumann HAM, Roos K-P de. Long cotton wool rolls as compression enhancers in macrosclerotherapy for varicose veins. Dermatol Surg 1999; 25: 38-40.

Roos K-P de, Beljaards RC, Gaastra MTW, Bruins FG. Botuline toxine A een nieuwe mogelijkheid bij behandeling van gelokaliseerde hyperhidrosis. Ned Tijdschr Dermatol Venereol. 2000; 10: 10-3.

Beliaards RC, Roos K-P de, Kerkhof PCM van de, Faber WR, Neumann HAM. Het veranderde profiel van de huidarts. Medisch Contact 2001; 56: 422-5.

Beljaards RC, Roos K-P. de. Profiel van de huidarts. Reactie op Molenaar MC 2001;16: 614. Medisch Contact 2001; 29-30: 1099. (letter)

Roos K-P de, Neumann HAM. Flebectomie op schapenpoten; het langetermijneffect van praktische instructie. Medisch Contact 56; 2001: $1382-4$.

Roos K-P de, Neumann HAM. Hematomas are under-represented in studies on complications of ambulatory phlebectomy. (letter). Dermatol Surg 2002; 26: $544-5$.

Roos K-P de, Neumann HAM. Flebologie in de dermatologische praktijk; een landelijke enquête. Ned Tijdschr Dermatol Venereol 2002; 12: 194-7.

Roos K-P de. Chronische veneuze insufficientie. Ingezonden. Ned Tijdschr Geneesk; 2002; 146: 822-3.

Bullens-Goessens YIJM, Roos K-P de, Kockaert MA, Neumann HAM. Survenue d'un vitiligo après phlébectomie ambulatoire. Phlébologic 2002; 55 : $275-7$.

Roos K-P de, Nicman FHM, Neumann HAM. Patient satisfaction after ambulatory phlebectomy for varicose veins in the foot. Dermatol Surg 2002; 28: $1027-30$.

Roos K-P de, Nieman FHM, Neumann HAM. Ambulatory phlebectomy versus compression sclerotherapy; results of a randomized controlled trial. Dermatol Surg 2003; 29: 221-6. 